\author{
UNIVERSIDADE DE SÃO PAULO \\ FACULDADE DE ECONOMIA, ADMINISTRAÇÃO E CONTABILIDADE \\ DEPARTAMENTO DE ADMINISTRAÇÃO \\ PROGRAMA DE PÓS-GRADUAÇÃO EM ADMINISTRAÇÃO
}

\title{
MENSURAÇÃO DA PERFORMANCE SOCIAL CORPORATIVA COM DADOS EXTRAÍDOS DO RELATÓRIO DE SUSTENTABILIDADE DA GRI
}

\author{
Cecilia Seravalli Soares
}

Orientador: Prof. Dr. João Maurício Gama Boaventura

SÃO PAULO 
Prof. Dr. Marco Antonio Zago

Reitor da Universidade de São Paulo

Prof. Dr. Adalberto Américo Fischmann

Diretor da Faculdade de Administração, Economia e Contabilidade Prof. Dr. Roberto Sbragia Chefe do Departamento de Administração Prof. Dr. Moacir de Miranda Oliveira Junior Coordenador do Programa de Pós-Graduação em Administração 


\author{
CECILIA SERAVALLI SOARES
}

\title{
MENSURAÇÃO DA PERFORMANCE SOCIAL CORPORATIVA COM DADOS EXTRAÍDOS DO RELATÓRIO DE SUSTENTABILIDADE DA GRI
}

\author{
Dissertação apresentada ao Programa de \\ Pós-Graduação em Administração do \\ Departamento de Administração da \\ Faculdade de Economia, Administração \\ e Contabilidade da Universidade de São \\ Paulo, como requisito parcial para \\ obtenção do título de Mestre em Ciências.
}

Orientador: Prof. Dr. João Maurício Gama Boaventura

Versão Corrigida

(versão original disponível na Faculdade de Economia, Administração e Contabilidade)

\section{SÃO PAULO}




\section{FICHA CATALOGRÁFICA}

\section{Elaborada pela Seção de Processamento Técnico do SBD/FEA/USP}

\section{Soares, Cecilia Seravalli}

Mensuração da performance social corporativa com dados extraídos do relatório de sustentabilidade da GRI / Cecilia Seravalli Soares. -- São Paulo, 2016.

$118 \mathrm{p}$.

Dissertação (Mestrado) - Universidade de São Paulo, 2016.

Orientador: João Maurício Gama Boaventura.

1. Stakeholder 2. Mensuração de desempenho organizacional 3. Responsabilidade social I. Universidade de São Paulo. Faculdade de Economia, Administração e Contabilidade. II. Título.

$$
\text { CDD }-658.401
$$


Aos meus pais, pelo amor, apoio e incentivo para realização deste trabalho.

Ao meu marido, pela compreensão e apoio, e por estar sempre ao meu lado. 



\section{AGRADECIMENTOS}

Para realizar esse trabalho, contei com o apoio de muitas pessoas. Por isso, gostaria de agradecê-las.

Ao meu marido, Adriano, por sempre me incentivar a realizar esse trabalho e compreender as ausências.

Agradeço aos meus pais Elisena e Vitor, que sempre me motivaram a estudar e a evoluir, e sempre foram um grande exemplo disso.

Ao meu orientador, Professor João Maurício, pelos ensinamentos e orientações, pelo exemplo, pela paciência e pela disposição em sempre ajudar.

À minha família, irmã Fernanda, avós Tere, Victor e Maria, cunhados Rodrigo, Juju e Lina, sogra Cristina, pelo incentivo e pela torcida de sempre.

Aos amigos do Grupo de Pesquisa Stakeholders e Networks, Greici Sarturi, Simone Barakat, Taiguara Langrafe, Keysa Mascena, Adso Castelo Branco, Cristina Pereira, Ana Cláudia Azevedo, Raíssa Barbosa e Editenete Garcia, por compartilharem ideias e momentos, e também, pelas inúmeras contribuições ao meu trabalho.

Aos professores Mônica e Flávio pelas importantes contribuições na banca de qualificação deste trabalho.

Aos meus amigos bandeirantes, atletas, de infância, de faculdade, que sempre respeitaram e compreenderam minhas ausências.

A todos vocês, meus sinceros agradecimentos! 



\section{RESUMO}

Cada vez mais presente em pesquisas na área da administração, a Corporate Social Performance (CSP), ou Performance Social Corporativa, vem sendo tema de muitas pesquisas nas últimas quatro décadas, principalmente, no que tange a sua mensuração. Com sua característica multidimensional, a CSP vem sendo medida de diversas maneiras, com a utilização de relatórios de sustentabilidade, surveys, banco de dados e índices. Essa pesquisa traz uma contribuição metodológica a essa temática, trazendo um modelo de mensuração de CSP com dimensões e variáveis identificadas na literatura. Depois, analisou-se a aderência desse modelo com indicadores dos Relatórios de Sustentabilidade que utilizam as diretrizes GRI-G4 e com o questionário ISE-2016. Então, propôs-se uma avaliação da aderência de ambas as medidas. Além das análises descritivas, utilizou-se os métodos de correlação de Pearson e de Spearman para avaliar a associação entre as pontuações das duas métricas diferentes e o Teste não paramétrico de Mann-Whitney para comparar as duas distribuições. Foram elaborados dois modelos de mensuração, considerando as dimensões identificadas na literatura correspondentes aos stakeholders primários. As análises de correlação de Pearson e Spearman resultaram em uma correlação muito baixa entre as duas métricas, GRI e ISE. O Teste Mann-Whitney mostrou que não há evidências que suportem a hipótese de que os relatórios de sustentabilidade GRI e o questionário ISE sejam diferentes para os stakeholders comunidade, clientes e fornecedores. Ainda, foi realizada a Regressão Linear Múltipla para que os efeitos de outras variáveis pudessem ser avaliados. Nessa análise foi possível verificar uma melhor associação entre as métricas de GRI e ISE para o stakeholder Empregados, o que pode ser explicado pelo maior número de variáveis encontradas. 


\begin{abstract}
The Corporate Social Performance (CSP) has been present in management scholarship for the past four decades, mainly concerning to the ways of its measurement. Due to its multidimensional characteristic, the CSP has been measured in different ways, such as using sustainability reports, surveys, database and indexes. This research aims to contribute to this subject, assessing the correlation of a measurement model that uses data from sustainability reporting aligned with the GRI-G4 guidelines, with a measurement model that uses the Índice de Sustentabilidade Empresarial - ISE-2016 survey data. In addition to the descriptive analysis, it was used the statistical methods of correlation of Pearson and correlation of Spearman to evaluate the association between the scores of the two different metrics and the Mann-Whitney U test. The analysis of Pearson and Spearman correlation resulted in a very low correlation between both scales, GRI and ISE. However, the Mann-Whitney test showed that there is a relationship between both distributions for the following stakeholders: employees, suppliers and customers. Finally, It was perfomed a Multiple Linear Regression and it was verified a better association between the GRI and ISE scales for the Employees stakeholder, which can be explained by the greater number of variables found.
\end{abstract}




\section{LISTA DE ABREVIATURAS E SIGLAS}

CFP: Corporate Financial Performance

CSP: Corporate Social Performance

CSR: Corporate Social Responsibility

DJSI: Dow Jones Sustainability Indexes

GRI: Global Reporting Initiative

ISE: Índice de Sustentabilidade Empresarial

KLD: Kinder, Lydenberg, Domini Research \& Analytics.

RSC: Responsabilidade Social Corporativa

EPS: Ganhos por ação

ROA: Retorno sobre ativos

ROE: Retorno sobre o patrimônio líquido 



\section{LISTA DE FIGURAS}

Figura 1. Pirâmide de Responsabilidade Social Corporativa (Carroll, 1991) .......................... 16

Figura 2. Mapa de Stakeholders de uma grande organização (Freeman, 1984)...................... 18

Figura 3. Aspectos da Teoria dos Stakeholders (Donaldson \& Preston, 1995) ...................... 19

Figura 4. Modelo de Corporate Social Performance (Carroll, 1979) ...................................2 21

Figura 5. Modelo de Corporate Social Performance (Wartick \& Cochran, 1985).................22

Figura 6. Modelo de Corporate Social Performance (Wood, 1991)......................................23

Figura 7. Modelo de Corporate Social Performance (Swanson, 1995) .................................24

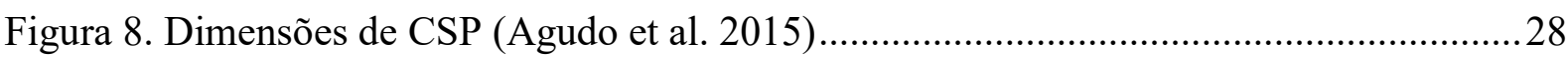

Figura 9. Valores para cada stakeholder (Tantalo \& Priem, 2014) ........................................29

Figura 10. Tipos de recursos (Sarturi \& Seravalli, 2015) ..................................................... 30

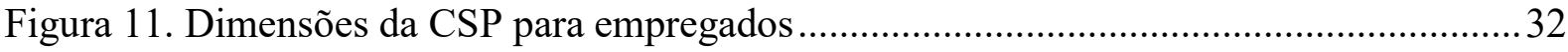

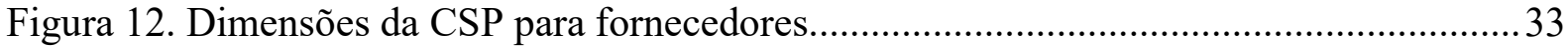

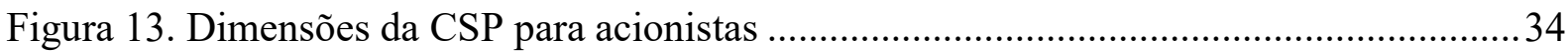

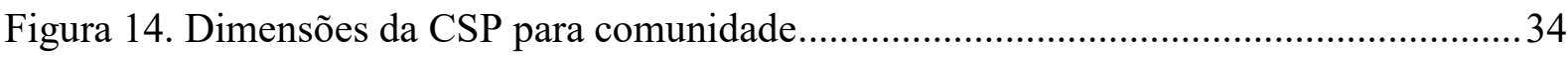

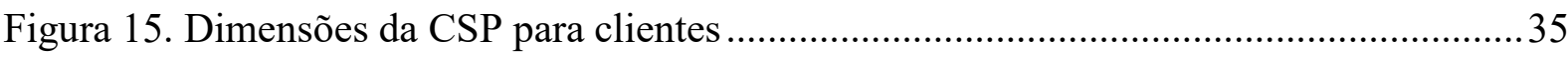

Figura 16. Escala de mensuração CSP pelos indicadores GRI (Fischer e Sawczyn, 2013).....40

Figura 17. Escala de mensuração CSP pelos indicadores GRI (M.J. Bonilla-Priego et al., 2014)

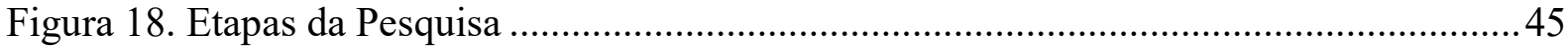

Figura 19. Relação das dimensões da CSP com os indicadores GRI e com o questionário ISE

Figura 20. Representação da matriz de materialidade (GRI, 2013) ......................................52

Figura 21. Exemplo de indicadores GRI (GRI, 2013)......................................................52

Figura 22. Aspectos e Categorias das diretrizes (GRI, 2013) ….........................................54

Figura 23. Exemplo do Questionário - ISE (ISE, 2015) ….................................................55

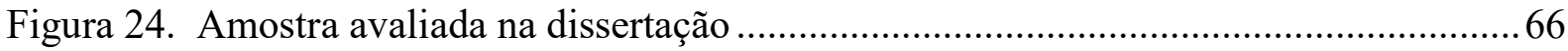

Figura 25. Empresas com informações sobre unidades de negócios abertas ...........................66

Figura 26. Resultados da mensuração de CSP utilizando GRI............................................... 75

Figura 27. Quantidade de indicadores GRI reportados no relatório de sustentabilidade 2014

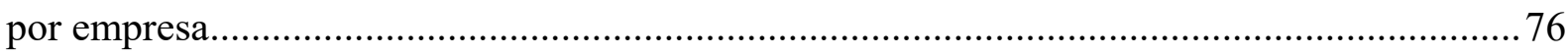

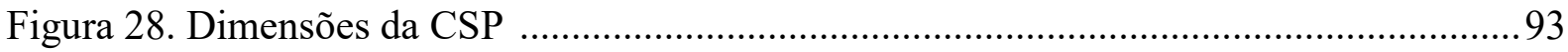





\section{LISTA DE TABELAS}

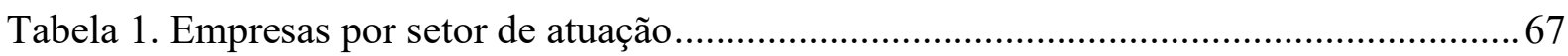

Tabela 2. Média, mediana e desvio padrão da CSP pelo GRI para cada Stakeholder .............69

Tabela 3. Média, mediana e desvio padrão da CSP pelo ISE para cada Stakeholder .............. 70

Tabela 4. Correlação de Pearson e Spearman do ranking stakeholder da dimensão ISE com relação ao ranking de dimensão GRI.................................................................................. 70

Tabela 5. Classificação dos stakeholders em relação a CSP ................................................... 70

Tabela 6. Teste não paramétrico de Mann-Whitney.................................................................... 71

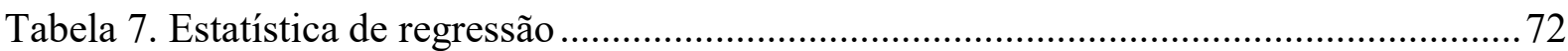





\section{SUMÁRIO}

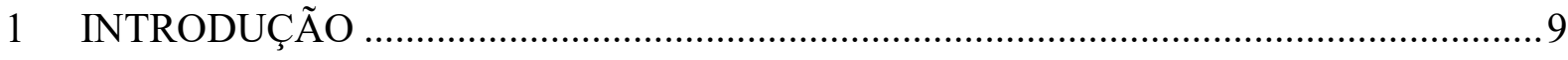

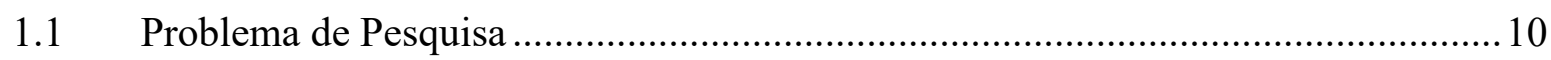

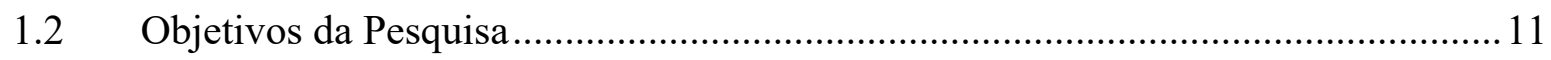

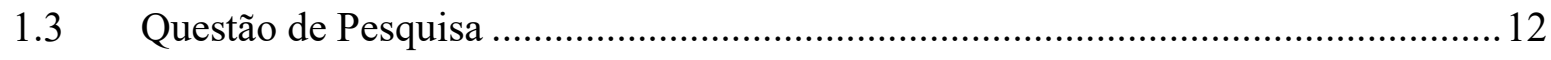

1.4 Delimitação de Pesquisa ..................................................................................... 12

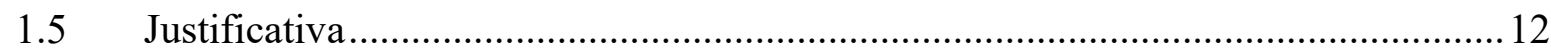

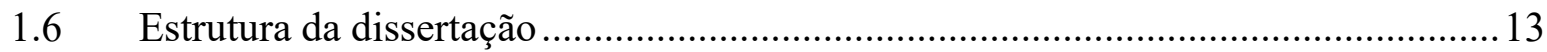

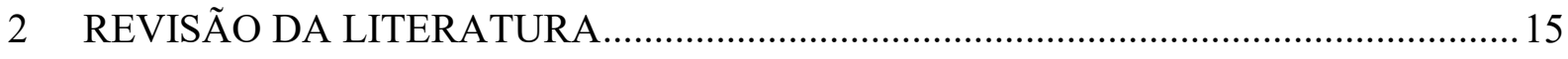

2.1 Corporate Social Responsibility - CSR .......................................................... 15

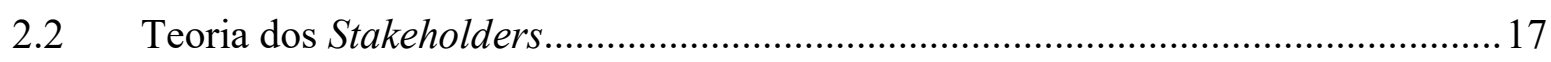

2.3 Performance Social Corporativa - CSP ................................................................20

2.3.1 A Performance Social Corporativa - CSP e a Responsabilidade Social

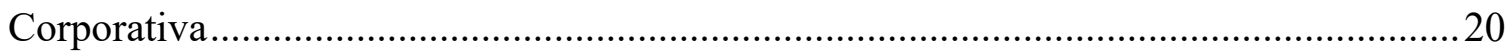

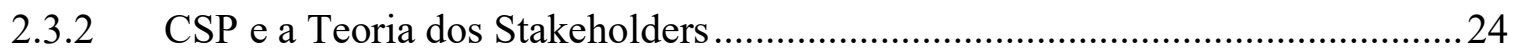

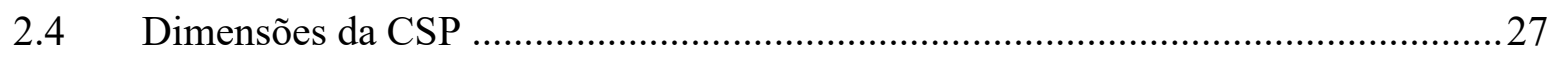

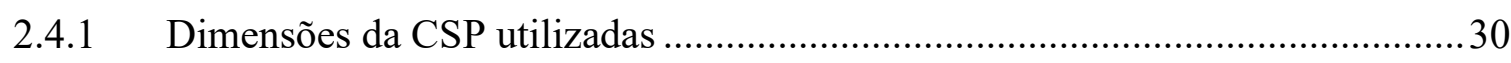

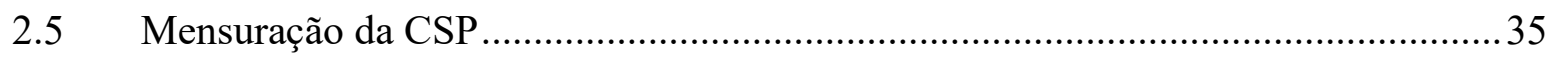

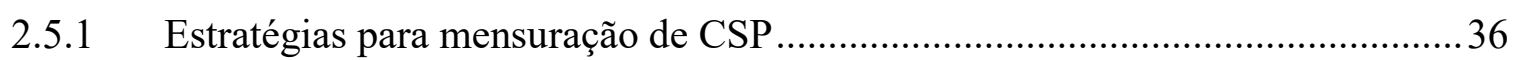

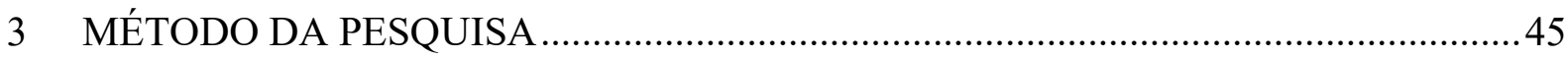

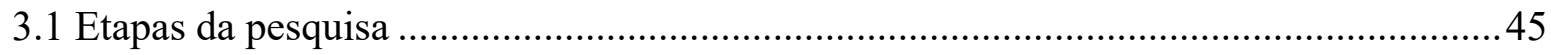

3.1.1 Definição das dimensões de acordo com a literatura ....................................... 46

3.1.2 Elaboração de framework relacionando as dimensões da CSP com os indicadores do relatório GRI e com o questionário ISE.................................................46

3.1.3 Verificação da aderência do Indicadores GRI com as dimensões da CSP .........55

3.1.4 Levantamento dos relatórios de sustentabilidade GRI das empresas elegíveis

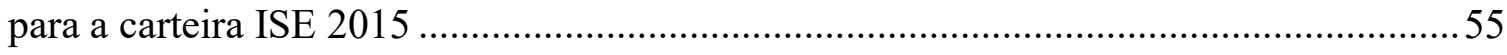

3.1.5 Mensuração de CSP a partir de dados do relatório GRI.....................................56

3.1.6 Verificação da aderência dos Indicadores GRI com as dimensões da CSP .......56

3.1.7 Mensuração da CSP a partir das respostas ao questionário ISE.........................56

3.1.8 Análise da aderência dos resultados do GRI com ISE .......................................58

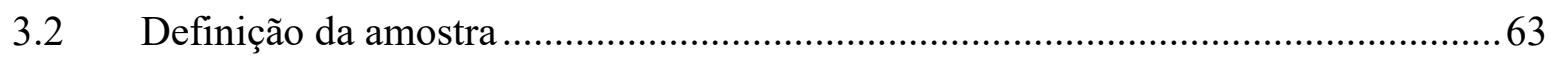

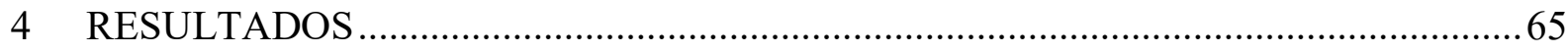




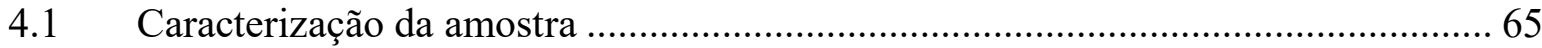

4.2 Aderência dos Indicadores GRI e do questionário ISE com as dimensões da CSP. 67

4.3 Análise da aderência dos resultados GRI com os resultados ISE .......................... 68

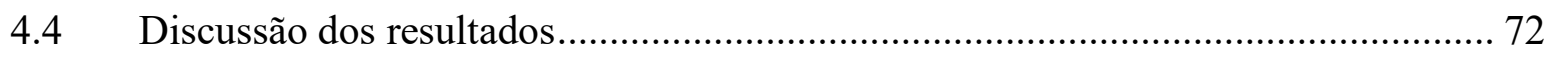

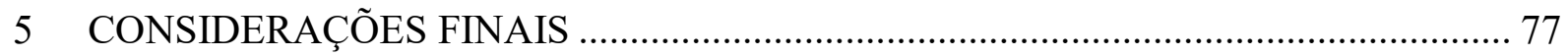

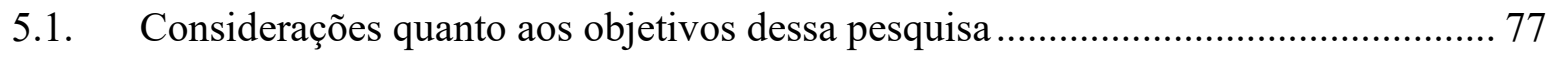

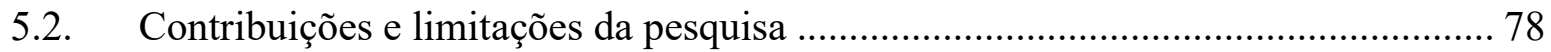

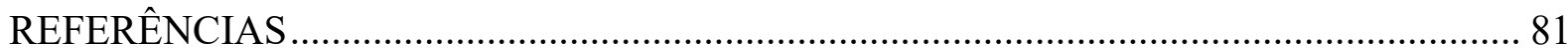




\section{INTRODUÇÃO}

A mensuração da performance corporativa é central na literatura de gestão estratégica Strategic Management (Chen; Delmas; \& Lieberman, 2015). Historicamente, a forma mais comum de se acompanhar o desempenho de uma organização é por meio da avaliação de sua performance financeira. A CFP - Corporate Financial Performance pode ser calculada por diversas formas, como: medidas de mercado (preço por ação ou valorização do preço das ações), medidas contábeis (retorno sobre ativos - ROA, retorno sobre o patrimônio líquido ROE e ganhos por ação - EPS), e medidas de percepção (surveys) (Orlitzky, Schmidt e Rynes, 2003). Dessa forma, independentemente da variável escolhida, existe suporte na literatura em relação às formas mais precisas de como medi-las (Boaventura; Silva; \& Bandeira-de-Mello, 2012).

O acompanhamento da CFP de uma empresa é de extrema importância, principalmente, para os acionistas, pois dão suporte nos processos de decisão e investimentos. Porém, a aceitabilidade de uma organização pela sociedade depende do atendimento das demandas dos stakeholders e a prestação de contas em relação às suas responsabilidades sociais e ambientais (Hahn; \& Kühnen, 2013; Boutena, Everaerta, Liedekerkeb, De Moord, \& Christiaensa, 2011). Assim, o conceito da Corporate Social Performance - CSP passa a ser relevante para uma organização que deseja obter sua licença para operar.

A Corporate Social Performance - CSP é um constructo que tem suas raízes nos estudos da Teoria Geral do Sistemas, que pontuava que as empresas, como sistemas abertos, deveriam trabalhar para aumentar os benefícios e reduzir os danos resultantes das interações de seus negócios em seu ambiente, nas esferas sociais, culturais, ambientais, legais, políticas e econômicas (Wood, 2010).

Apesar de estar presente na literatura de Administração por volta de 50 anos, até hoje não se tem estabelecido uma forma consolidada para mensuração da CSP (Wood, 2010). Ao contrário da mensuração da performance financeira de uma empresa, que possui métricas claras e amplamente utilizadas, para o cálculo da CSP não há um consenso de qual a melhor métrica a se empregar devido a uma ampla variedade de métricas (Chen \& Delmas, 2010). Waddock e Graves (1997) reforçam que CSP é um constructo multidimensional, e assim sendo, uma grande diversidade de variáveis e indicadores contribuem para sua medição. 
Além disso, outros fatores influenciam na CSP: cada organização tem suas próprias características, histórias e desempenho, além de inúmeras questões, decisões gerenciais e comportamentos corporativos que estão englobadas no termo performance social corporativa. Ainda, vários stakeholders podem estar envolvidos de diferentes formas em uma única instância do comportamento da empresa (Wood \& Jones, 1995).

A mensuração da Corporate Social Performance (CSP) exige o uso de variáveis que consideram diferentes dimensões e aspectos (Agudo, Gargallo, \& Salvador, 2015). De acordo com Orlitzty, Schimidt e Rynes (2003), são associadas 4 formas de mensuração ao constructo CSP. São elas: disclosures (relatórios de sustentabilidade, relatórios anuais, cartas aos acionistas, por exemplo); índices de reputação, por exemplo: Revista Exame Maiores e Melhores (Domingos e Moura, 2015); Fortune Magazine (Wood, 1995; Orlitzty, Schimidt e Rynes, 2003; Wartick, 2002); Dow Jones Sustainability Indexes (Darren, Faff \& LangfieldSmith, 2009); auditorias sociais, processos e resultados observados; e, por último, os princípios e valores corporativos inerentes à cultura da organização. Dessa maneira, independente da abordagem teórica utilizada para definição da CSP, se faz necessária a realização de estudos empíricos que avaliem a aderência entre os modelos que meçam a performance social corporativa com as formas de mensuração utilizadas. Nesse estudo serão abordadas duas formas: relatórios de sustentabilidade, alinhados às diretrizes da Global Reporting Initiative - GRI e um índice, o ISE - Índice de Sustentabilidade Empresarial.

\subsection{Problema de Pesquisa}

Em resposta ao artigo "A Brand New Brand of Corporate Social Performance”, de Rowley e Berman (2000) que argumentava que a CSP seria um constructo inviável para ser desenvolvido teórica e metodologicamente, Griffin (2000) pontuou que apesar da complexidade e multidimensionalidade da CSP, existem temas que poderiam direcionar pesquisas futuras, como por exemplo, novos modelos para mensuração que compreendam tanto a dinâmica interna de uma organização, quanto fatores externos, entre eles, o ambiente dos stakeholders.

Carroll (2000) sugere que existe espaço para pesquisas sobre mensuração da CSP, mas há necessidade de que algumas melhorias sejam feitas. Sua principal preocupação se relaciona com a abrangência da CSP, ou seja, é importante que sejam capturados pela métrica escolhida 
todos aspectos e dimensões importantes associados às relações entre a empresa e seus stakeholders. Ou seja, para medir CSP, é preciso que o pesquisador considere medidas amplas e robustas, e não medidas unidimensionais. Essas questões levam a compreender que ainda há oportunidade para desenvolvimento teórico e metodológico da literatura de CSP e suas formas de mensuração.

Além disso, as maneiras existentes e aceitas para medir CSP, não são muito acessíveis e abrangentes, principalmente, quando falamos de empresas brasileiras. Por exemplo, o KLD, que é uma das bases de dados mais encontradas na literatura de mensuração de CSP, não está disponível para consulta pública. Ademais, algumas das dimensões utilizadas no KLD, como, “poder nuclear" e “envolvimento com a África do Sul”, não são amplamente aplicáveis por serem relevantes apenas para organizações americanas.

O problema de pesquisa se insere na dificuldade de se encontrar métricas acessíveis, cujas dimensões possam ser aplicadas para medir a performance social corporativa em empresas no Brasil. Também, há a necessidade de realização de estudos que avaliem a aderência de bases de dados, que englobem uma ampla diversidade de variáveis, e que também, sejam de fácil acesso a pesquisadores, com modelos de CSP.

\subsection{Objetivos da Pesquisa}

Essa pesquisa tem como objetivo avaliar se relatórios de sustentabilidade que seguem as diretrizes da Global Reporting Initiative - GRI, são fontes de dados apropriadas para cálculo da Corporate Social Performance - CSP, demonstrando assim, se é possível medi-la de forma objetiva e compará-la com os resultados obtidos de diferentes relatórios.

Para atingir esse objetivo principal, alguns objetivos específicos foram estabelecidos. São eles:

1) Elaborar um framework das dimensões da Corporate Social Performance - CSP e suas variáveis;

2) Apresentar e validar um modelo de mensuração de CSP que utilize como fonte de dados as informações contidas nos indicadores dos relatórios de sustentabilidade que seguem as diretrizes da GRI; 
3) Elaborar um modelo de mensuração de CSP que utilize como fonte de dados as informações contidas nos questionários do Índice de Sustentabilidade Empresarial ISE que sirva como padrão;

4) Comparar os resultados obtidos com informações contidas nos relatórios de sustentabilidade GRI com o padrão.

\subsection{Questão de Pesquisa}

A questão de pesquisa que esse trabalho pretende responder se dá por: "Qual o nível de aderência do Relatório GRI como fonte de dados para mensuração de CSP? ”

\subsection{Delimitação de Pesquisa}

A amostra analisada nessa pesquisa foi formada por 29 empresas que compõe a Carteira ISE2016, a última carteira divulgada pela BM\&F BOVESPA, que avalia as empresas em relação às suas atividades no ano de 2014. Além disso, as empresas deveriam ter publicado seu relatório de sustentabilidade referente ao ano de 2014, de acordo com a diretrizes GRI-G4, e também, terem as respostas de seus questionários ISE publicados na página da BM\&F BOVESPA.

Para essa pesquisa, a definição operacional utilizada, foi dada por Wood e Jones (1995), e estabelece que a CSP consiste na avaliação da efetividade de uma empresa em atender a certas necessidades e interesses de stakeholders. Essa definição foi selecionada, pois é a mais adequada para responder aos objetivos desse trabalho e é compatível com tipo de informação disponível na fonte de dados escolhida para mensuração da CSP. Dentre os stakeholders avaliados, foram selecionados aqueles considerados primários para a organização, sendo eles: empregados, fornecedores, acionistas, comunidade e clientes.

\subsection{Justificativa}

Nesse contexto, o presente trabalho justifica-se por trazer uma contribuição metodológica aos estudos da CSP, por apresentar uma avaliação de mensuração, utilizando como fonte de dados, os relatórios de sustentabilidade GRI. 
Essa pesquisa utiliza como principal fonte de dados, os relatórios de sustentabilidade reportados pelas empresas, que seguem os padrões da Global Reporting Initiative - GRI, o que se consolida em uma segunda justificativa a esse trabalho. As diretrizes GRI têm sido amplamente utilizadas por grandes empresas no mundo inteiro na divulgação de relatórios de sustentabilidade, e dada a sua consolidação e padronização, a tendência é que cada vez mais, organizações de todos os portes utilizem seus manuais na elaboração de seus reportes. Os relatórios de sustentabilidade são fontes abertas e disponíveis e a possibilidade de se obter uma ferramenta de mensuração que seja compatível com esses dados informados publicamente, traria uma facilidade aos pesquisadores do tema.

A pesquisa pretende avaliar a compatibilidade das informações reportadas voluntariamente por empresas nos relatórios de sustentabilidade GRI com as dimensões da CSP encontradas na literatura. Além disso, avalia o nível de relacionamento entre os dados fornecidos pelos relatórios de sustentabilidade GRI com as respostas dos questionários ISE, na mensuração de CSP. O ISE é utilizado como padrão, uma vez que atende às dimensões de CSP adequadamente, e tem vantagens em relação ao GRI. Entre elas, a obrigatoriedade de responder a todas as perguntas do questionário ISE e a necessidade de comprovação das respostas com envio de documentos. No GRI, a escolha dos indicadores está condicionada a análise de materialidade e não há obrigatoriedade de comprovação do que é reportado.

\subsection{Estrutura da dissertação}

Esta dissertação possui 5 capítulos. O Capítulo 1 apresenta a introdução, o problema de pesquisa e os objetivos da pesquisa. O Capítulo 2 traz a revisão da literatura, tratando sobre as diversas definições de CSP e suas formas de mensuração. O Capítulo 3 aborda o método da pesquisa, com as etapas dessa pesquisa e os procedimentos metodológicos utilizados. Os resultados da pesquisa são apresentados no Capítulo 4. E no Capítulo 5 são apresentadas as considerações finais dessa dissertação. 


\section{REVISÃO DA LITERATURA}

Este capítulo tem como objetivo apresentar um histórico da pesquisa da Corporate Social Performance - CSP, considerando as duas correntes teóricas principais por onde se encaminham as pesquisas sobre esse constructo: Corporate Social Responsibility - CSR e a Teoria dos Stakeholders. Em seguida, serão abordadas as dimensões da CSP e as diversas formas de mensuração encontradas na literatura.

\subsection{Corporate Social Responsibility - CSR}

A publicação "Social Responsibilities of the Businessman" de Howard R. Bowen em 1953 marca o início do período moderno das pesquisas sobre o tema, onde o autor levantava a seguinte questão: “Quais as responsabilidades perante a sociedade se esperam que os homens de negócio assumam?" (Carroll, 1999). Apesar disso, a ideia da CSR não foi muito desenvolvida durante a década de 1950. A comunidade empresarial continuava com as velhas práticas de doações corporativas e suporte à educação em suas comunidades.

Já na década de 1960, o conceito de CSR ganhou mais algumas contribuições. Keith Davis, em 1960, argumentou que a Responsabilidade Social se referia às decisões e ações dos empresários tomadas, pelo menos em parte, por razões além do interesse econômico ou técnico da empresa. William C. Frederick também contribuiu para o avanço das pesquisas em CSR. No mesmo ano, definiu que os empresários deveriam supervisionar a operação de uma empresa para que satisfizesse as expectativas do público, melhorando o bem-estar socioeconômico total. Nessa década, as ações de filantropia e doações ganharam mais critérios, sendo direcionadas a programas mais formalizados de acordo com os interesses de toda a organização (Carroll, 2015). Durante esse período, a ideia de CSR sofreu oposições de pesquisadores, como Milton Friedman, com a alegação de que imporia um fardo injusto e caro aos acionistas (Lee, 2008).

$\mathrm{Na}$ década de 1970, as empresas passaram a gerenciar a responsabilidade social, de modo a formalizar e institucionalizar suas respostas a questões sociais e públicas, motivadas pelo próprio interesse em atuar socialmente ou pelo surgimento de diversas leis nos Estados Unidos que regulamentaram temas como proteção ambiental, saúde e segurança ocupacional, responsabilidade sobre o produto e igualdade em oportunidades de trabalho. Nessa década, 
houve também uma proliferação de definições de CSR. Na década seguinte, os estudos de CSR deixaram de focar apenas em novas definições e passaram a se concentrar em conceitos e temas alternativos, como: responsividade social corporativa, CSP, políticas públicas, ética empresarial e gestão de stakeholders (Carroll, 1999).

Umas das definições mais conhecidas de RSC, foi dada por Carroll (1979) e estabelece que para atender plenamente todas as obrigações que tem com a sociedade, a empresa deve incorporar as responsabilidades econômicas, legais, éticas e discricionárias aos seus negócios. Em 1991, Carroll revisou sua definição de RSC, trocando a responsabilidade discricionária, por responsabilidade filantrópica, conforme representado na Pirâmide da Responsabilidade Social Corporativa, na Figura 1.

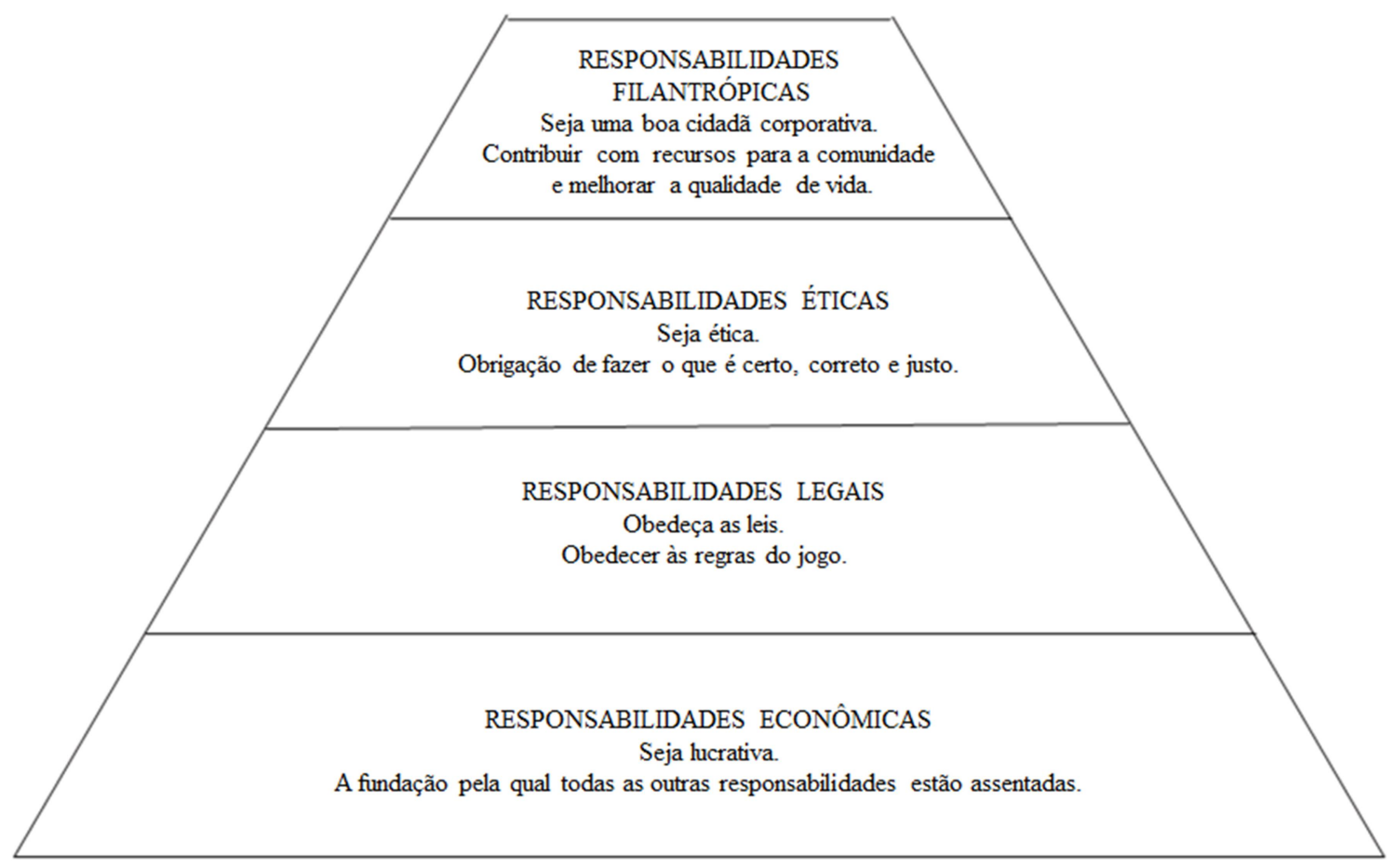

Figura 1. Pirâmide de Responsabilidade Social Corporativa (Carroll, 1991)

Nesse mesmo artigo, Carroll (1991) sinalizou um ajuste natural entre a ideia da responsabilidade social das empresas e os stakeholders de uma organização. O conceito de stakeholders personaliza as responsabilidades sociais indicando os grupos específicos que as organizações devem considerar. 
Atualmente, a Responsabilidade Social Corporativa é mais comumente vista pelos stakeholders como as atividades desenvolvidas pelas empresas que não são exigidas por lei ou seja, as categorias éticas e filantrópicas na definição apresentada da Figura 1. Nessa concepção, no entanto, a responsabilidade econômica permanece vital, pois os proprietários e investidores esperam que as empresas os forneçam, como condição de existência, retorno financeiro. As empresas se envolvem na RSC, porque percebem benefícios para seus negócios e para a sociedade. Isso representa a forma mais ampla de capitalismo consciente visto até agora, e enquanto a economia mundial continuar crescendo, espera-se que a RSC também cresça. Seu apoio global está aumentando diariamente entre as economias desenvolvidas e em desenvolvimento, e esta tendência assegura a continuação dos estudos desse tema. (Carroll, 2015).

\subsection{Teoria dos Stakeholders}

A teoria dos stakeholders foi proposta inicialmente na publicação Strategic Management: $a$ stakeholder approach, de Freeman (1984). De acordo com Freeman, a definição do termo stakeholder é qualquer grupo ou indivíduo que pode afetar ou é afetado pela realização dos objetivos da empresa. A Teoria dos Stakeholders argumenta que os acionistas (shareholders) são apenas um entre os vários stakeholders e a organização deve se esforçar para atender aos interesses de todos os stakeholders (Lin, Lee, \& Lee, 2011).

Os grupos de stakeholders de uma empresa podem ser representados conforme a Figura 2. 


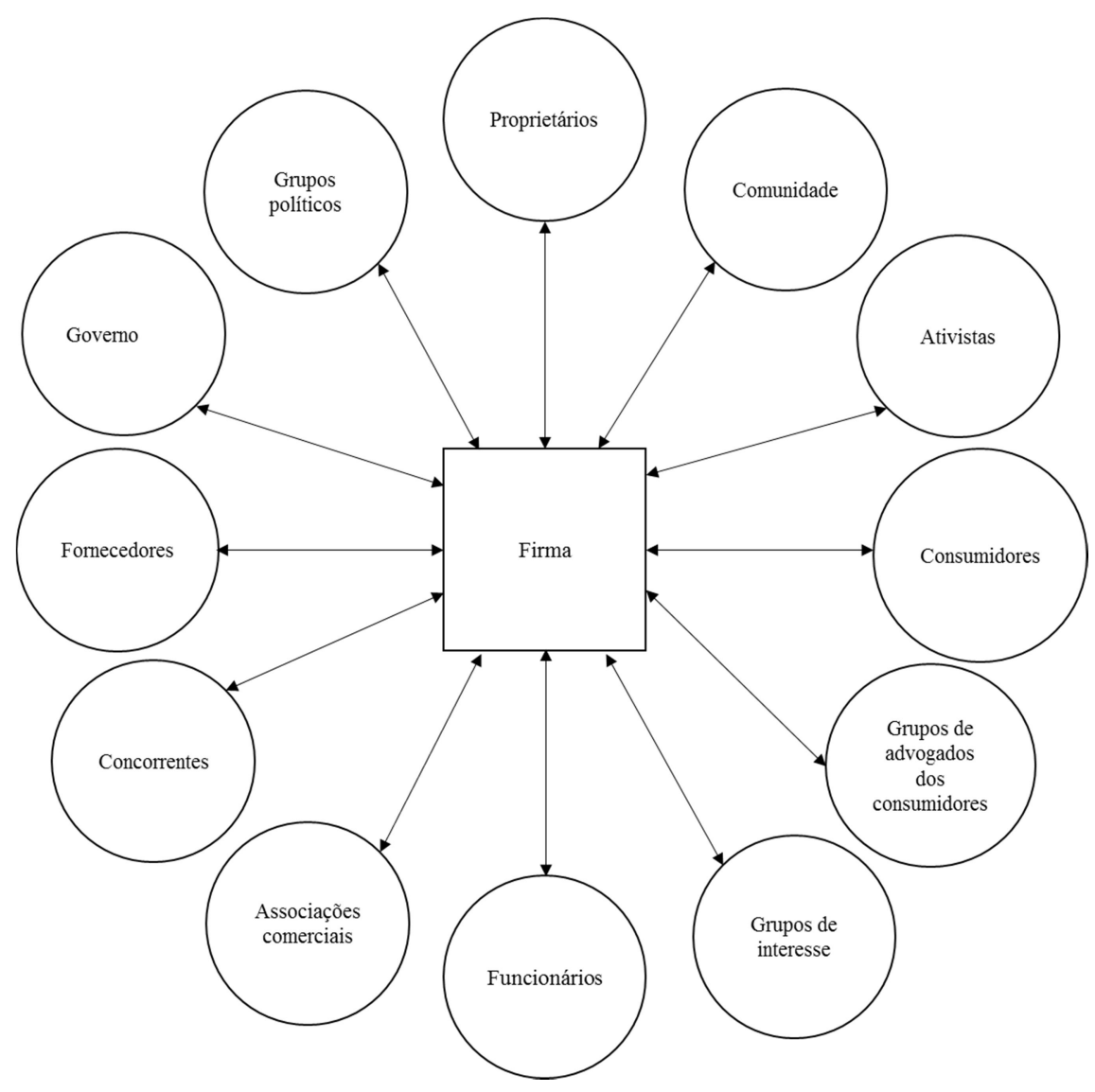

Figura 2. Mapa de Stakeholders de uma grande organização (Freeman, 1984)

Clarkson (1995) também trouxe uma importante contribuição para essa área de estudos, definindo stakeholder como pessoas ou grupos que possuem ou reivindicam propriedade, direitos ou interesses de uma companhia e suas atividades. Tais direitos ou interesses são o resultado de transações ou ações tomadas pela corporação, e pode ser legal ou moral, individual ou coletiva. As partes interessadas com interesses semelhantes, reivindicações ou direitos podem ser classificados como pertencentes ao mesmo grupo. Dessa forma, Clarkson (1995) classifica os stakeholders em primários e secundários.

Os stakeholders primários são aqueles cruciais para a sobrevivência da empresa, sendo que, sem os quais, ela não sobreviveria. Por isso, para continuar existindo, a empresa deve ter habilidade de criar riqueza, valor e satisfação suficientes para cada grupo de stakeholders primários, a fim de evitar a falha no sistema da corporativo. Os stakeholders primários são essencialmente: acionistas e investidores, empregados, clientes e fornecedores, governos e comunidades (Clarkson, 1995). 
Já os stakeholders secundários, influenciam ou afetam, ou são influenciados ou afetados pela organização, mas não são fundamentais para sua sobrevivência, como por exemplo, a mídia. A empresa não é dependente desse grupo de stakeholders, porém estes podem causar danos relevantes à imagem da empresa (Clarkson, 1995). A característica que distingue os stakeholders primários dos stakeholders secundários, reside na natureza da relação com a empresa. Os stakeholders primários são aqueles que têm uma relação de troca recíproca e direta com a corporação, ao passo que stakeholders secundários tentam influenciar essas relações de troca muito mais indiretamente (Van der Laan, Van Ees, \& Van Witteloostuijn, 2008).

Outra contribuição importante a literatura da Teoria dos Stakeholders foi dada por Donaldson e Preston (1995), que dividiram a análise da teoria em três dimensões: descritiva, instrumental e normativa. Os diferentes aspectos são apresentados na Figura 3.

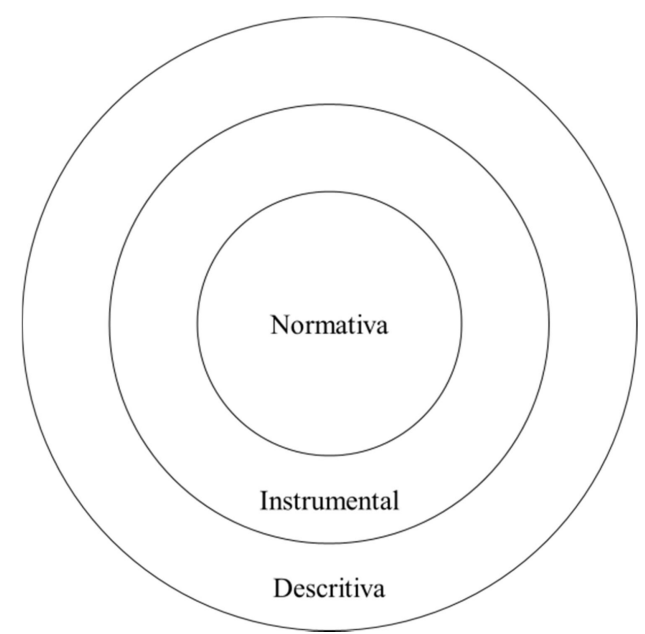

Figura 3. Aspectos da Teoria dos Stakeholders (Donaldson \& Preston, 1995)

Na dimensão descritiva, a teoria é usada para descrever, e algumas vezes, para explicar, os comportamentos e características específicos da corporação. Ela apresenta e explica as relações que são observadas na parte externa à corporação. Por isso, é representada no aro mais externo da Figura 3. Na dimensão instrumental, a teoria é usada para identificar as conexões, ou a falta delas, entre o gerenciamento de stakeholders e o alcance dos objetivos tradicionais de uma corporação (por exemplo, lucro e crescimento). Por último, na dimensão normativa, a teoria é usada para interpretar a função da corporação, incluindo a identificação dos manuais morais ou filosóficos da gestão e da operação da corporação (Donaldson \& Preston, 1995). 
Os stakeholders tem suas reivindicações e interesses para com a empresa. Balancear os interesses de cada grupo de stakeholders é o processo de avaliar e responder a essas demandas por recursos da organização (Reynolds, Schultz, \& Hekman, 2006). Segundo os autores, atender aos interesses dos stakeholders pode ser crucial para manter seu apoio, mesmo em períodos de crise. Para ajudar na avaliação e no balanceamento dos interesses dos stakeholders, existe o conceito de priorização de stakeholders, que também vem sendo estudado na literatura. Mitchell, Agle e Wood (1997) propuseram o modelo da Saliência dos Stakeholders, cuja definição se dá por: grau pelo qual gestores dão prioridade às reivindicações concorrentes dos stakeholders. Essa priorização varia de acordo com: (1) poder que os stakeholder tem de influenciar a firma; (2), a legitimidade do relacionamento dos stakeholders com a firma; e (3) urgência da reivindicação do stakeholder.

\subsection{Performance Social Corporativa - CSP}

A CSP é um constructo que coexiste com diversos outros conceitos, incluindo Corporate Social Responsibility - CSR, Teoria dos Stakeholders, Ética Empresarial e Cidadania Corporativa, na literatura de Business \& Society, e vem sendo estudado desde a década de 70 (Wood, 2010; Gond e Crane, 2010).

A origem da CSP começa a ser desenhada na década de 1950, quando emergiu a Teoria Geral dos Sistemas, que dizia que as empresas são sistemas abertos, que retiram recursos e devolvem produtos ou serviços aos seus ambientes, e que devem se responsabilizar por aumentar os benefícios oferecidos à sociedade e mitigar os danos que possam vir a causar (Wood, 2010).

\subsubsection{A Performance Social Corporativa - CSP e a Responsabilidade Social Corporativa}

No princípio, a definição de CSP esteve relacionada com os estudos sobre filantropia e responsabilidade social corporativa (RSC ou CSR). Para Carroll (2015), a ideia da CSP se tornou popular, pois materializou o conceito da CSR, em resultados práticos, o que traria motivação para buscá-la. 
As primeiras conceituações de CSP foram dadas por Sethi (1975) e por Carroll (1979). Sethi (1975) desenvolveu um modelo de avaliação estrutural para facilitar a análise das atividades sociais de uma empresa, por meio da adaptação do comportamento corporativo, que poderia ser identificado em três estágios: obrigações sociais, responsabilidade social e responsividade social. O comportamento motivado pelas obrigações sociais, seria aquele proveniente das pressões legais e do mercado. A responsabilidade social seria um estágio onde as ações da empresa superariam as exigências legais. E por último, seria o estágio da responsividade social, onde o comportamento corporativo da empresa teria a intenção de minimizar os possíveis efeitos colaterais de suas atividades antes deles acontecerem, ou seja, seriam as atividades sociais que visariam o longo prazo. Por sua vez, Carroll (1979) estabeleceu o primeiro modelo conceitual de CSP. Argumentando que "responsabilidade social" sugere motivação, e não é mensurável, o pesquisador optou pelo termo "performance social" para operacionalizar o conceito (Wood, 2010). Dessa forma, a CSP deveria ser avaliada levando em consideração a integração de três dimensões: as diferentes categorias da responsabilidade social, a filosofia da responsividade social e as questões sociais envolvidas, conforme Figura 4.

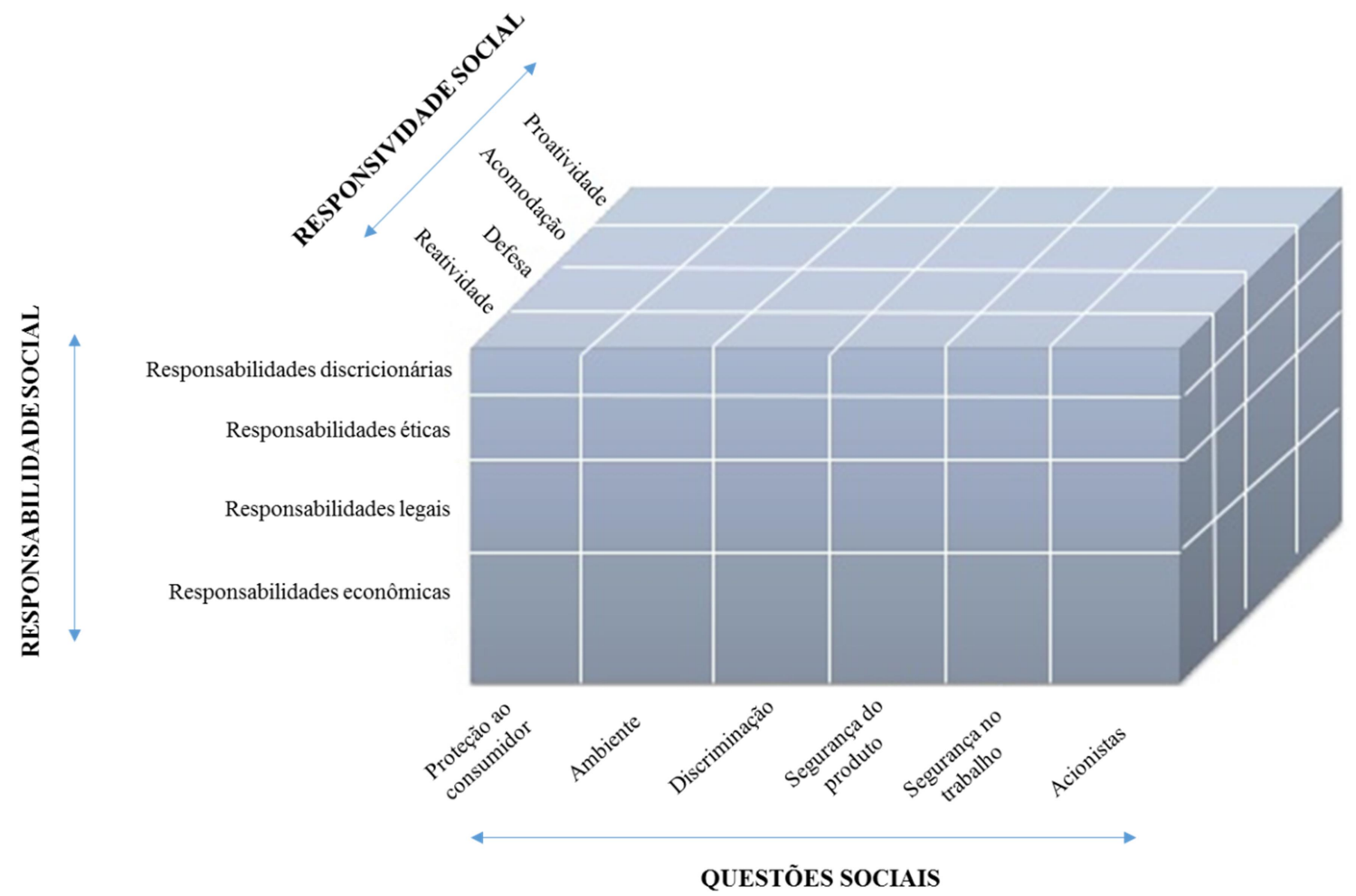

Figura 4. Modelo de Corporate Social Performance (Carroll, 1979) 
Tanto no modelo de Sethi (1975), quanto no modelo de Carroll (1979), observou-se um enfoque mais qualitativo, sem muita preocupação com a quantificação da CSP.

Em 1985, Wartick e Crochran sugeriram algumas melhorias ao modelo de Carroll, trazendo alguns conceitos adicionais, que tornaram o modelo de CSP mais robusto e lógico (Wood, 2010). Foi proposto que o envolvimento social das empresas deveria se apoiar sobre os princípios de responsabilidade social, o processo de responsividade social e as políticas de gestão das questões sociais, que representariam orientações filosóficas, institucionais e organizacionais, respectivamente. Segundo os próprios autores, uma contribuição importante do artigo foi a definição de responsividade social como a forma de uma empresa realizar sua responsabilidade social; e a gestão das questões sociais seria para operacionalizar a responsividade social. Dessa forma, foram apresentados mais itens para quantificação da responsividade social, importante contribuição para pesquisas empíricas. O modelo de Wartick e Cochran (1985) é apresentado na Figura 5.

\begin{tabular}{|l|l|}
\hline \multicolumn{2}{|c|}{ Princípios } \\
\hline & \multicolumn{1}{|c|}{$\begin{array}{c}\text { Responsabilidades Sociais } \\
\text { Corporativas }\end{array}$} \\
\hline 1 & Econômicas \\
\hline 2 & Legais \\
\hline 3 & Éticas \\
\hline 4 & Discricionárias \\
\hline
\end{tabular}

Direcionadas ao:

\begin{tabular}{|l|l|}
\hline 1 & Contrato social dos negócios \\
\hline 2 & $\begin{array}{l}\text { Negócio como um agente da } \\
\text { moral }\end{array}$ \\
\hline
\end{tabular}

Orientação filosófica

\begin{tabular}{|l|l|}
\hline \multicolumn{2}{|c|}{ Processos } \\
\hline & \multicolumn{1}{|c|}{$\begin{array}{c}\text { Responsividades Sociais } \\
\text { Corporativas }\end{array}$} \\
\hline 1 & Reativa \\
\hline 2 & Defensiva \\
\hline 3 & Acomodativa \\
\hline 4 & Proativa \\
\hline
\end{tabular}

\begin{tabular}{|l|l|}
\hline \multicolumn{2}{|c|}{ Políticas } \\
\hline & \multicolumn{1}{|c|}{ Gestão das questões sociais } \\
\hline 1 & Identificação das questões \\
\hline 2 & Análise das questões \\
\hline 3 & Elaboração das respostas \\
\hline
\end{tabular}

Direcionadas à:

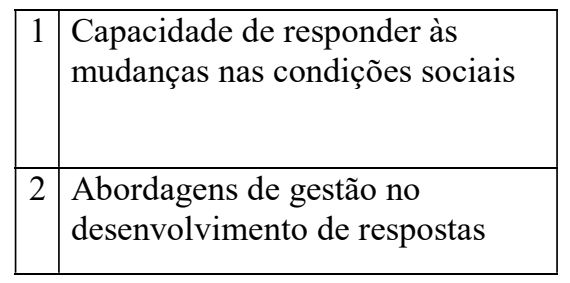

Orientação institucional
Direcionadas à:

\begin{tabular}{|l|l|}
\hline 1 & Minimizar surpresas \\
\hline 2 & $\begin{array}{l}\text { Determinar políticas sociais } \\
\text { corporativas efetivas }\end{array}$ \\
\hline
\end{tabular}

Orientação organizacional

Figura 5. Modelo de Corporate Social Performance (Wartick \& Cochran, 1985)

Uma atualização do conceito de CSP foi proposta por Wood (1991), que endereçou algumas questões não resolvidas no modelo de Wartick e Cochran, em 1985 (Wood, 2010). Dessa forma, a nova definição de CSP se deu por: "uma configuração de uma organização de 
princípios de responsabilidade social, processos de responsividade social e políticas, programas e resultados observáveis, e como eles se conectam com as relações sociais da empresa”. Nesse modelo, apresentado na Figura 6, Wood argumentou que a CSP seria um conjunto de categorizações descritivas da atividade empresarial, com foco nos impactos e resultados para a sociedade, para os stakeholders e para a própria empresa (Wood, 2010). Dessa maneira, para avaliar a CSP seria necessário analisar o grau em que os princípios de responsabilidade social motivam as ações sociais da empresa; o grau no qual as empresas respondem às questões, fazendo uso de processos de responsividade social; e a existência de políticas e programas, elaborados para gerenciar as relações sociais e os impactos sociais causados pela existência desses programas e políticas.

\begin{tabular}{|l|}
\hline \multicolumn{1}{|c|}{ Princípios da Responsabilidade Social Corporativa } \\
\hline $\begin{array}{l}\text { Princípio institucional: Legitimidade } \\
\text { Princípio organizacional: responsabilidade pública } \\
\text { Princípio individual: critérios gerenciais }\end{array}$ \\
\hline \multicolumn{1}{|c|}{ Processos da Responsividade Social Corporativa } \\
\hline $\begin{array}{l}\text { Análise do ambiente } \\
\text { Gestão dos stakeholders } \\
\text { Questões gerenciais }\end{array}$ \\
\hline \multicolumn{1}{|c|}{ Resultados do Comportamento Corporativo } \\
\hline $\begin{array}{l}\text { Impactos sociais } \\
\text { Programas sociais } \\
\text { Políticas sociais }\end{array}$ \\
\hline
\end{tabular}

Figura 6. Modelo de Corporate Social Performance (Wood, 1991)

Seguindo a linha dos pesquisadores de CSP até então, Swanson (1995) propôs algumas reorientações no modelo de Wood (1991), alegando falta de integração entre as perspectivas econômicas e normativas, além de problemas no desenvolvimento da teoria. Segundo a autora, o modelo de Wood (1991) levaria em consideração apenas as perspectivas da linha teórica de administração e não consideraria o desenvolvimento da literatura de ética empresarial. À vista disso, no modelo proposto por Swanson (1995), não existe uma hierarquia entre os princípios de CSR. Os níveis individuais, organizacionais e sociais interagem com os princípios, valores e resultados. No modelo apresentado na Figura 7, os tópicos de pesquisa são apresentados em quadros e suas relações ou conexões são representados pelas setas. 


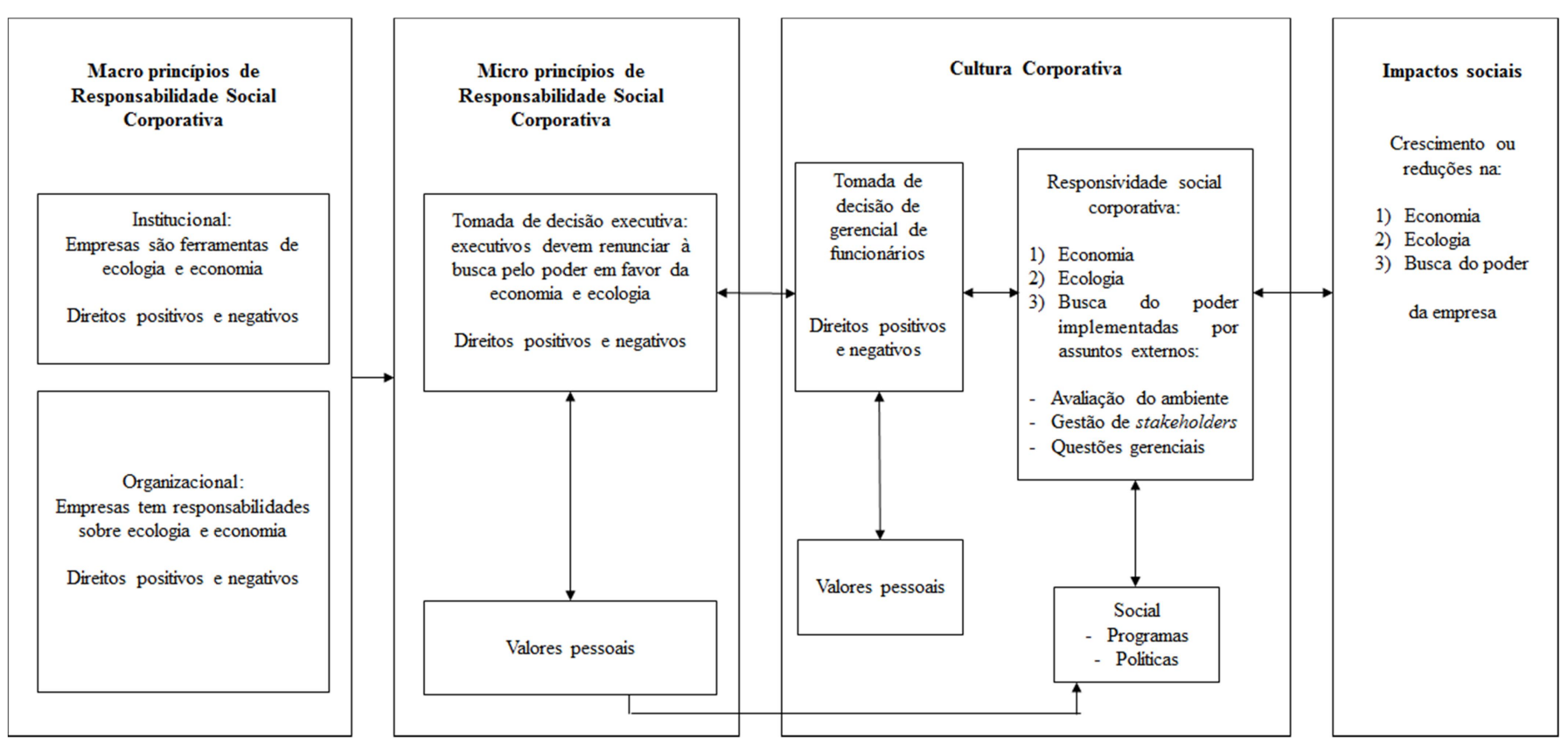

Figura 7. Modelo de Corporate Social Performance (Swanson, 1995)

Ainda, Swanson (1995) define os termos: "ecologia", como as ligações de integração entre as organizações e seus ambientes que funcionam de forma adaptativa para garantir a sustentabilidade, baseadas no comportamento cooperativo e colaborativo; "economia", como a habilidade da organização converter insumos em produtos, por meio do comportamento competitivo; e "busca de poder", como o comportamento egocêntrico da organização que pretende adquirir e usar o poder coercitivo por meio de acordos hierárquicos. Em 1999, Swanson voltou a publicar um artigo sobre o tema, endereçando a falta de integração das abordagens normativas (o que a empresa deve ou não fazer) e descritivas (o que a empresa pode ou não fazer) para o negócio e a para sociedade, que existe devido aos diferentes estilos dos pesquisadores.

\subsubsection{CSP e a Teoria dos Stakeholders}

Ao fazer uma revisão de toda a literatura de Corporate Social Performance, outra estratégia de definição e mensuração de CSP é encontrada, além da CSR: a análise dos stakeholders (Gao, 2008). Clarkson (1995) foi o pesquisador que promoveu essa ruptura, com a publicação de seu artigo "A stakeholder framework for analyzing and evaluating corporate social performance", propondo uma nova abordagem para a conceituação da CSP. Segundo o autor, a CSP poderia ser analisada e avaliada de forma mais eficaz por meio da utilização de um 
framework ou modelo, baseado na gestão dos relacionamentos de uma corporação com seus stakeholders, do que usando modelos e metodologias baseadas em conceitos relativos a responsabilidade e responsividade social. As principais conclusões de sua pesquisa foram: (a) é necessário distinguir as questões dos stakeholders e as questões sociais, pois as empresas e seus gestores regem as relações com seus stakeholders e não com a sociedade; (b) é necessário conduzir análises no nível apropriado: institucional, organizacional ou individual; (c) é possível analisar e avaliar a performance social da empresa e a performance de seus líderes em gerenciar as responsabilidades da empresa e suas responsabilidades com seus stakeholders (Clarkson, 1995).

No mesmo ano de 1995, em uma publicação sobre as dificuldades de se encontrar referenciais teóricos robustos em pesquisas empíricas sobre CSP, Wood e Jones (1995), também propuseram a Teoria dos Stakeholders como linha teórica mais relevante na elaboração de constructos de CSP, uma vez que, o constructo seria influenciado pelo nível de engajamento de uma empresa em seus relacionamentos com a sociedade e sua responsabilidade com seus deveres.

A escolha da Teoria dos Stakeholders para conceituar a CSP justificou-se, pois, a teoria é a chave para entender as dimensões das relações entre as empresas e a sociedade, sendo assim, fundamental para discernir as relações entre os vários indicadores da performance social corporativa. Os stakeholders trazem a resposta para a questão: "Por quem a empresa deve ser responsável?" (Wood \& Jones, 1995)

Sendo assim, os stakeholders cumprem pelo menos três papéis com respeito ao desempenho social das empresas: (a) apontam expectativas quanto ao desempenho corporativo desejável e indesejável; (b) experimentam os efeitos do comportamento empresarial, uma vez que são os destinatários das ações relacionadas; (c) avaliam os resultados das interações das empresas, verificando se suas expectativas foram cumpridas; e avaliam como o comportamento das empresas afetou os grupos e as organizações em seu ambiente interno e externo (Wood \& Jones, 1995).

A amplitude de CSP depende da sensibilidade da organização às demandas dos stakeholders; a diversidade das demandas dos stakeholders; e exposição à observação e avaliação do stakeholders (Brower \& Mahajan, 2013). Isso significa, que a CSP de uma organização está 
ligada com a maneira que ela se relaciona com seus stakeholders, reforçando as ideias de Clarkson (1995) e Wood e Jones (1995). Quando uma organização investe em CSP, ela está construindo relações fortes, aumentando sua diferenciação e criando vantagem competitiva sustentável (Brower \& Mahajan, 2013).

Os estudos mais recentes trouxeram novas possibilidades de abordagens para o conceito da CSP. Griffin (2000) revisitou os estudos relacionados a CSP e fez uma análise das possíveis pesquisas futuras relacionadas ao tema. Também se posicionou contra à publicação de Rowley e Berman (2000) que argumentaram que a CSP não era um constructo viável, por isso não deveria mais ser utilizado. Griffin (2000) sugeriu também, que o constructo da CSP poderia ser estudado por outras áreas de pesquisa, como marketing e recursos humanos. Assim como Griffin (2000), Carroll (2000) também fez sugestões sobre o futuro das pesquisas em CSP, principalmente no que diz respeito a sua mensuração. Ambas as publicações tratam a CSP com uma abordagem mista, cujo desempenho social poderia ser obtido pelas ações relativas às questões sociais, mas também com o atendimento das demandas dos stakeholders.

Ainda, Carroll (2000) afirmou que para a CSP ser uma boa forma de avaliação do desempenho social de uma empresa, as pesquisas no tema devem ser aprimoradas, capturando todas as dimensões e aspectos associados às relações entre a empresa e seus stakeholders, e não isolada no desempenho da empresa em relação a apenas uma questão social (por exemplo, meio ambiente, filantropia, segurança do produto) ou um stakeholder.

Diferenças entre CSP e CSR foram apresentadas por Barnett (2007). Para o autor, a CSP é uma fotografia do desempenho social de uma empresa em um determinado ponto no tempo. Além disso, as relações com os stakeholders devem ser a base para fundamentar o seu desempenho social.

Wood (2010) fez uma revisão da literatura de CSP que sugeriu, que apesar dos mais de 45 anos de pesquisa, ainda existiam áreas onde havia maior ênfase de estudo, porém com maior foco na firma do que nos stakeholders, além de grandes gaps em áreas de pesquisa, que poderiam ser motivadas pela dificuldade de se conseguir bases de dados confiáveis. Como conclusão, Wood (2010) enfatizou a necessidade dos pesquisadores de CSP voltarem a focar os estudos nos stakeholders e na sociedade, e também, incorporarem aos estudos de CSP, literatura de outras áreas de pesquisa. 
Gond e Crane (2010) também fizeram uma avaliação do desenvolvimento teórico da CSP, afirmando que ainda falta uma base teórica forte e maior validação empírica para evitar que o constructo caia em desuso. Siltaoja (2014), em um dos artigos mais recentes publicados sobre o tema, revisita o modelo de Wood (1991), conceituando CSP como uma forma de traduzir a responsabilidade social corporativa na prática, centrando-se em quatro características principais de atuação: princípios, processos, resultados e a dimensão de criação do conhecimento.

Nessa pesquisa foi considerada a definição de CSP dada por Wood e Jones (1995) que estabelece que a CSP tem relação com a capacidade de uma empresa em atender às necessidades e interesses de stakeholders. As empresas capazes de atender ou exceder a essas necessidades podem desenvolver reputações positivas, reforçar a legitimidade da empresa, fortalecer a imagem da empresa, reduzir riscos, desenvolver capacidades organizacionais valiosas e são mais propensas a serem vistas como éticas (Slater \& Dixon-Fowler, 2009).

\subsection{Dimensões da CSP}

Tomando como base a definição operacional de CSP considerada nessa pesquisa, na qual o constructo deve avaliar a efetividade de uma empresa em atender a certas necessidades e expectativas de stakeholders (Wood \& Jones, 1995), as dimensões da CSP devem ser alinhadas ao atendimento desses diferentes interesses.

A estratégia dos stakeholders para mensuração da CSP é usada para identificar mais especificamente as atividades de negócio que são consideradas responsabilidade da corporação para servir cada stakeholder (Gao, 2009).

Inúmeros pesquisadores propuseram a utilização de diversas dimensões para a mensuração de CSP. Como exemplo, seguindo a Teoria dos Stakeholders, Agudo et al. (2015) propuseram as dimensões, apresentadas na Figura 8. 


\begin{tabular}{|c|c|}
\hline Governança corporativa / Shareholders & $\begin{array}{l}\text { Código de conduta para os órgãos de governo } \\
\text { Representação em órgãos de governo } \\
\text { Formação e sensibilização em CSR } \\
\text { Estratégia de comunicação com stakeholders } \\
\text { Relatório do governo corporativo }\end{array}$ \\
\hline Empregados & $\begin{array}{l}\text { Planos de prevenção de riscos trabalhistas } \\
\text { Formação em prevenção de riscos trabalhistas } \\
\text { Programas de exames médicos } \\
\text { Programas de horários flexíveis } \\
\text { Facilidades para permissões especiais } \\
\text { A igualdade de oportunidades na contratação } \\
\text { Desenvolvimento, promoção e formação dos trabalhadores } \\
\text { Salários } \\
\text { Pesquisas de satisfação do empregado } \\
\text { Avaliação de desempenho do empregado } \\
\text { Planos de comunicação interna } \\
\text { Canais de reclamações e sugestões dos funcionários } \\
\text { Planos de pensão } \\
\text { Auxílios para serviços de cuidados para parentes } \\
\text { Seguro saúde e de acidentes } \\
\text { aconselhamento jurídico } \\
\text { representação sindical } \\
\text { Diálogo aberto com os representantes dos trabalhadores }\end{array}$ \\
\hline Clientes & $\begin{array}{l}\text { Sistemas de medição de satisfação do cliente } \\
\text { Canais de reclamações e sugestões dos clientes } \\
\text { Princípios de transparência e de defesa do consumidor } \\
\text { Não recorrência de publicidade desleal } \\
\text { Cumprimento das leis de proteção de informações e } \\
\text { privacidade } \\
\text { Informação e aconselhamento ao cliente } \\
\text { Desenvolvimento da ISO } 9001\end{array}$ \\
\hline Fornecedores & $\begin{array}{l}\text { Código de ética com fornecedores } \\
\text { Critérios de selecção transparentes de fornecedores } \\
\text { Negociações com base no benefício mútuo } \\
\text { Acompanhamento (Follow up) do fornecedor } \\
\text { Canais de diálogo com fornecedores }\end{array}$ \\
\hline Meio Ambiente & $\begin{array}{l}\text { Minimização do consumo de recursos naturais } \\
\text { Medidas de correção da poluição } \\
\text { Sistemas de gestão ambiental } \\
\text { Educação e sensibilização ambiental } \\
\text { Elaboração de relatório ambiental } \\
\text { Design de produtos ecológicos } \\
\text { Fomento do consumo responsável } \\
\end{array}$ \\
\hline Relações com a sociedade & $\begin{array}{l}\text { Apoio às atividades culturais } \\
\text { Apoio de atividades esportivas } \\
\text { Apoio das atividades de saúde e bem-estar } \\
\text { Participação em atividades públicas } \\
\text { Apoio aos grupos desfavorecidos } \\
\text { Apoio às atividades de formação/ treinamento } \\
\text { Apoio da protecção do ambiente } \\
\text { Campanhas de apoio às ONGs } \\
\text { Interessado em adotar iniciativas de CSR } \\
\text { Grau de implantação CSR }\end{array}$ \\
\hline
\end{tabular}

Figura 8. Dimensões de CSP (Agudo et al. 2015) 
Sob a ótica de atendimento dos interesses dos stakeholders, Tantalo e Priem (2014) argumentam que as organizações utilizam estratégias para criação de valor para satisfação de suas demandas. Esses valores são representados na Figura 9.

\begin{tabular}{|l|l|}
\hline Shareholders & $\begin{array}{l}\text { Retorno esperado } \\
\text { Risco do negócio } \\
\text { Investimento em um horizonte de tempo } \\
\text { Responsabilidade Social Corporativa }\end{array}$ \\
\hline Clientes & $\begin{array}{l}\text { Valor percebido } \\
\text { Preço do produto } \\
\text { Acessibilidade - tempo gasto para efetuar a compra } \\
\text { Tempo necessário para dominar o uso do novo produto } \\
\text { Qualidade percebida } \\
\text { Responsabilidade ambiental e produtos "ecofriendly" }\end{array}$ \\
\hline Empregados & $\begin{array}{l}\text { Salário } \\
\text { Responsabilidade Social Corporativa } \\
\text { Justiça percebida no ambiente de trabalho } \\
\text { Características do trabalho e habilidades variadas } \\
\text { Políticas de balanço entre trabalho e vida pessoal }\end{array}$ \\
\hline Fornecedores & $\begin{array}{l}\text { Procedimento de compra } \\
\text { Relações de longo prazo } \\
\text { Preço recebido } \\
\text { Termos de pagamento } \\
\text { Imagem } \\
\text { Possibilidade de venda cruzada }\end{array}$ \\
\hline Comunidade & $\begin{array}{l}\text { Quantidade e tipos de vagas de emprego criadas } \\
\text { Impostos e taxas a serem pagas } \\
\text { Suporte para a infraestrutura exigida } \\
\text { Externalidades ligadas ao negócio (por exemplo, ruído ou } \\
\text { poluição) } \\
\text { Clusters locais }\end{array}$ \\
\hline
\end{tabular}

Figura 9. Valores para cada stakeholder (Tantalo \& Priem, 2014)

Da mesma forma, Sarturi e Seravalli (2015) fizeram uma análise da literatura, onde verificouse quais os recursos tangíveis e intangíveis são distribuídos pelas organizações, afim de atenderem as demandas e interesses dos stakeholders. Os recursos estão apresentados na Figura 10. 


\begin{tabular}{|c|c|c|}
\hline Stakeholder & Recursos tangíveis & Recursos intangíveis \\
\hline Acionista & $\begin{array}{l}\text { Dividendos (BROWN; FORSTER, 2013), } \\
\text { (CLARKE, 1998) } \\
\text { Preço de mercado (CLARKE, 1998) }\end{array}$ & $\begin{array}{l}\text { Informação e transparência (HARRISON; } \\
\text { WICKS, 2013) }\end{array}$ \\
\hline Funcionário & $\begin{array}{l}\text { Salários mais altos (BROWN; FORSTER, } \\
\text { 2013), (CLARKE, 1998), (BOSSE; PHILLIPS; } \\
\text { HARRISON, 2010) } \\
\text { Direitos de propriedade (ZATTONI, 2011) } \\
\text { Compensação com ações (DEUTSCH; } \\
\text { VALENTE, 2013) }\end{array}$ & $\begin{array}{l}\text { Ambiente de trabalho agradável (BROWN; } \\
\text { FORSTER, 2013) } \\
\text { Bem-estar (GARCIA-CASTRO, ARIÑO, } \\
\text { CANELA, 2011) } \\
\text { Respeito e inclusão (HARRISON; WICKS, } \\
\text { 2013) }\end{array}$ \\
\hline Comprador & $\begin{array}{l}\text { Produtos com qualidade e funcionalidade } \\
\text { (HARRISON; BOSSE, 2013) }\end{array}$ & $\begin{array}{l}\text { Repetição de negócios e respeito } \\
\text { (HARRISON; WICKS, 2013) } \\
\text { Serviços (OGDEN; WATSON, 1999) }\end{array}$ \\
\hline Fornecedor & $\begin{array}{l}\text { Natureza de pagamentos } \quad \text { (o tamanho) } \\
\text { (HARRISON; WICKS, 2013) }\end{array}$ & $\begin{array}{l}\text { Relacionamento estável e duradouro } \\
\text { (DEUTSCH; VALENTE, 2013) } \\
\text { Natureza de pagamentos (a velocidade) } \\
\text { (HARRISON; WICKS, 2013) }\end{array}$ \\
\hline Comunidade & $\begin{array}{l}\text { Programas sociais (REYNOLDS; SCHULTZ; } \\
\text { HEKMAN, 2006) } \\
\text { Saúde física, conforto e conveniência (CRAGG; } \\
\text { GREENBAUM, 2002) } \\
\text { Contribuições de infraestrutura (HARRISON; } \\
\text { WICKS, 2013) }\end{array}$ & $\begin{array}{l}\text { Proteção às tradições culturais (CRAGG; } \\
\text { GREENBAUM, 2002) } \\
\text { Serviço comunitário (HARRISON; WICKS, } \\
\text { 2013) }\end{array}$ \\
\hline
\end{tabular}

Figura 10. Tipos de recursos (Sarturi \& Seravalli, 2015)

\subsubsection{Dimensões da CSP utilizadas}

Para essa pesquisa, as dimensões de CSP foram definidas após uma análise da literatura de Corporate Social Performance nas bases Web of Knowledge e Scopus. Como a CSP se constitui em uma medida que avalia o desempenho de uma organização no atendimento dos interesses e demandas de seus stakeholders (Boaventura, Silva, \& Bandeira-de-Mello, 2012), buscou-se as dimensões mais utilizadas para cada um dos stakeholders: empregados, fornecedores, comunidade, acionistas, e clientes, que atendessem a esse critério. Os stakeholders foram escolhidos por se tratarem de stakeholders primários, ou seja, por serem fundamentais para a sobrevivência da empresa. Apesar do meio-ambiente aparecer em algumas pesquisas como dimensão de CSP, considerar o meio-ambiente um stakeholder implicaria em uma extensão do conceito original da Teoria dos Stakeholders (Boaventura, 
Silva, \& Bandeira-de-Mello, 2012), por isso, o meio-ambiente não foi considerado como stakeholder nessa pesquisa.

Nos itens a seguir estão apresentadas as dimensões encontradas na literatura que atendem aos interesses e demandas de cada um dos stakeholders (empregados, fornecedores, acionistas, comunidade e clientes). Para operacionalização da mensuração da CSP, observou-se em muito artigos, que cada dimensão foi representada por diferentes variáveis alinhadas ao tema. No

\subsubsection{STAKEHOLDER: EMPREGADOS}

Os empregados são reconhecidos como stakeholders organizacionais, na medida em que podem afetar ou serem afetados pela realização dos objetivos de uma organização (Freeman, 1984). Os empregados fazem um grande investimento por seus anos de serviço, podem ter muito menos capacidade de se retirar da organização e podem ter uma participação maior no futuro da empresa do que muitos de seus acionistas. Além disso, hoje em dia, os empregados têm sua importância reconhecida por meio de diversas regulamentações, como as de saúde e segurança ocupacional e igualdade de oportunidades (Willians, S. J., \& Adams, C.A., 2013). Isto justifica o maior número de dimensões e variáveis encontradas, entre os stakeholders avaliados, apresentadas na Figura 11. 


\begin{tabular}{|l|l|l|}
\hline Stakeholder & Dimensões & Variáveis \\
\hline
\end{tabular}

\begin{tabular}{|c|c|c|}
\hline \multirow{21}{*}{ 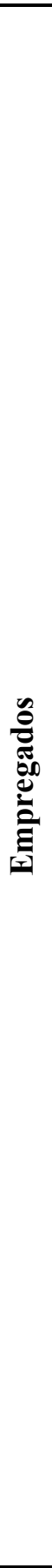 } & \multirow{2}{*}{$\begin{array}{l}\text { Equilíbrio entre vida } \\
\text { profissional, pessoal e } \\
\text { familiar }\end{array}$} & $\begin{array}{l}\text { Programa de flexibilidade no trabalho (horários flexíveis, home- } \\
\text { office) }\end{array}$ \\
\hline & & Programas especiais de licença maternidade \\
\hline & \multirow{2}{*}{$\begin{array}{l}\text { Saúde e segurança } \\
\text { ocupacional }\end{array}$} & $\begin{array}{l}\text { Políticas de promoção de um ambiente de trabalho saudável e } \\
\text { seguro (análise de riscos ocupacionais, plano de prevenção, } \\
\text { treinamentos) }\end{array}$ \\
\hline & & $\begin{array}{l}\text { Informações sobre ocorrência e redução de lesões, doenças } \\
\text { ocupacionais, dias perdidos e absenteísmo, e número de óbitos } \\
\text { relacionados ao trabalho }\end{array}$ \\
\hline & \multirow{2}{*}{$\begin{array}{l}\text { Compromisso com direitos } \\
\text { humanos nas práticas de } \\
\text { trabalho }\end{array}$} & $\begin{array}{l}\text { Políticas para garantir a inexistência de trabalho forçado ou } \\
\text { análogo ao escravo na cadeia }\end{array}$ \\
\hline & & Políticas para garantir a inexistência de trabalho infantil na cadeia \\
\hline & Treinamento e educação & $\begin{array}{l}\text { Treinamentos disponíveis para os empregados (programas / horas } \\
\text { de treinamento) }\end{array}$ \\
\hline & \multirow[b]{2}{*}{ Perspectivas de carreira } & $\begin{array}{l}\text { Programas de gestão de carreira (plano, sistemas de avaliação de } \\
\text { desempenho) }\end{array}$ \\
\hline & & Redução do turnover (estatísticas e programas) \\
\hline & \multirow{4}{*}{$\begin{array}{l}\text { Diversidade e igualdades } \\
\text { de oportunidades }\end{array}$} & Emprego de mulheres na liderança \\
\hline & & Pessoas com deficiência empregadas \\
\hline & & $\begin{array}{l}\text { Programas para estimulem a diversidade na contratação e } \\
\text { igualdade no tratamento, envolvendo temas como: gênero, } \\
\text { deficiência, LGBT, Etnia }\end{array}$ \\
\hline & & Igualdade de salários entre homens e mulheres \\
\hline & \multirow{3}{*}{$\begin{array}{l}\text { Salários, recompensas e } \\
\text { benefícios justos }\end{array}$} & Programas e políticas formais de salários, recompensas e mérito \\
\hline & & $\begin{array}{l}\text { Benefícios para aposentadoria: existência de fundos, plano de } \\
\text { aposentadoria }\end{array}$ \\
\hline & & $\begin{array}{l}\text { Oferecimento de benefícios além dos obrigatórios por lei (FGTS, } \\
13^{\circ} \text {, férias e vale transporte) }\end{array}$ \\
\hline & Anti-discriminação & Esforços anti-discriminação (políticas ou programas) \\
\hline & $\begin{array}{l}\text { Envolvimento com a } \\
\text { comunidade }\end{array}$ & Programas de voluntariado empresarial \\
\hline & \multirow{2}{*}{$\begin{array}{l}\text { Satisfação do empregado e } \\
\text { clima organizacional }\end{array}$} & $\begin{array}{l}\text { Canais de comunicação para sugestões e reclamações, com } \\
\text { garantia de confidencialidade }\end{array}$ \\
\hline & & Pesquisas de clima organizacional / satisfação do empregado \\
\hline & $\begin{array}{l}\text { Relacionamento com } \\
\text { sindicatos e união de } \\
\text { trabalhadores }\end{array}$ & Liberdade de associação sindical e direito à negociação coletiva \\
\hline
\end{tabular}

\section{Figura 11. Dimensões da CSP para empregados}

\section{Fonte: do autor}


As empresas carregam a responsabilidade pela performance social e ambiental de seus fornecedores, ou seja, são corresponsáveis pelas irregularidades cometidas por eles, uma vez que as empresas têm o potencial de influenciar diretamente o CSP dos seus fornecedores, por exemplo através do processo de seleção e das decisões de concepção de produtos (Schleper, M. C., \& Busse, C., 2013). Por isso, as dimensões e variáveis de CSP para os fornecedores buscam garantir o relacionamento e parcerias entre as partes, e estão apresentadas na Figura 12.

\begin{tabular}{|c|c|c|}
\hline Stakeholder & Dimensões & Variáveis \\
\hline \multirow{3}{*}{ 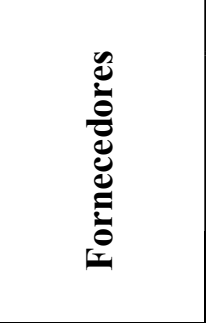 } & \multirow[b]{2}{*}{$\begin{array}{l}\text { Relacionamento com } \\
\text { fornecedores }\end{array}$} & Parceria entre a empresa e fornecedores \\
\hline & & $\begin{array}{l}\text { Programas para contratação e manutenção de fornecedores } \\
\text { para assegurar a responsabilidade socioambiental de } \\
\text { fornecedores (cláusulas contratuais, código de ética ou } \\
\text { conduta) }\end{array}$ \\
\hline & $\begin{array}{l}\text { Fornecedores locais } \mathrm{e} \\
\text { menores }\end{array}$ & $\begin{array}{l}\text { Priorização e estímulo a parcerias com fornecedores locais e } \\
\text { menores. }\end{array}$ \\
\hline
\end{tabular}

Figura 12. Dimensões da CSP para fornecedores

Fonte: do autor

\subsubsection{STAKEHOLDER: ACIONISTAS}

$\mathrm{O}$ atendimento dos interesses dos stakeholders acionistas é que tem maior relação com os ganhos financeiros da organização. Aspectos de governança corporativa também são encontrados no que diz respeito às dimensões e variáveis de CSP para este stakeholder (Gargouri et al., 2010). As dimensões e variáveis da CSP utilizadas nessa pesquisa estão apresentadas na Figura 13. 


\begin{tabular}{|l|l|l|}
\hline Stakeholder & Dimensões & Variáveis \\
\hline
\end{tabular}

\begin{tabular}{|c|c|c|}
\hline \multirow{5}{*}{.} & \multirow{2}{*}{$\begin{array}{l}\text { Informações sobre o } \\
\text { conselho de Administração } \\
\text { (BOARD) }\end{array}$} & $\begin{array}{l}\text { Apresentação da composição do conselho de administração e } \\
\text { função }\end{array}$ \\
\hline & & Independência do conselho de administração \\
\hline & \multirow{2}{*}{ Remuneração } & Aumento do valor do acionista (retorno econômico) \\
\hline & & Política clara de distribuição e pagamento de dividendos \\
\hline & Estratégia de longo prazo & $\begin{array}{l}\text { Estratégia de negócios clara visando à sustentabilidade do } \\
\text { negócio a longo prazo }\end{array}$ \\
\hline
\end{tabular}

\section{Figura 13. Dimensões da CSP para acionistas}

Fonte: do autor

\subsubsection{STAKEHOLDER: COMUNIDADE}

As organizações são responsáveis pelos impactos de seus negócios sobre a comunidade, assim como tem obrigações de promover proativamente os interesses comuns para garantir sua licença para operar, principalmente, quando o negócio de uma empresa tem alto impacto na comunidade (Vong, \& Wong, 2013). Por isso, é fundamental que a organização atenda aos interesses da comunidade ao redor de suas instalações. As dimensões e variáveis da CSP que atendem a esse critério estão apresentadas na Figura 14.

\begin{tabular}{|l|l|l|}
\hline Stakeholder & Dimensões & Variáveis \\
\hline
\end{tabular}

\begin{tabular}{|l|l|l|}
\hline \multirow{2}{*}{} & Doações / Filantropia & Doações financeiras e de bens e patrocínios \\
\cline { 2 - 3 } & $\begin{array}{l}\text { Transparência, ética e } \\
\text { combate à corrupção }\end{array}$ & $\begin{array}{l}\text { Existência de Programa de Ética e Compliance/ Combate à } \\
\text { Corrupção e Análise de Riscos de Corrupção }\end{array}$ \\
\cline { 2 - 3 } & $\begin{array}{l}\text { Comprometimento e impacto } \\
\text { na comunidade }\end{array}$ & $\begin{array}{l}\text { Programas e práticas para avaliar e gerenciar impactos da atuação } \\
\text { da empresa na comunidade }\end{array}$ \\
\hline
\end{tabular}

\section{Figura 14. Dimensões da CSP para comunidade}

\section{Fonte: do autor}


A lealdade do consumidor e maneira pela qual uma empresa é percebida pelos seus clientes é fundamental para garantir a sobrevivência de uma empresa (Costa, \& Menichini, 2013). Por isso, os interesses desse stakeholder não pode ser negligenciado. As dimensões e variáveis encontradas na literatura para representar esses interesses estão apresentadas na Figura 15.

\begin{tabular}{|c|c|c|}
\hline Stakeholder & Dimensões & Variáveis \\
\hline \multirow{7}{*}{ } & Qualidade do produto & Certificação, programas e práticas de garantia de qualidade \\
\hline & $\begin{array}{l}\text { Inovação e introdução de } \\
\text { novas tecnologias }\end{array}$ & $\begin{array}{l}\text { Investimentos de Pesquisa \& Desenvolvimento para } \\
\text { produtos e serviços considerando a sustentabilidade }\end{array}$ \\
\hline & & Informações sobre o produto e rotulagem precisas e claras \\
\hline & $\begin{array}{l}\text { Responsabilidade pelo } \\
\text { Produto }\end{array}$ & $\begin{array}{l}\text { Procedimentos para assegurar que a composição e a } \\
\text { produção de produtos e serviços garantam a saúde e a } \\
\text { segurança do consumidor }\end{array}$ \\
\hline & $\begin{array}{l}\text { Ações de comunicação e } \\
\text { promoção }\end{array}$ & Não veiculação de propagandas falsas e enganosas \\
\hline & Satisfação dos clientes & Sistemas de mensuração da satisfação dos clientes \\
\hline & Privacidade do Cliente & Confidencialidade das informações dos clientes \\
\hline
\end{tabular}

Figura 15. Dimensões da CSP para clientes

Fonte: do autor

\subsection{Mensuração da CSP}

Um grande problema para mensuração de CSP, é que não há um modelo padrão e uniforme para mensurá-la (Dam e Scholtens, 1998). Ruf, Miralidhar e Paul (1998), identificaram as seguintes etapas para o desenvolvimento de um modelo: 1) Identificação e seleção das dimensões de responsabilidade social corporativa; 2) Avaliação da relativa importância relativa de cada dimensão; 3) Avaliação da performance de cada organização em cada uma das dimensões; 4) Síntese do resultados relativos e determinação das pontuações da CSP. O método utilizado para o desenvolvimento do instrumento de pesquisa dessa dissertação tem alinhamento com o modelo de Ruf et al. (1998). 


\subsubsection{Estratégias para mensuração de CSP}

Diversas estratégias são utilizadas na literatura para mensuração da CSP, entre as mais encontradas, estão: surveys (Wood, 2010; Agudo, Gargallo, \& Salvador, 2015; Stites, \& Michael, 2011); índices de reputação e de sustentabilidade (Wood, 2010; Ullmann, 1985; Liston-Heyes, \& Ceton, 2009), entre eles o KLD (Valiente, Ayerbe, \& Figueras, 2012; Liston-Heyes, \& Ceton, 2009); e disclosure (relatórios) social e de sustentabilidade (Wood, 2010; Fischer, \& Sawczyn, 2013; Kansal, \& Singh, 2012).

\subsubsection{SURVEYS}

De acordo com Tanur (1982, apud Pinsonneault \& Kraemer, 1993), uma survey é um meio de coletar informações sobre características, ações ou opiniões de um grande grupo de pessoas, representantes de uma população, por meio de um instrumento de pesquisa (questionário). Survey é um método quantitativo e requer informação padronizada sobre o objeto estudado. A utilização de surveys para cálculo de CSP pode significar uma metodologia mais flexível para medir as dimensões e os indicadores, além, de identificar outras características das organizações, como padrões de comportamento (Agudo, Gargallo, \& Salvador, 2015). Uma desvantagem desse método é que as respostas consideram apenas o ponto de vista da empresa e principalmente, refletem as percepções do respondente (Soana, 2011).

\subsubsection{DISCLOSURE}

Uma das técnicas de mensuração de CSP é a análise do que é divulgado (disclosure) pelas empresas na forma de relatórios anuais e sustentabilidade, que mede a quantidade de ações de responsabilidade social declarada voluntariamente por elas (Soana, 2011).

O disclosure pode ser definido como sendo a divulgação de informações, de natureza quantitativa ou qualitativa, por uma organização, por intermédio de veículos formais ou informais, e possui como objetivo principal o fornecimento de informações úteis à tomada de decisões dos stakeholders (Gibbins et al., 1990 apud Yamamoto; \& Salotti, 2006). As publicações de relatórios sociais e de sustentabilidade são uma forma de disclosure voluntário. O disclosure voluntário é a livre escolha dos gestores de uma empresa em 
informar dados contábeis e outras informações consideradas relevantes no processo de tomada de decisão de seus stakeholders (Meek, Roberts, \& Gray, 1995).

Cada vez mais, as empresas estão adotando o conceito da sustentabilidade e da responsabilidade social em seus negócios colocando esforços para aumentar sua transparência, com a publicação de relatórios de sustentabilidade. Hoje, muitas empresas (embora muitas vezes pressionados por grupos de ativistas) publicam relatórios que divulgam o seu desempenho em domínios sociais, econômicos e ambientais.

Estes relatórios foram chamados por muitos nomes ao longo dos anos, mas relatório de sustentabilidade parece ser um dos descritores mais recentes e mais populares (Carroll, 2015). Além de detalhar os impactos ambientais, sociais e econômicos das operações para seus stakeholders, esses relatórios avaliam o progresso da empresa em relação aos seus objetivos de CSR e sustentabilidade, e também, explicam quais são as estratégias para abordar questões ambientais e sociais (Santos, 2011).

O argumento para divulgar as informações sobre a performance social e ambiental da organização foi motivada não somente para interesses de sustentabilidade corporativa, recursos ambientais finitos, transparência e responsabilidade, mas também, uma ferramenta de legitimidade, que pode ser usada para influenciar atitudes e percepções dos stakeholders, ajudando a construir maior confiança e até mesmo possibilitar o desenvolvimento de relações de negócio mais rentáveis (Lee, Faff, \& Langfield-Smith, 2009).

Os relatórios de sustentabilidade e responsabilidade social abriram uma nova janela para as organizações informarem seus stakeholders, sobre o sucesso e falhas em seus negócios, e também, seus compromissos em endereçar questões que ainda não foram alcançadas em suas atividades de responsabilidade social (Weber \& Marley, 2010). A divulgação das práticas socioambientais de organizações em relatórios se consolidou com uma ferramenta de prestação de contas da organização para seus stakeholders. Para isso, os relatórios devem fornecer uma informação objetiva que permita aos stakeholders fazer uma estimativa real do desempenho social e ambiental da organização (Boutena et al., 2011). É possível encontrar uma relação favorável entre o disclosure e a CSP: quando uma empresa entende que divulgar informações aos seus stakeholders é parte de sua responsabilidade, pode haver melhorias na 
reputação, na capacidade de influenciar os stakeholders e no capital moral (Dawkins \& Fraas, 2013).

Como a divulgação de informações sobre a performance corporativa tem recebido uma considerável atenção dos stakeholders, como parte do diálogo com as organizações, uma pergunta fundamental tem sido feita: as informações encontradas nesses relatórios correspondem ao real desempenho social e ambiental das empresas? Por isso, as organizações têm buscados utilizar políticas, procedimentos e sistemas para dar maior credibilidade aos seus relatos de sustentabilidade. (Toppinen, Li, Tuppura, \& Xiong, 2012).

O Global Reporting Initiative (GRI) é o modelo mais conhecido para reporte voluntário de performance social e ambiental, utilizado mundialmente por empresas e organizações diversas. A GRI dá instruções de quais e como as informações devem ser fornecidas para o stakeholders e recomenda diretrizes específicas para cada aspecto econômico, ambiental e social da Responsabilidade Social Corporativa, a fim de articular e compreender as contribuições de empresas para o desenvolvimento sustentável (Giannarakis, Litinas, \& Sariannidis, 2011). Os relatórios de sustentabilidades elaborados sob as diretrizes da GRI, por seguirem um mesmo padrão, pressupõem-se ser uma ferramenta poderosa para fins de comparação, benchmarking e classificação, além de servir como um artifício para uma empresa se apresentar aos seus stakeholders, como socialmente responsável e transparente (Brown, Jong, \& Levy, 2009).

A Global Reporting Initiative, GRI, promove a elaboração de relatórios de sustentabilidade que pode ser adotada por todas as organizações. A GRI, uma é organização nãogovernamental composta por uma rede multistakeholders. Ela conta com os representantes regionais, os Pontos Focais (Focal Points) nos países: Austrália, Brasil, China, Índia e Estados Unidos e uma rede mundial de 30.000 pessoas (GRI, 2013).

A estrutura para Relatórios de Sustentabilidade da GRI consiste de um conjunto de materiais de orientação para o relato. Tal estrutura compreende as Diretrizes, os Conteúdos Setoriais, os Limites do Relatório e os Protocolos Técnicos. Ela pode ser aplicada por organizações de qualquer tamanho, tipo, setor ou de qualquer região. A estrutura é usada por milhares de 
organizações no mundo inteiro como referência na elaboração de seus relatórios de sustentabilidade (GRI, 2013).

A categoria Social, que concentra os indicadores sociais, é dividida em 4 subcategorias. São elas: práticas trabalhistas e trabalho decente; direitos humanos; sociedade; e responsabilidade pelo produto. A categoria Ambiental abrange impactos relacionados a insumos (por exemplo: energia e água) e saídas (por exemplo: emissões, efluentes e resíduos); impactos relacionados à biodiversidade, aos transportes e a produtos e serviços, bem como a conformidade com leis e regulamentos ambientais e gastos e investimentos na área ambiental (GRI, 2013).

Fischer e Sawczyn (2013) construíram um índice para mensuração de CSP, utilizando 31 indicadores GRI, sociais e ambientais, apresentado na Figura 16. As informações fornecidas voluntariamente nos relatórios, foram avaliadas em uma escala de pontuação de 0 (sem informações) a 6 (informação detalhada). 
Indicadores ambientais da GRI (pontuação máxima: 54)

Mapa para

o GRI

Escala de pontuação

\begin{tabular}{|l|l|c|}
\hline Porcentagem de materiais utilizados que são reciclados & EN2 & $0-6$ \\
\hline Consumo de energia direta e indireta por fonte de energia primária & EN3 / EN4 & $0-6$ \\
\hline Retirada total de água (descarga de água) por fonte & EN8 / EN 21 & $0-6$ \\
\hline $\begin{array}{l}\text { Descrição dos impactos significativos de atividades, produtos e serviços sobre a biodiversidade em } \\
\text { áreas protegidas e em áreas de alta índice de biodiversidade fora das áreas protegidas }\end{array}$ & $\begin{array}{l}\text { EN11 / } \\
\text { EN12 }\end{array}$ & $0-6$ \\
\hline $\begin{array}{l}\text { Total de emissões de gases com efeito de estufa diretas e indiretas (emissões de } \\
\text { substâncias que destroem o ozônio e, NOx, SOx, e outras emissões atmosféricas significativas) por } \\
\text { peso }\end{array}$ & $\begin{array}{l}\text { EN16/ } \\
\text { EN17 } \\
\text { (EN19/ } \\
\text { EN20) }\end{array}$ & $0-6$ \\
\hline Peso total de resíduos, por tipo e método de descarte & EN22 & $0-6$ \\
\hline Iniciativas para mitigar os impactos ambientais de produtos e serviços & EN26 & $0-6$ \\
\hline Percentual de produtos e suas embalagens que são recuperados, por categoria & EN27 & $0-6$ \\
\hline $\begin{array}{l}\text { Implicações financeiras e outros riscos e oportunidades para as atividades da organização devido a } \\
\text { mudanças climáticas }\end{array}$ & EC2 & $0-6$ \\
\hline
\end{tabular}

\section{Indicadores de sociais da GRI (pontuação máxima: 84)}

Mapa para

o GRI

Escala de pontuação

\begin{tabular}{|l|l|c|}
\hline $\begin{array}{l}\text { Total de trabalhadores por tipo de emprego, contrato, e região, número total } \\
\text { número e taxa de rotatividade de empregados por faixa etária, gênero e região }\end{array}$ & LA1 / LA2 & $0-6$ \\
\hline $\begin{array}{l}\text { Taxas de lesões, doenças ocupacionais, dias perdidos e absenteísmo, } \\
\text { e número de óbitos relacionados ao trabalho, por região }\end{array}$ & LA7 & $0-6$ \\
\hline Média de horas de treinamento por ano, por empregado, por categoria funcional & LA10 & $0-6$ \\
\hline $\begin{array}{l}\text { Composição dos órgãos de governança e discriminação de empregados por categoria, de acordo } \\
\text { com gênero, faixa etária, minorias associação, e outros indicadores de diversidade }\end{array}$ & LA13 & $0-6$ \\
\hline Proporção de salário base entre homens e mulheres, por categoria funcional & LA14 & $0-6$ \\
\hline Cobertura do plano de benefícios definidos pela organização & EC3 & $0-6$ \\
\hline Número total de casos de discriminação e as medidas tomadas & HR4 & $0-6$ \\
\hline $\begin{array}{l}\text { Operações identificadas como de risco significativo de ocorrência de trabalho infantil, } \\
\text { e medidas tomadas para contribuir para a eliminação do trabalho infantil }\end{array}$ & HR6 & $0-6$ \\
\hline $\begin{array}{l}\text { Operações identificadas como de risco significativo de ocorrência de trabalho forçado ou } \\
\text { compulsório, e medidas que contribuam para a eliminação do trabalho forçado ou obrigatório }\end{array}$ & HR7 & $0-6$ \\
\hline $\begin{array}{l}\text { Percentual e número total de unidades de negócios que fizeram análise de riscos de corrupção e as } \\
\text { medidas tomadas em resposta a casos de corrupção }\end{array}$ & SO2-SO4 & $0-6$ \\
\hline Políticas, práticas e proporção de gastos com fornecedores locais & EC6 & $0-6$ \\
\hline $\begin{array}{l}\text { Impactos indiretos de investimentos da organização em infraestrutura e serviços oferecidos para a } \\
\text { comunidade }\end{array}$ & EC8 & $0-6$ \\
\hline $\begin{array}{l}\text { Fases do ciclo de vida em que os impactos na saúde e segurança dos produtos e serviços são } \\
\text { avaliados visando melhoria, e o percentual de produtos e serviços sujeitos a esses procedimentos }\end{array}$ & PR1 & $0-6$ \\
\hline $\begin{array}{l}\text { Tipo de informações sobre produtos e serviços exigidos pelos procedimentos da organização } \\
\text { referentes a informação e rotulagem de produtos e serviços e percentual de categorias significativas } \\
\text { sujeitas à essas exigências. }\end{array}$ & PR3 & $0-6$ \\
\hline
\end{tabular}

Corporate social performance (pontuação máxima: 138)

Figura 16. Escala de mensuração CSP pelos indicadores GRI (Fischer e Sawczyn, 2013) 
Bonilla-Priego, Font e Pacheco-Olivares (2014) também desenvolveram uma escala de mensuração considerando os indicadores GRI, para avaliar a CSP do setor cruzeiros, relacionando cada indicador GRI com a dimensão da CSP, em três categorias: ambiental, social e econômica, conforme Figura 17.

\begin{tabular}{|l|l|}
\hline \multicolumn{2}{|c|}{ Indicadores ambientais } \\
\hline A1 & Estrutura de Governança e sistemas de gestão \\
\hline A2 & Credibilidade \\
\hline A3 & $\begin{array}{l}\text { Indicadores de desempenho ambiental: materiais, } \\
\text { água, biodiversidade, emissões, efluentes, } \\
\text { desperdício, produtos e serviços }\end{array}$ \\
\hline A4 & Indicadores ambientais financeiros \\
\hline A5 & Visão e estratégia \\
\hline A6 & Perfil ambiental \\
\hline A7 & Iniciativas ambientais \\
\hline
\end{tabular}

\begin{tabular}{|l|l|}
\hline \multicolumn{2}{|c|}{ Indicadores sociais } \\
\hline B1 & Estrutura de Governança e sistemas de gestão \\
\hline B2 & Credibilidade \\
\hline B3 & $\begin{array}{l}\text { Indicadores de desempenho social: trabalho decente, } \\
\text { direitos humanos, sociedade, responsabilidade pelo } \\
\text { produto }\end{array}$ \\
\hline B4 & Gastos sociais \\
\hline B5 & Visão e estratégia \\
\hline B6 & Perfil social \\
\hline
\end{tabular}

\begin{tabular}{|l|l|}
\hline \multicolumn{2}{|c|}{ Indicador econômico } \\
\hline $\mathrm{C} 1$ & Desempenho e impacto econômico \\
\hline
\end{tabular}

Figura 17. Escala de mensuração CSP pelos indicadores GRI (M.J. Bonilla-Priego et al., 2014)

Para avaliar a CSP, M.J. Bonilla-Priego et al. (2014) utilizaram as seguintes regras para codificação: se as informações encontradas no relatório de sustentabilidade de uma empresa específica são relativas a um dos itens incluídos na Figura 17, foi atribuído "1" para esse item. Se as informações relacionadas a um item específico não foram encontradas na publicação da empresa, o "0" foi atribuído ao item. Os autores também não se propuseram a testar se a informação fornecida mostra um elevado nível de performance, ou seja, simplesmente avalia se a empresa reconhece publicamente o que estão fazendo em relação a cada dimensão. 


\subsubsection{3 ÍNDICES DE REPUTAÇÃO E SUSTENTABILIDADE}

Outra forma de mensuração encontrada na literatura de CSP é a utilização de índices de reputação e de sustentabilidade, baseado na premissa que esses índices refletem bem os valores e comportamentos da organização em termos de CSP (Liston-Heyes, \& Ceton, 2009).

O interesse em práticas de sustentabilidade passou a ser utilizado por investidores como um critério para ser considerado na configuração de suas carteiras de investimento e motivou o surgimento de índices ligados ao financeiro. Esses índices foram desenvolvidos por organizações de prestígio e deram credibilidade à noção de investimentos em empresas que empregam critérios de sustentabilidade empresarial (Lopez; Garcia; \& Lazaro, 2007).

As organizações que fazem essas classificações coletam os dados de várias maneiras, como: estudo dos relatórios de responsabilidade social corporativa, administração de surveys e pesquisas voluntárias, análise de publicações na mídia, investigações independentes e comunicação frequente com os gestores das empresas participantes (Scalet, \& Kelly, 2010).

\subsection{KLD}

KLD é um índice de desempenho social para empresas americanas desenvolvido por Kinder, Lydenberg, Domini Research \& Analytics. O KLD é um índice confiável e seguro, pois abrange as principais questões do constructo CSP (Sharfman, 1996). Porém, as informações do KLD não são de domínio público, por isso é necessário pagar pela utilização a base de dados que compõe o índice. Além disso, algumas dimensões são muito peculiares às empresas americanas, e não se aplicam a realidade brasileira.

\subsection{FORTUNE}

A revista americana Fortune divulga todos os anos a lista das 50 empresas americanas mais admiradas. Lançado no início da década de 80, o índice entrevista executivos, diretores e analistas de mercados nas seguintes dimensões: qualidade da gestão; qualidade dos produtos ou serviços; valor como investimento de longo prazo; capacidade de inovação; solidez da posição financeira; capacidade de atrair, desenvolver e manter pessoas talentosas; responsabilidade com a comunidade e meio ambiente; e uso racional dos ativos corporativos. 
O ranking da Fortune é considerado um índice de reputação e seu uso, é bastante encontrado em pesquisas relacionadas à CSP (Quevedo-Puente, Fuente-Sabaté, \& Delgado-García, 2007).

\subsection{DJSI - DOW JONES SUSTAINABILITY INDEXES}

O outro índice utilizado na literatura para mensurar a CSP é Dow Jones Sustainability Indexes

- DJSI (Darren, Faff \& Langfield-Smith, 2009). O DJSI - Índice Dow Jones de Sustentabilidade - acompanha o desempenho das ações das empresas líderes mundiais em relação a critérios econômicos, ambientais e sociais, proporcionando aos investidores mais informações para o gerenciamento de suas carteiras de investimento de sustentabilidade. As dimensões utilizadas para elaboração do índice são: Análise de Risco e Gestão de Crises; Códigos de Conduta / Compliance / Combate à Corrupção; Práticas Trabalhistas e Direitos Humanos; Desenvolvimento do Capital Humano; Engajamento de Stakeholders; Cidadania Corporativa e Filantropia, Ecoeficiência; Estratégia de Mudanças Climáticas; Sistema de Gestão e Políticas Ambientais. Lopez et al. (2007) utilizaram o DJSI, como um constructo multidimensional para representar a CSP de empresas. No estudo, os autores consideram apenas empresas listadas no índice, como as que possuíam CSP mais elevada.

\subsection{ISE - ÍNDICE DE SUSTENTABILIDADE EMPRESARIAL}

Seguindo a linha do DJSI, no Brasil, existe o Índice de Sustentabilidade Empresarial BM\&F BOVESPA - ISE. O ISE foi o quarto índice de ações no mundo criado com o objetivo de mostrar o desempenho de mercado de uma carteira formada por empresas que adotam os princípios de gestão sustentável.

O primeiro deles foi o Dow Jones Sustainability Indexes (DJSI), criado em 1999, em Nova Iorque; o segundo foi o FTSE4Good, de Londres, criado em 2001; e o terceiro, lançado em 2003, foi o JSE, de Johanesburgo, África do Sul. Em $1^{\circ}$ de dezembro de 2005, o Brasil entrou para esse grupo de pioneiros ao apresentar, em São Paulo, a sua primeira carteira teórica do Índice de Sustentabilidade Empresarial, que reuniu 34 ações de 28 empresas avaliadas como as mais avançadas na implementação de práticas de sustentabilidade empresarial no país. Esta iniciativa inovadora na América Latina foi projetada para criar um ambiente de investimento compatível com a necessidade da sociedade para o desenvolvimento sustentável, e para encorajar as empresas a ser eticamente responsável (KPMG, 2013). 
Para participar do ISE, uma empresa obedecer alguns critérios de inclusão. São eles: estar entre os ativos elegíveis que, no período de vigência das 3 (três) carteiras anteriores, em ordem decrescente de Índice de Negociabilidade (IN), ocupem as 200 primeiras posições; ter presença em pregão de $50 \%$ (cinquenta por cento) no período de vigência das 3 (três) carteiras anteriores; não ser classificado como "Penny Stock"; atender aos critérios de sustentabilidade e ser selecionado pelo Conselho Deliberativo do ISE.

Os objetivos do ISE são: atuar como indutor de boas práticas no meio empresarial brasileiro e ser uma referência para o investimento socialmente responsável (ISE, 2014). 


\section{MÉTODO DA PESQUISA}

O método de pesquisa deve ser entendido como um excelente elemento facilitador da produção de conhecimento, uma ferramenta capaz de auxiliar o entendimento do processo de busca de respostas e o adequado posicionamento das perguntas importantes sobre o que se ignora (Charoux, 2006). Dessa maneira, este capítulo apresenta as etapas e os procedimentos metodológicos utilizados para alcançar os objetivos propostos.

\subsection{Etapas da pesquisa}

Essa pesquisa segue as etapas apresentadas na Figura 18.

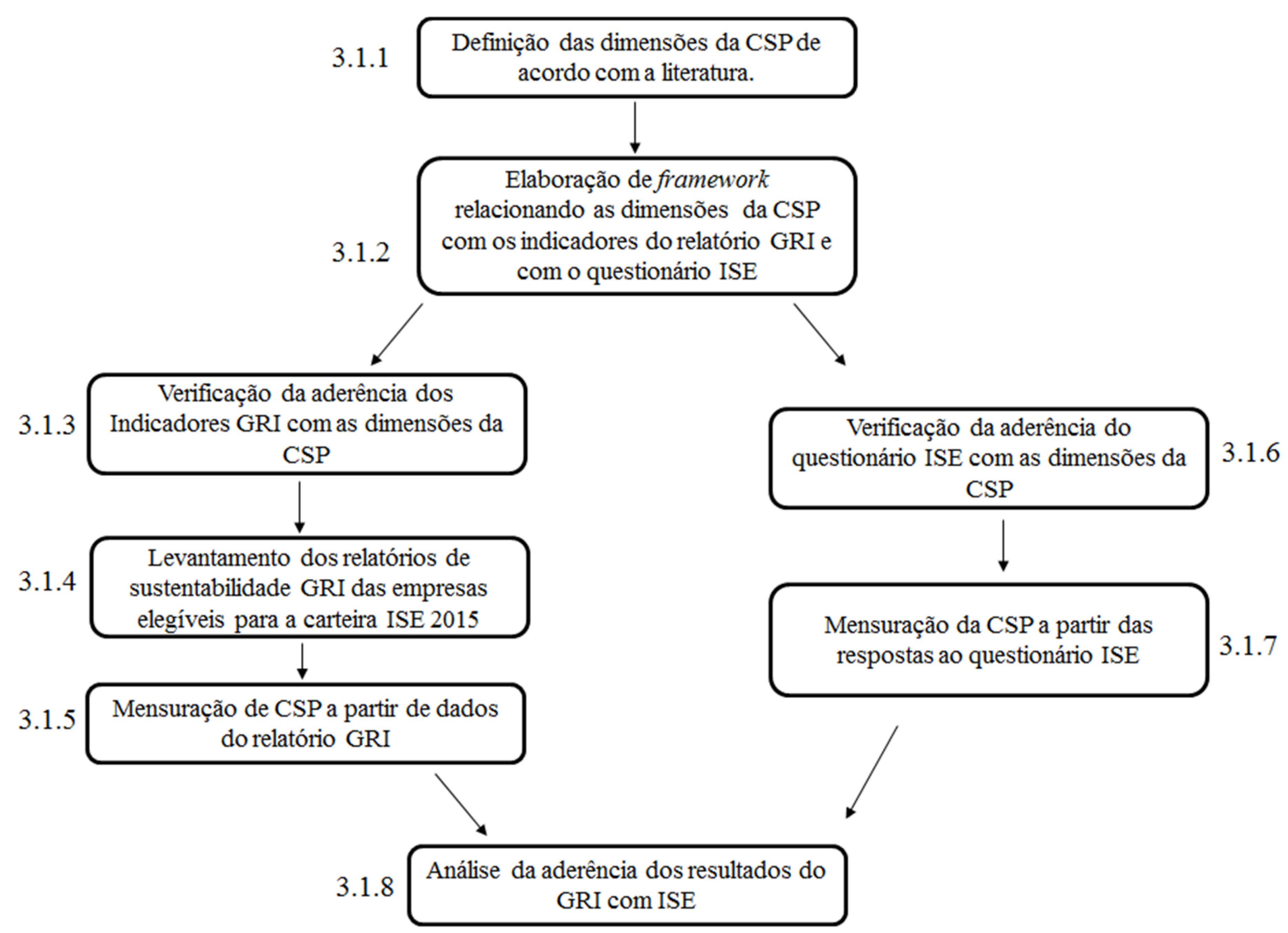

Figura 18. Etapas da Pesquisa

As etapas da pesquisa estão descritas nos itens a seguir: 


\subsubsection{Definição das dimensões de acordo com a literatura}

As dimensões de CSP definidas para essa pesquisa, após uma análise da literatura de nas bases Web of Knowledge e Scopus, estão apresentadas no item 2.4.1.

\subsubsection{Elaboração de framework relacionando as dimensões da CSP com os indicadores do relatório GRI e com o questionário ISE.}

Após identificar as dimensões de CSP mais utilizadas na literatura, realizou-se uma busca nas diretrizes GRI-G4 e nos Questionários do ISE-2016, para encontrar os indicadores e questões que mais se relacionavam com cada dimensão. O framework elaborado está apresentado na Figura 19.

Para cada stakeholder são encontrados 3 níveis de mensuração: dimensão, variáveis e questões ISE/ indicadores GRI. Tanto para GRI, quanto para o ISE, foi considerado o mesmo peso para cada dimensão, ou seja, as dimensões têm o mesmo nível de importância. Isto também vale para as variáveis. Para chegar no valor da CSP para cada dimensão, foi considerada a média aritmética do resultado das variáveis. 


\begin{tabular}{|c|c|c|c|c|}
\hline Stakeholder & Dimensões & Variáveis & GRI G4 & ISE \\
\hline \multirow{7}{*}{ 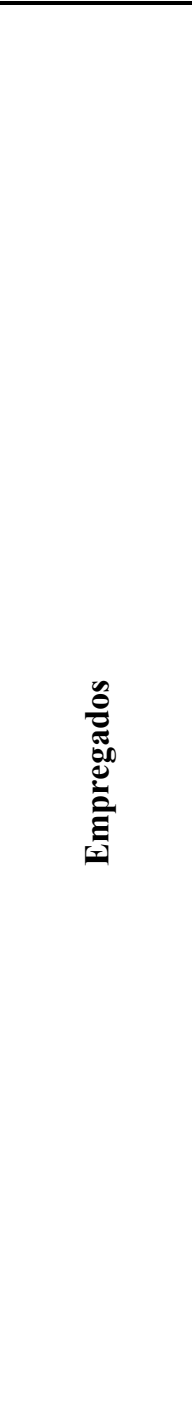 } & \multirow{2}{*}{$\begin{array}{l}\text { Equilíbrio entre vida } \\
\text { profissional, pessoal } \\
\text { e familiar }\end{array}$} & $\begin{array}{l}\text { Programa de flexibilidade no } \\
\text { trabalho (horários flexíveis, } \\
\text { home-office) }\end{array}$ & & \\
\hline & & $\begin{array}{l}\text { Programas especiais de licença } \\
\text { maternidade }\end{array}$ & G4-LA3 & SOC 30 \\
\hline & \multirow{2}{*}{$\begin{array}{l}\text { Saúde e segurança } \\
\text { ocupacional }\end{array}$} & $\begin{array}{l}\text { Políticas de promoção de um } \\
\text { ambiente de trabalho saudável e } \\
\text { seguro (análise de riscos } \\
\text { ocupacionais, plano de } \\
\text { prevenção, treinamentos) }\end{array}$ & $\begin{array}{c}\text { G4-LA5 } \\
\text { G4-DMA-Saúde e } \\
\text { Segurança no Trabalho }\end{array}$ & $\begin{array}{l}\text { SOC } 13 \\
\text { AMB-IF } 21 \\
\text { AMB-X } 2\end{array}$ \\
\hline & & $\begin{array}{l}\text { Informações sobre ocorrência e } \\
\text { redução de lesões, doenças } \\
\text { ocupacionais, dias perdidos e } \\
\text { absenteísmo, e número de óbitos } \\
\text { relacionados ao trabalho }\end{array}$ & G4-LA6 & \\
\hline & \multirow{2}{*}{$\begin{array}{l}\text { Compromisso com } \\
\text { direitos humanos nas } \\
\text { práticas de trabalho }\end{array}$} & $\begin{array}{l}\text { Políticas para garantir a } \\
\text { inexistência de trabalho forçado } \\
\text { ou análogo ao escravo na cadeia. }\end{array}$ & $\begin{array}{c}\text { G4-HR2 } \\
\text { G4-HR6 } \\
\text { G4-DMA-Trabalho } \\
\text { Forçado ou Análogo ao } \\
\text { Escravo }\end{array}$ & $\begin{array}{l}\text { SOC } 1 \text { - b } \\
\quad(\mathrm{TF}) \\
\text { SOC } 6(\mathrm{TF}) \\
\text { SOC } 37 \mathrm{~b}\end{array}$ \\
\hline & & $\begin{array}{l}\text { Políticas para garantir a } \\
\text { inexistência de trabalho infantil } \\
\text { na cadeia. }\end{array}$ & $\begin{array}{c}\text { G4-HR2 } \\
\text { G4-HR5 } \\
\text { G4-DMA-Trabalho } \\
\text { Infantil } \\
\end{array}$ & $\begin{array}{l}\text { SOC } 1-\text { a (TI) } \\
\text { SOC } 6(\mathrm{TI}) \\
\text { SOC } 37 \text { a }\end{array}$ \\
\hline & $\begin{array}{l}\text { Treinamento e } \\
\text { educação }\end{array}$ & $\begin{array}{l}\text { Treinamentos disponíveis para os } \\
\text { empregados (programas / horas } \\
\text { de treinamento) }\end{array}$ & $\begin{array}{c}\text { G4-LA9 } \\
\text { G4-DMA-Treinamento e } \\
\text { Educação }\end{array}$ & SOC 6 (ED) \\
\hline
\end{tabular}

Figura 19. Relação das dimensões da CSP com os indicadores GRI e com o questionário ISE

Fonte: do autor 


\begin{tabular}{|c|c|c|c|c|}
\hline Stakeholder & Dimensões & Variáveis & GRI G4 & ISE \\
\hline \multirow{14}{*}{ 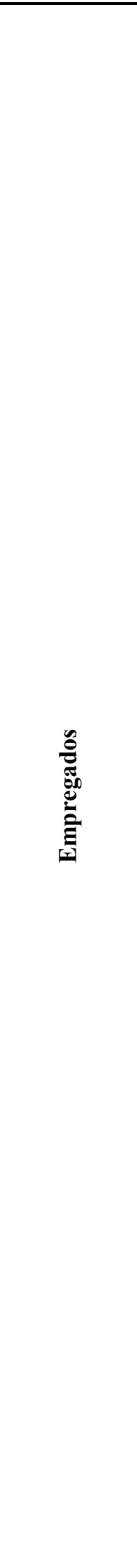 } & \multirow{2}{*}{$\begin{array}{l}\text { Perspectivas de } \\
\text { carreira }\end{array}$} & $\begin{array}{l}\text { Programas de gestão de } \\
\text { carreira (plano, sistemas de } \\
\text { avaliação de desempenho) }\end{array}$ & G4-LA11 & \\
\hline & & $\begin{array}{l}\text { Redução do turnover } \\
\text { (estatísticas e programas) }\end{array}$ & G4-LA1 & \\
\hline & \multirow{4}{*}{$\begin{array}{l}\text { Diversidade e } \\
\text { igualdades de } \\
\text { oportunidades }\end{array}$} & $\begin{array}{l}\text { Emprego de mulheres na } \\
\text { liderança }\end{array}$ & G4-LA12 & $\begin{array}{l}\text { SOC } 19-\mathrm{a} / \mathrm{c} \\
\text { GOV } 21\end{array}$ \\
\hline & & $\begin{array}{l}\text { Pessoas com deficiência } \\
\text { empregadas }\end{array}$ & & $\begin{array}{l}\text { SOC } 32 \\
\text { SOC } 39\end{array}$ \\
\hline & & $\begin{array}{l}\text { Programas para estimulem } \\
\text { a diversidade na } \\
\text { contratação e igualdade no } \\
\text { tratamento, envolvendo } \\
\text { temas como: gênero, } \\
\text { deficiência, LGBT, etnia. }\end{array}$ & $\begin{array}{l}\text { G4-DMA - Diversidade e Igualdade } \\
\text { de Oportunidades }\end{array}$ & $\begin{array}{l}\text { SOC } 1-d(D V) \\
\text { SOC } 6(D V) \\
\text { SOC } 9 \\
\text { SOC } 31\end{array}$ \\
\hline & & $\begin{array}{l}\text { Igualdade de salários entre } \\
\text { homens e mulheres }\end{array}$ & $\begin{array}{c}\text { G4-LA13 } \\
\text { G4-DMA- Igualdade de } \\
\text { Remuneração para Mulheres e } \\
\text { Homens }\end{array}$ & SOC $24-\mathrm{a} / \mathrm{c}$ \\
\hline & \multirow{3}{*}{$\begin{array}{l}\text { Salários, } \\
\text { recompensas e } \\
\text { benefícios } \\
\text { justos }\end{array}$} & $\begin{array}{l}\text { Programas e políticas } \\
\text { formais de salários, } \\
\text { recompensas e mérito }\end{array}$ & G4-LA2 & SOC 11 \\
\hline & & $\begin{array}{l}\text { Benefícios para } \\
\text { aposentadoria: existência } \\
\text { de fundos, plano de } \\
\text { aposentadoria. }\end{array}$ & $\begin{array}{l}\text { G4-EC3 } \\
\text { G4-LA10 }\end{array}$ & \\
\hline & & $\begin{array}{l}\text { Oferecimento de } \\
\text { benefícios além dos } \\
\text { obrigatórios por lei (FGTS, } \\
13^{\circ}, \text { férias e vale } \\
\text { transporte) }\end{array}$ & G4-LA2 & SOC 13 \\
\hline & $\begin{array}{l}\text { Anti- } \\
\text { discriminação }\end{array}$ & $\begin{array}{l}\text { Esforços anti- } \\
\text { discriminação (políticas ou } \\
\text { programas) }\end{array}$ & G4-HR3 & $\begin{array}{l}\text { SOC } 1-\mathrm{c}(\mathrm{DI}) \\
\text { SOC } 6(\mathrm{DI}) \\
\text { SOC } 8\end{array}$ \\
\hline & $\begin{array}{l}\text { Envolvimento } \\
\text { com a } \\
\text { comunidade }\end{array}$ & $\begin{array}{l}\text { Programas de voluntariado } \\
\text { empresarial }\end{array}$ & & SOC 17 \\
\hline & \multirow{2}{*}{$\begin{array}{l}\text { Satisfação do } \\
\text { empregado e } \\
\text { clima } \\
\text { organizacional }\end{array}$} & $\begin{array}{l}\text { Canais de comunicação } \\
\text { para sugestões e } \\
\text { reclamações, com garantia } \\
\text { de confidencialidade. }\end{array}$ & G4-LA16 & SOC 6 (DL) \\
\hline & & $\begin{array}{l}\text { Pesquisas de clima } \\
\text { organizacional / satisfação } \\
\text { do empregado }\end{array}$ & & SOC $12-a$ \\
\hline & $\begin{array}{l}\text { Relacionamento } \\
\text { com sindicatos } \\
\text { e união de } \\
\text { trabalhadores }\end{array}$ & $\begin{array}{l}\text { Liberdade de associação } \\
\text { sindical e direito à } \\
\text { negociação coletiva }\end{array}$ & $\begin{array}{c}\text { G4-HR4 } \\
\text { G4-DMA-Liberdade de Associação } \\
\text { e Negociação Coletiva }\end{array}$ & $\begin{array}{l}\text { SOC } 1-\mathrm{f}(\mathrm{LA}) \\
\text { SOC } 6(\mathrm{LA}) \\
\quad \text { SOC } 7\end{array}$ \\
\hline
\end{tabular}

Figura 19. Relação das dimensões da CSP com os indicadores GRI e com o questionário ISE (continuação) 


\begin{tabular}{|c|c|c|c|c|}
\hline Stakeholder & Dimensões & Variáveis & GRI G4 & ISE \\
\hline \multirow[t]{2}{*}{ 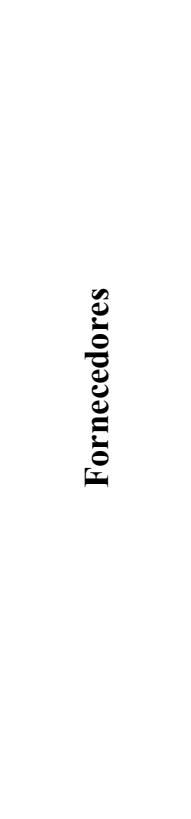 } & $\begin{array}{l}\text { Relacionamento com } \\
\text { fornecedores }\end{array}$ & $\begin{array}{l}\text { Programas para } \\
\text { contratação e } \\
\text { manutenção de } \\
\text { fornecedores para } \\
\text { assegurar a } \\
\text { responsabilidade } \\
\text { socioambiental de } \\
\text { fornecedores (cláusulas } \\
\text { contratuais, código de } \\
\text { ética ou conduta) }\end{array}$ & $\begin{array}{l}\text { G4-DMA- } \\
\text { Avaliação } \\
\text { Ambiental de } \\
\text { Fornecedores } \\
\text { G4-DMA- } \\
\text { Avaliação de } \\
\text { Fornecedores em } \\
\text { Práticas } \\
\text { Trabalhistas } \\
\text { G4-DMA- } \\
\text { Avaliação de } \\
\text { Fornecedores em } \\
\text { Direitos Humanos }\end{array}$ & $\begin{array}{c}\text { GER } 17 \\
\text { GER } 17.1 \\
\text { AMB-A } 11\end{array}$ \\
\hline & $\begin{array}{l}\text { Fornecedores locais e } \\
\text { menores }\end{array}$ & $\begin{array}{l}\text { Priorização e estímulo a } \\
\text { parcerias com } \\
\text { fornecedores locais e } \\
\text { menores. }\end{array}$ & $\begin{array}{c}\text { G4-EC9 } \\
\text { G4-DMA-Práticas } \\
\text { de Compra }\end{array}$ & SOC 36 \\
\hline \multirow{5}{*}{ 产 } & \multirow{2}{*}{$\begin{array}{l}\text { Informações sobre o } \\
\text { conselho de } \\
\text { Administração } \\
\text { (BOARD) }\end{array}$} & $\begin{array}{l}\text { Apresentação da } \\
\text { composição do conselho } \\
\text { de administração e } \\
\text { função }\end{array}$ & G4-34 & \\
\hline & & $\begin{array}{l}\text { Independência do } \\
\text { conselho de } \\
\text { administração }\end{array}$ & $\begin{array}{l}\text { G4-38 } \\
\text { G4-39 }\end{array}$ & $\begin{array}{l}\text { GOV } 18 \\
\text { GOV } 31\end{array}$ \\
\hline & \multirow[b]{2}{*}{ Remuneração } & $\begin{array}{l}\text { Aumento do valor do } \\
\text { acionista (retorno } \\
\text { econômico) } \\
\end{array}$ & G4-EC1 & \\
\hline & & $\begin{array}{l}\text { Política clara de } \\
\text { distribuição e } \\
\text { pagamento de } \\
\text { dividendos }\end{array}$ & G4-51 & $\begin{array}{l}\text { GER } 8 \\
\text { GER } 9 \\
\text { GOV } 2\end{array}$ \\
\hline & $\begin{array}{l}\text { Estratégia de longo } \\
\text { prazo }\end{array}$ & $\begin{array}{l}\text { Estratégia de negócios } \\
\text { clara visando à } \\
\text { sustentabilidade do } \\
\text { negócio a longo prazo }\end{array}$ & $\begin{array}{l}\text { G4-1 } \\
\text { G4-2 }\end{array}$ & $\begin{array}{c}\text { GOV } 29 \\
\text { GOV } 36 \\
\text { GOV } 39 \\
\text { ECO } 10 \\
\text { GER } 1\end{array}$ \\
\hline
\end{tabular}

Figura 19. Relação das dimensões da CSP com os indicadores GRI e com o questionário ISE (continuação)

Fonte: do autor 


\begin{tabular}{|c|c|c|c|c|}
\hline Stakeholder & Dimensões & $\begin{array}{c}\text { Variáveis } \\
\end{array}$ & GRI G4 & ISE \\
\hline \multirow{4}{*}{ ن̃ } & Doações / Filantropia & $\begin{array}{l}\text { Doações financeiras e de } \\
\text { bens e patrocínios }\end{array}$ & G4-EC1 & $\begin{array}{c}\text { SOC 3 } \\
\text { SOC } 15\end{array}$ \\
\hline & & $\begin{array}{l}\text { Código de conduta } \\
\text { empresarial }\end{array}$ & G4-56 & GOV 46 \\
\hline & $\begin{array}{l}\text { Transparência, ética e } \\
\text { combate à corrupção }\end{array}$ & $\begin{array}{l}\text { Existência de Programa } \\
\text { de Ética e Compliance/ } \\
\text { Combate à Corrupção e } \\
\text { Análise de Riscos de } \\
\text { Corrupção }\end{array}$ & $\begin{array}{c}\text { G4-57 } \\
\text { G4-SO3 } \\
\text { G4-SO4 } \\
\text { G4-DMA- } \\
\text { Combate à } \\
\text { Corrupção } \\
\end{array}$ & $\begin{array}{l}\text { GER } 23 \\
\text { GER } 25 \\
\text { SOC } 10\end{array}$ \\
\hline & $\begin{array}{l}\text { Comprometimento e } \\
\text { impacto na comunidade }\end{array}$ & $\begin{array}{l}\text { Programas e práticas para } \\
\text { avaliar e gerenciar } \\
\text { impactos da atuação da } \\
\text { empresa na comunidade; }\end{array}$ & $\begin{array}{c}\text { G4-EC7 } \\
\text { G4-EC8 } \\
\text { G4-SO1 } \\
\text { G4-SO2 } \\
\text { G4-DMA- } \\
\text { Impactos } \\
\text { Econômicos } \\
\text { Indiretos }\end{array}$ & $\begin{array}{l}\text { SOC } 2 \\
\text { SOC } 14.1 \\
\text { SOC } 14.2 \\
\text { ECO } 6\end{array}$ \\
\hline \multirow{7}{*}{ 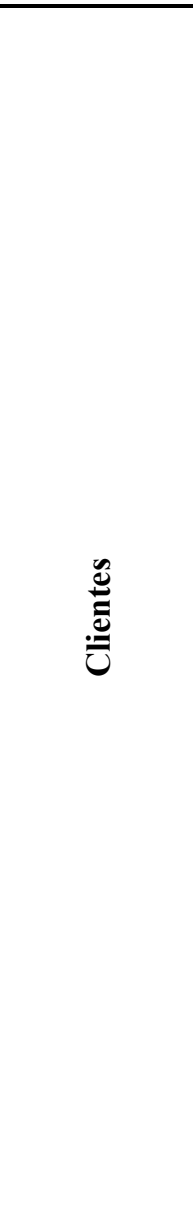 } & Qualidade do produto & $\begin{array}{l}\text { Certificação, programas e } \\
\text { práticas de garantia de } \\
\text { qualidade }\end{array}$ & & \\
\hline & $\begin{array}{l}\text { Inovação e introdução de } \\
\text { novas tecnologias }\end{array}$ & $\begin{array}{l}\text { Investimentos de } \\
\text { Pesquisa \& } \\
\text { Desenvolvimento para } \\
\text { produtos e serviços } \\
\text { considerando a } \\
\text { sustentabilidade. } \\
\end{array}$ & & GER 13 \\
\hline & & $\begin{array}{l}\text { Informações sobre o } \\
\text { produto e rotulagem } \\
\text { precisas e claras }\end{array}$ & G4-PR3 & $\begin{array}{l}\text { SOC } 18.6 \\
\text { S0C } 18.7\end{array}$ \\
\hline & $\begin{array}{l}\text { Responsabilidade pelo } \\
\text { Produto }\end{array}$ & $\begin{array}{l}\text { Procedimentos para } \\
\text { assegurar que a } \\
\text { composição e a produção } \\
\text { de produtos e serviços } \\
\text { garantam a saúde e a } \\
\text { segurança do consumidor }\end{array}$ & $\begin{array}{l}\text { G4-PR1 } \\
\text { G4-DMA-Saúde } \\
\text { e Segurança do } \\
\text { Cliente }\end{array}$ & NAT 4 \\
\hline & $\begin{array}{l}\text { Ações de comunicação e } \\
\text { promoção }\end{array}$ & $\begin{array}{l}\text { Não veiculação de } \\
\text { propagandas falsas e } \\
\text { enganosas }\end{array}$ & G4-PR7 & SOC5 \\
\hline & Satisfação dos clientes & $\begin{array}{l}\text { Sistemas de mensuração } \\
\text { da satisfação dos clientes }\end{array}$ & $\begin{array}{l}\text { G4-PR5 } \\
\text { G4-DMA- } \\
\text { Rotulagem de } \\
\text { Produtos e } \\
\text { Serviços }\end{array}$ & SOC 18.8 \\
\hline & Privacidade do Cliente & $\begin{array}{l}\text { Confidencialidade das } \\
\text { informações dos clientes }\end{array}$ & $\begin{array}{c}\text { G4-PR8 } \\
\text { G4-DMA- } \\
\text { Privacidade do } \\
\text { cliente }\end{array}$ & SOC4 \\
\hline
\end{tabular}

Figura 19. Relação das dimensões da CSP com os indicadores GRI e com o questionário ISE (continuação) Fonte: do autor 
A seguir, são apresentadas algumas informações sobre a diretrizes GRI-G4 e os Questionários ISE-2016.

\subsubsection{DIRETRIZES GRI-G4}

As Diretrizes GRI para Relato de Sustentabilidade são revisadas periodicamente para oferecer orientações mais adequadas e atualizadas para a preparação eficaz de relatórios de sustentabilidade, sendo as diretrizes G4, a quarta atualização. Além de mais amigáveis que as versões anteriores, as Diretrizes G4 enfatizam ainda mais a necessidade de as organizações concentrarem o processo de elaboração do relatório e o produto final em tópicos materiais para suas atividades e principais stakeholders (partes interessadas ou públicos de interesse) (GRI, 2013).

Os tópicos materiais são aqueles refletem os impactos econômicos, ambientais e sociais significativos da organização ou aqueles que possam influenciar, substantivamente, as avaliações e decisões de stakeholders. Esse enfoque na "materialidade" tem como objetivo tornar os relatórios mais relevantes, confiáveis e compreensíveis, permitindo que as organizações ofereçam melhores informações a mercados e à sociedade sobre questões relacionadas à sustentabilidade (GRI, 2013).

Para identificar os aspectos materiais que deverão ser reportados, as organizações devem construir uma matriz de materialidade, ilustrada na Figura 20, construída pela organização e validada pelos stakeholders. Cada ponto na matriz, indica um aspecto ambiental, social ou econômico. 


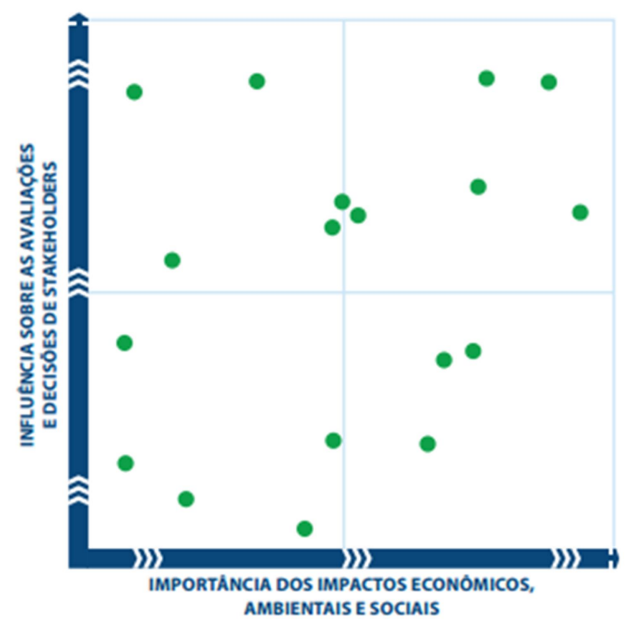

Figura 20. Representação da matriz de materialidade (GRI, 2013)

Cada aspecto ou categoria é formado por diversos indicadores, conforme exemplo na Figura 21. A empresa relata esses indicadores de acordo com sua materialidade.

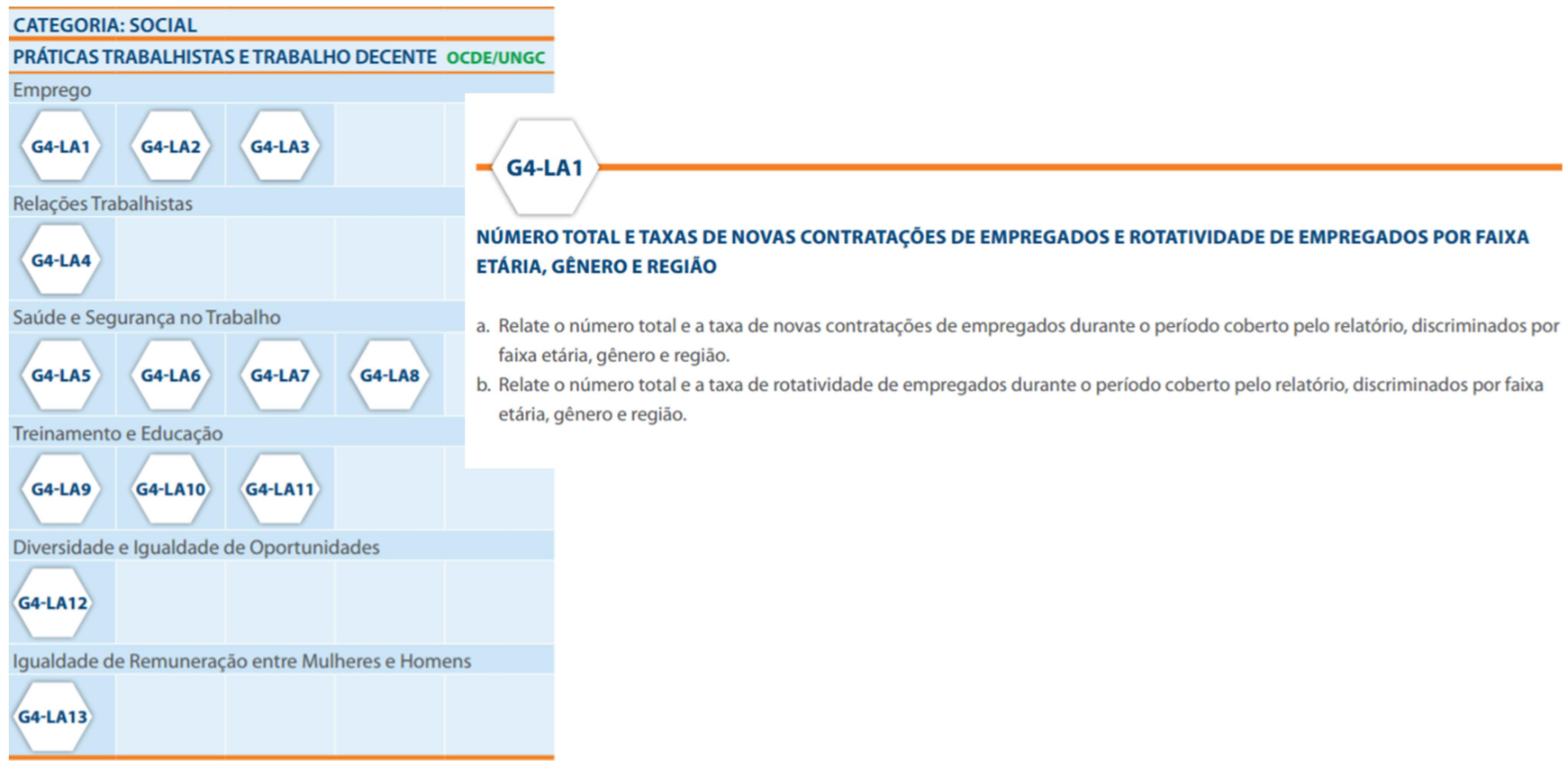

Figura 21. Exemplo de indicadores GRI (GRI, 2013)

As diretrizes GRI-G4 possuem 58 indicadores relacionados ao perfil de cada empresa, que são importantes para apresentar a visão estratégica geral da sustentabilidade da organização; 91 indicadores relacionados a aspectos, entre eles, Impactos Econômicos Indiretos, Práticas de Compra, Avaliação Ambiental de Fornecedores, Saúde e Segurança no Trabalho, 
Treinamento e Educação, Diversidade e Igualdade de Oportunidades, Igualdade de Remuneração entre Mulheres e Homens, Avaliação de Fornecedores em Práticas Trabalhistas, Não discriminação, Liberdade de Associação e Negociação Coletiva, Trabalho Infantil, Trabalho Forçado ou Análogo ao Escravo, Avaliação de Fornecedores em Direitos Humanos, Saúde e Segurança do Cliente, Rotulagem de Produtos e Serviços, Comunicações de Marketing, Privacidade do Cliente e Combate à Corrupção; e 46 indicadores relacionados à forma de gestão da organização referente aos aspectos listados.(GRI, 2013).

De acordo com as diretrizes GRI-G4, as organizações têm duas opções para elaborar seu relatório de sustentabilidade "de acordo" com as Diretrizes, a saber: "Essencial" e "Abrangente", que designam o conteúdo a ser reportado pela empresa. Cada empresa decide se vai reportar mais ou menos informação, dependendo do seu porte, setor ou localização (GRI, 2013).

Depois, existem dois tipos de conteúdo: padrão gerais e padrão específicos. Os conteúdos padrão gerais devem ser reportados por todas as organizações. Os principais tópicos de relato são: estratégia e análise; perfil organizacional; aspectos materiais identificados e limites; engajamento de stakeholders; perfil do relatório; governança; ética e integridade. Já os conteúdos padrão específicos, são reportados de acordo com os aspectos materiais de cada empresa (GRI, 2013). Os conteúdos padrão específicos são apresentados em Categorias e Aspectos, como mostrado na Figura 22. 


\begin{tabular}{|c|c|c|c|c|}
\hline Categoria & \multicolumn{2}{|l|}{ Econômica } & \multicolumn{2}{|l|}{ Ambiental } \\
\hline Aspectos II & \multicolumn{2}{|l|}{$\begin{array}{l}\text { - Desempenho Econômico } \\
\text { - Presença no Mercado } \\
\text { - Impactos Econômicos Indir } \\
\text { - Práticas de Compra }\end{array}$} & \multicolumn{2}{|c|}{$\begin{array}{l}\text { - Materiais } \\
\text { - Energia } \\
\text { - Agua } \\
\text { - Biodiversidade } \\
\text { - Emissóes } \\
\text { - Efluentes e Residuos } \\
\text { - Produtos e Serviços } \\
\text { - Conformidade } \\
\text { - Transportes } \\
\text { - Geral } \\
\text { - Avaliação Ambiental de Fornecedores } \\
\text { - Mecanismos de Queixas e Reclamaçóes Relacionadas } \\
\text { a Impactos Ambientais }\end{array}$} \\
\hline Categoria & \multicolumn{4}{|l|}{ Social } \\
\hline $\begin{array}{l}\text { Subcategorias } \\
\text { Aspectos }\end{array}$ & $\begin{array}{l}\text { Práticas Trabalhistas } \\
\text { e Trabalho Decente } \\
\text { - Emprego } \\
\text { - Relaçóes Trabalhistas } \\
\text { - Saúde e Segurança no } \\
\text { Trabalho } \\
\text { - Treinamento e Educaçáo } \\
\text { - Diversidade e lgualdade } \\
\text { de Oportunidades } \\
\text { - Igualdade de } \\
\text { Remuneraçáo entre } \\
\text { Homens e Mulheres } \\
\text { - Avaliaçáo de } \\
\text { Fornecedores em } \\
\text { Práticas Trabalhistas } \\
\text { - Mecanismos de } \\
\text { Queixas e Reclamaçóes } \\
\text { Relacionadas a Práticas } \\
\text { Trabalhistas }\end{array}$ & $\begin{array}{l}\text { - Investimento } \\
\text { - Liberdade de Associaçáo } \\
\text { e Negociaçáo Coletiva } \\
\text { - Trabalho Infantil } \\
\text { - Trabalho Forçado ou } \\
\text { Análogo ao Escravo } \\
\text { - Práticas de Segurança } \\
\text { - Direitos Indigenas } \\
\text { - Avaliaçáo } \\
\text { - Avaliaçáo de } \\
\text { Fornecedores em } \\
\text { Direitos Humanos } \\
\text { - Mecanismos de } \\
\text { Queixas e Reclamaçóes } \\
\text { Relacionadas a Direitos } \\
\text { Humanos }\end{array}$ & $\begin{array}{l}\text { Sociedade } \\
\text { - Comunidades Locais } \\
\text { - Combate à Corrupçáo } \\
\text { - Concorticas Públicas } \\
\text { - Conformia Desleal } \\
\text { - Avaliaçáo de } \\
\text { Fornecedores em } \\
\text { Impactos na Sociedade } \\
\text { - Mecanismos de } \\
\text { Queixas e Reclamaçóes } \\
\text { Relacionadas a Impactos } \\
\text { na Sociedade }\end{array}$ & $\begin{array}{l}\text { Responsabilidade } \\
\text { pelo Produto } \\
\text { - Saúde e Segurança do } \\
\text { - Rotulente } \\
\text { e Serviços } \\
\text { - Comunicaçóes de } \\
\text { Marketing } \\
\text { - Privacidade do Cliente } \\
\text { - Conformidade }\end{array}$ \\
\hline
\end{tabular}

Figura 22. Aspectos e Categorias das diretrizes (GRI, 2013)

Os indicadores GRI-G4 utilizados nessa dissertação estão apresentados no APÊNDICE 2.

\subsubsection{QUESTIONÁRIO ISE}

O Índice de Sustentabilidade Empresarial BM\&F - ISE é um índice que mede o retorno médio de uma carteira teórica de ações de empresas de capital aberto e listadas na BM\&FBOVESPA com as melhores práticas em sustentabilidade. Para uma empresa ser listada na carteira do ISE, ela deve seguir a seguinte metodologia: análise quantitativa (pontuação no questionário); análise qualitativa (verificação dos documentos); avaliação e decisão do Conselho do ISE. Entre as 200 empresas elegíveis anualmente, apenas 40 empresas podem fazer parte da carteira. 
O questionário do ISE tem diversas dimensões, sendo elas: Geral, Econômica, Financeira, Governança Corporativa, Mudanças Climáticas, Social, Ambiental e Natureza do Produto. Na Figura 23 é apresentado um exemplo de questão do ISE.

\section{INDICADOR 1. COMPROMISSO COM PRINCIPIOS E DIREITOS FUNDAMENTAIS NAS RELAÇÖES DE TRABALHO}

Soc 1. Assinale os temas para os quais a companhia possui compromisso formal:

(P) Os temas apontados nesta pergunta constam das principais convenções da OIT e de outros acordos internacionais. O objetivo é avaliar o engajamento da companhia no enfrentamento destas questões, ainda que elas não estejam diretamente relacionadas à companhia. Por exemplo, a "erradicação" e "combate" devem ser considerados de maneira ampla e não se restringir à esfera da companhia.

(GRI G3.1) Indicadores HR1, HR2, HR4, HR5, HR6 e HR7 / (GRI G4) Indicadores HR1, HR3, HR4, HR5, HR6 e HR10

\section{(ISO 26000) Subseção 4.71}

a) Erradicação do trabalho infantil (TI)

b) Erradicação do trabalho forçado ou compulsório (TF)

c) Combate à prática de discriminação em todas as suas formas (DI)

d) Valorização da diversidade (DV)

e) Prevenção do assédio moral e do assédio sexual (AS)

f) Respeito à livre associação sindical e direito à negociação coletiva (LA)

g) Nenhum dos anteriores

Figura 23. Exemplo do Questionário - ISE (ISE, 2015)

As questões do ISE utilizadas nessa dissertação estão apresentadas no APÊNDICE 3.

\subsubsection{Verificação da aderência do Indicadores GRI com as dimensões da CSP}

Nessa etapa, foi verificado se existem indicadores GRI-G4 que correspondam às variáveis de cada dimensão de CSP e avaliado qual o nível de aderência.

\subsubsection{Levantamento dos relatórios de sustentabilidade GRI das empresas elegíveis para a carteira ISE 2015}

Os relatórios de Sustentabilidade GRI das empresas selecionadas para amostra foram retirados das páginas na internet das próprias empresas ou na página do GRI (http://database.globalreporting.org/). 


\subsubsection{Mensuração de CSP a partir de dados do relatório GRI}

Como o objetivo dessa pesquisa é avaliar se relatórios de sustentabilidade que seguem as diretrizes da GRI, são fontes de dados apropriada para cálculo da Corporate Social Performance - CSP, de forma objetiva, o critério utilizado para avaliação considerou apenas o reporte ou não, de determinado indicador, portanto, se a empresa não reportou o indicador, o escore atribuído foi " 0 ". E se a empresa reportou o indicador, o escore foi " 1 ".

\subsubsection{Verificação da aderência dos Indicadores GRI com as dimensões da CSP}

Nessa etapa, foi verificado se existem questões do ISE que correspondam às variáveis de cada dimensão de CSP e avaliado qual o nível de aderência.

\subsubsection{Mensuração da CSP a partir das respostas ao questionário ISE}

No ISE existem vários tipos de questões diferentes e para cada tipo foi aplicado um tratamento diferente.

Para questões, onde havia apenas uma resposta correta, foi atribuído "1" para a empresa que respondeu corretamente e " 0 " para a empresa que assinalou a resposta errada. Alguns exemplos estão apresentados a seguir:

SOC 5. A companhia tem política corporativa visando autorregular o uso de instrumentos de marketing de suas atividades e produtos, incorporando preceitos éticos e de respeito ao consumidor, ao cidadão e ao meio ambiente?
a) $\mathrm{Sim}$
a) 1
b) Não
b) 0 
SOC 18.7 Se SIM para a PERGUNTA 18, alternativa (b), na relação com seus clientes a companhia:

a) Pratica de maneira sistemática o diálogo e engajamento em busca de soluções

a) 0

que reduzam impactos socioambientais de produtos e serviços

b) Promove iniciativas, influenciando a adoção de práticas de modo a contribuir

b) 0 com o desenvolvimento sustentável

c) Articula com clientes em favor da comunidade local, de modo a contribuir com

c) 0

o desenvolvimento territorial

d) Garante aos clientes mecanismos de queixas e reclamações relativas à violação

d) 0

de privacidade, sigilo e perda de dados

e) Disponibiliza aos clientes canais de atendimento alternativos ou pós-venda, em

e) 0

casos onde o canal principal de atendimento ao cliente não tenha sido capaz de

resolver a demanda

f) Fornece aos clientes informações claras, compreensíveis e acessíveis, relacionadas aos seus produtos e serviços

g) Adota medidas para evitar práticas abusivas na relação com clientes

g) 0

h) Nenhuma das anteriores

h) 0

Em outros casos, a empresa candidata ao ISE pode assinalar mais de uma alternativa. Nesse caso, o escore do indicador é dado pela soma das alternativas assinaladas.

SOC 4. A companhia tem política corporativa visando impedir que sejam utilizadas de forma não previamente autorizada as informações sobre clientes/consumidores ou outras partes com as quais se relaciona no curso de suas atividades usuais ou em seus esforços comerciais, visando preservar a privacidade do cliente/consumidor e do cidadão em geral?

a) Não

b) Sim, incluindo orientações para as áreas responsáveis pela atividade comercial (como marketing e vendas)

$\begin{array}{ll}\text { c) Sim, incluindo orientações para as áreas responsáveis pela coleta, guarda e } & \text { c) } 1\end{array}$ análise de dados (como tecnologia da informação e sistemas)

d) Sim, identificando os responsáveis pela implementação e cumprimento

d) 1 dessa política

e) Sim, estabelecendo as sanções para os responsáveis em caso de falhas na

e) 1 aplicação dessa política

Ainda, em algumas questões, a empresa pode assinalar apenas uma alternativa, mas o peso dado para cada questão varia de acordo com a escolha feita. 
GER 8. A companhia divulga a remuneração dos seus administradores (conselheiros de administração e diretores)?

a) Separadamente (valores individuais)

a) 5

b) Separadamente (valores individuais), identificando a remuneração fixa e a

b) 4 variável

c) Em blocos (um bloco para o Conselho e outro bloco para a Diretoria)

c) 3

d) Em blocos (um bloco para o Conselho e outro bloco para a Diretoria),

d) 2 identificando a remuneração fixa e a variável

e) Consolidada (montante global)

e) 1

Por fim, há questões que a empresa precisa responder todas as alternativas, e para cada alternativa, pode ser dado um peso diferente. Nesse caso, a pontuação para a questão, será dada pela soma dos valores atribuídos para cada alternativa.

SOC 36. Indique abaixo o volume de negócios realizados com:

a) Fornecedores locais

b) Pequenos e médios a)

b)

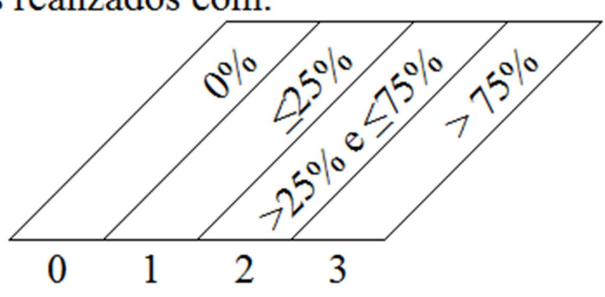

$\begin{array}{llll}0 & 1 & 2 & 3\end{array}$

Todas as diferentes avaliações estão apresentadas no APÊNDICE 3.

\subsubsection{Análise da aderência dos resultados do GRI com ISE}

Umas das razões pela qual a área de estudos organizacionais não conseguiu se desenvolver em um ritmo mais rápido é que os pesquisadores têm sido negligentes nas validações das medidas que empregam (Sharfman, 1996). Para avaliar a mensuração do constructo CSP pelo KLD, Sharfman (1996) correlacionou a medida em questão com outra forma de medida do mesmo constructo, no caso, o índice Fortune. Então, se a correlação fosse boa, seria possível confiar mais na medição de CSP pelo índice KLD. O método estatístico utilizado na pesquisa de Sharfman (1996) foi a correlação de Pearson. 
Da mesma maneira, para avaliar a mensuração de CSP utilizando dados dos relatórios de sustentabilidade GRI, o presente estudo realizará uma correlação entre duas escalas. Uma delas, será a elaborada com dados dos relatórios GRI. A outra, será elaborada com dados dos questionários ISE.

O ISE foi utilizado para essa análise como padrão, uma vez que atende a grande maioria das dimensões encontradas na literatura para mensurar a CSP, e ainda, tem vantagens em relação aos relatórios de sustentabilidade GRI. Além do relatório de sustentabilidade ser uma ação voluntária de organizações, ao seguir as diretrizes GRI, a empresa só publica os indicadores com informações que são materiais, ou relevantes, ao seu negócio e aos seus stakeholders. No ISE, o preenchimento de todo o questionário é obrigatório para as empresas participantes. Outra diferença entre as fontes de dados utilizadas nessa pesquisa, é a verificação das respostas aos indicadores e questões. No GRI, não é obrigatório. No ISE, para fazer parte da carteira, após a análise da pontuação do questionário, ainda há verificação dos documentos que comprovem as respostas e uma avaliação e decisão do Conselho do ISE.

Para responder aos objetivos do estudo, além de técnicas básicas de análise exploratória como, média, mediana e desvio padrão, foram utilizadas outras metodologias: a análise de correlação de Pearson, a análise de correlação não paramétrica de Spearman e o teste nãoparamétrico de Mann-Whitney.

\subsubsection{COEFICIENTE DE CORRELAÇÃO DE PEARSON}

O coeficiente de correlação de Pearson é uma medida de associação linear entre duas variáveis $\mathrm{X}$ e $\mathrm{Y}$ :

$$
r=\frac{1}{n-1} \sum\left(\frac{x i-\bar{X}}{s x}\right)\left(\frac{y i-\bar{Y}}{s y}\right)
$$

Neste caso a associação é dada por uma medida da variância compartilhada entre duas variáveis, e o modelo linear supõe que o aumento ou decremento de uma unidade na variável $\mathrm{X}$ gera o mesmo impacto em Y. Em termos gráficos, por relação linear entende-se que a melhor forma de ilustrar o padrão de relacionamento entre duas variáveis é através de uma 
linha reta. Portanto, a Correlação de Pearson (r) exige um compartilhamento de variância e que essa variação seja distribuída linearmente (BUSSAB, \& MORETTIN, 2006).

O coeficiente de correlação Pearson (r) varia de -1 a 1 . O sinal indica direção positiva ou negativa do relacionamento e o valor sugere a força da relação entre as variáveis. Uma correlação perfeita (-1 ou 1) indica que o escore de uma variável pode ser determinado exatamente ao se saber o escore da outra. Por outro lado, uma correlação de valor zero indica que não há relação linear entre as variáveis (Bussab, \& Morettin, 2006).

\subsubsection{COEFICIENTE DE CORRELAÇÃO DE SPEARMAN}

A medida de correlação mais usual, conhecida como Coeficiente de Correlação de Pearson, mede a relação linear entre duas variáveis. Porém, quando essa relação não for linear, o Coeficiente de Correlação de Spearman pode ser utilizado, realizando uma transformação de postos.

A atribuição de postos é feita separadamente para cada uma das duas variáveis, ou seja, quando queremos mediar a correlação de uma variável X com uma variável Y atribui-se, para cada uma das variáveis de forma independente, o posto 1 para o menor valor, 2 para o segundo menor, e assim por diante. Valores iguais (empates) recebem o mesmo posto. Dessa forma, o Coeficiente de Correlação de Spearman é dado por:

$$
r_{S}=1-\frac{6 \times \sum_{i=1}^{n} d_{i}^{2}}{n^{3}-n}
$$

em que $d_{i}=r_{X_{i}}-r_{Y_{i}}$, com $r_{X_{i}}$ e $r_{Y_{i}}$ variam de $I$ a $n$.

Assim como no Coeficiente de Correlação de Pearson, o Coeficiente de Correlação de Spearman varia entre -1 e 1, sendo -1 a máxima correlação negativa, 1 a máxima correlação positiva e 0 a correlação nula.

A hipótese a ser testada é:

$\mathrm{H}_{0}: \mathrm{r}_{\mathrm{s}}=0$ (o Coeficiente de Correlação de Spearman é igual a zero) 
$\mathrm{H}_{1}: \mathrm{r}_{\mathrm{s}} \neq 0$ (o Coeficiente de Correlação de Spearman é diferente de zero)

Rejeitar a hipótese nula $\left(\mathrm{H}_{0}\right)$ significa que a correlação encontrada é significativamente diferente de zero ou, em outras palavras, significa que a correlação encontrada é estatisticamente significativa (Barrow, 2006

\subsubsection{TESTE NÃO PARAMÉTRICO DE MANN-WHITNEY}

O teste de Mann-Whitney é um teste não-paramétrico utilizado com alternativa ao teste tStudent na comparação entre as médias de duas amostras independentes e serve para comparar as tendências centrais de duas amostras independentes de tamanhos iguais. Não dependem do conhecimento da distribuição das variáveis na população e a única exigência necessária para a aplicação do teste é que as duas amostras sejam independentes e aleatórias, e que as variáveis em análise sejam numéricas, contínuas ou ordinais.

A estatística do teste é calculada combinando as observações das duas amostras em uma única variável de tamanho $\mathrm{N} 1+\mathrm{N} 2$, sendo identificadas as respectivas amostras. Feito isso, essa variável é ordenada (ordem crescente) e é atribuído o posto 1 à primeira observação, 2 à segunda, e assim por diante. No caso de empates, é atribuído o posto médio que essas observações teriam se não fossem empates. Em seguida, calcula-se a soma dos postos das observações de cada amostra (W1 e W2). São calculadas as quantidades:

$$
\begin{aligned}
& U_{1}=N_{1} N_{2}+\frac{N_{2}\left(N_{2}+1\right)}{2}-W_{2} \\
& U_{2}=N_{1} N_{2}+\frac{N_{1}\left(N_{1}+1\right)}{2}-W_{1}
\end{aligned}
$$

A estatística do teste é:

$$
U=\min \left(U_{1}, U_{2}\right)
$$


E a hipótese a ser testada é:

$\mathrm{H}_{0}$ : as distribuições das duas amostras são iguais

Para rejeitar $\mathrm{H}_{0}$, foi considerado uma significância de $5 \%$, ou seja, a hipótese nula foi rejeitada quando valor-P foi menor ou igual a 0,05 . Nesse caso, a rejeição da $\mathrm{H}_{0}$ significa que as duas amostras apresentam distribuições significativamente distintas (Lehmann, 2006). Os valores de $\mathrm{U}$, resultantes do cálculo da estatística do teste, analisam o nível de entrelaçamento dos dados dos dois grupos de amostras após serem colocadas em ordem.

\subsubsection{REGRESSÃO LINEAR MÚLTIPLA}

Regressão linear múltipla é uma coleção de técnicas estatísticas para construir modelos que descrevem de maneira razoável relações entre várias variáveis explicativas de um determinado processo. A regressão permite avaliar a relação entre uma variável dependente e diversas variáveis independentes. É o método de análise apropriado quando o problema de pesquisa envolve uma única variável dependente métrica considerada relacionada a duas ou mais variáveis independentes métricas. O objetivo da técnica é prever as mudanças nas variáveis dependentes como resposta as mudanças nas variáveis independentes (Hair et al., 2009; Tabachnick, \& Fidell, L.S., 2001).

$$
Y_{1}=a+b_{1} X_{1}+b_{2} X_{2}+b_{3} X_{3}+. . \quad+b_{n} X_{n}
$$

(variável dependente ) (variáveis independentes)

Para isso propõe-se o seguinte modelo:

$\mathrm{CSP}^{\text {ISE }}$ Empregados $=$ Equilíbrio entre vida profissional, pessoal e familiar ${ }^{\mathrm{GRI}}+$ Saúde e segurança ocupacional $^{\mathrm{GRI}}+$ Compromisso com direitos humanos nas práticas de trabalho ${ }^{\mathrm{GRI}}+$ Treinamento e educação ${ }^{\text {GRI }}+$ Perspectivas de carreira ${ }^{\text {GRI }}+$ Diversidade e igualdades de oportunidades $^{\mathrm{GRI}}+$ Salários, recompensas e benefícios justos ${ }^{\mathrm{GRI}}+$ Anti-discriminação $^{\mathrm{GRI}}+$ Envolvimento com a comunidade ${ }^{\text {GRI }}+$ Satisfação do empregado e clima organizacional ${ }^{\text {GRI }}+$ Relacionamento com sindicatos e união de trabalhadores ${ }^{\text {GRI }}+$ Tamanho + Setor + 
$\mathrm{CSP}^{\mathrm{ISE}}$ Fornecedores $=$ Relacionamento com fornecedores ${ }^{\mathrm{GRI}}+$ Fornecedores locais $\mathrm{e}$ menores $^{\text {GRI }}+$ Tamanho + Setor +

$\operatorname{CSP}^{\mathrm{ISE}}$ Acionistas $=$ Informações sobre o conselho de Administração ${ }^{\text {GRI }}+$ Remuneração $^{\text {GRI }}$ + Estratégia de longo prazo ${ }^{\text {GRI }}+$ Tamanho + Setor +

$\operatorname{CSP}^{\mathrm{ISE}}$ Comunidade $=$ Doações $/$ Filantropia ${ }^{\text {GRI }}+$ Transparência, ética e combate à corrupção $^{\text {GRI }}+$ Comprometimento e impacto na comunidade ${ }^{\text {GRI }}+$ Tamanho + Setor +

$\operatorname{CSP}^{\mathrm{ISE}}$ Clientes $=$ Qualidade do produto ${ }^{\mathrm{GRI}}+$ Inovação e introdução de novas tecnologias $^{\mathrm{GRI}}$

+ Responsabilidade pelo Produto ${ }^{\text {GRI }}+$ Ações de comunicação e promoção ${ }^{\text {GRI }}+$ Satisfação dos clientes ${ }^{\text {GRI }}+$ Privacidade do Cliente ${ }^{\text {GRI }}+$ Tamanho + Setor +

Para essa pesquisa buscou-se avaliar o coeficiente de determinação $\left(\mathrm{R}^{2}\right)$ para verificar se as dimensões medidas pelo GRI têm significância e um alto poder de explicação.

\subsection{Definição da amostra}

A amostra foi selecionada de acordo com as organizações listadas na Carteira ISE $2015 / 2016$.

A carteira ISE 2015/2016 foi a décima primeira carteira e vigora entre 04 de janeiro de 2016 a 29 de dezembro 2016. A carteira reúne 38 ações de 34 companhias, que representam 16 setores e somam R $\$ 960,52$ bilhões em valor de mercado, o equivalente a 54,50\% do total do valor das companhias com ações negociadas na BM\&FBOVESPA (em 24/11/2015). O 
processo da carteira 2016 do ISE contou com a Asseguração Externa da KPMG, que emitiu parecer de "Asseguração Limitada sem ressalvas". A asseguração do processo do ISE é realizada desde 2012, o que confere ainda mais credibilidade e confiabilidade ao índice. Além disso, o ISE segue com a parceria de monitoramento diário de imprensa feito pela empresa Imagem Corporativa (http://isebvmf.com.br/?r=site/conteudo\&id=2).

Os questionários utilizados estão publicados na página do ISE na internet. (http://www.isebvmf.com.br/index.php?r=relatorio\&qid=2015). 


\section{RESULTADOS}

O presente capítulo apresentará os resultados da realização das etapas descritas no capítulo 0 , com o objetivo de atender aos objetivos dessa dissertação: (i) Elaborar um framework das dimensões da CSP e suas variáveis; (ii) Apresentar e validar um modelo de mensuração de CSP que utilize como fonte de dados as informações contidas nos indicadores dos relatórios de sustentabilidade que seguem as diretrizes da GRI; (iii) Elaborar um modelo de mensuração de CSP que utilize como fonte de dados as informações contidas nos questionários do Índice de Sustentabilidade Empresarial - ISE que sirva como padrão; (iv) Comparar os resultados obtidos com informações contidas nos relatórios de sustentabilidade GRI com o padrão.

\subsection{Caracterização da amostra}

A amostra analisada foi composta por 29 empresas, sendo que 5 delas, possuem mais de uma unidade de negócios. Por isso, essas unidades de negócio foram avaliadas separadamente, aumentando o tamanho da amostra para 41. As empresas compõem a carteira do Índice de Sustentabilidade Empresarial - ISE - 2016, da BM\&F Bovespa. Além disso, essas empresas divulgaram as respostas de seus questionários publicamente e, também, utilizaram a diretriz GRI mais recente, a G4. Como as respostas dos questionários ISE são referentes ao ano de 2014, os relatórios de sustentabilidade GRI também são referentes ao mesmo ano.

O ISE-2016 é composto por 34 empresas, porém foram consideradas para essa pesquisa, 29 empresas. As empresas Cesp e TIM não autorizaram a divulgação das respostas dos questionários ISE. Além disso, os relatórios de sustentabilidade da Cesp, TIM, Eletrobrás, Fleury e CCR foram elaborados seguindo as diretrizes GRI-G3.1, pois o ano de 2014 ainda compreendia em um período de transição entre as diretrizes, e nessa pesquisa, só foram utilizados os relatórios que seguiram as diretrizes GRI-G4.

As empresas avaliadas estão apresentadas na Figura 24. 


\begin{tabular}{|l|l|l|l|l|}
\hline AES Tietê & CEMIG & EDP & ITAÚSA & SANTANDER \\
\hline B2W & CIELO & ELETROPAULO & KLABIN & $\begin{array}{l}\text { SUL } \\
\text { AMERICA }\end{array}$ \\
\hline $\begin{array}{l}\text { BANCO DO } \\
\text { BRASIL }\end{array}$ & COPEL & EMBRAER & LIGHT & TELEFONICA \\
\hline BRADESCO & CPFL & EVEN & $\begin{array}{l}\text { LOJAS } \\
\text { AMERICANAS }\end{array}$ & TRACTEBEL \\
\hline BRASKEM & DURATEX & FIBRIA & LOJAS RENNER & WEB \\
\hline BRF SA & ECORODOVIAS & ITAÚ UNIBANCO & NATURA & \multicolumn{2}{|l}{} \\
\cline { 1 - 2 } & & & &
\end{tabular}

Figura 24. Amostra avaliada na dissertação

As empresas que possuem controladas estão apresentadas na Figura 25.

\begin{tabular}{|c|c|}
\hline \multirow{2}{*}{ CEMIG } & CEMIG - Distribuição S.A. \\
\hline & CEMIG - Geração e Transmissão S.A. \\
\hline \multirow{2}{*}{ COPEL } & COPEL - Distribuição S.A. \\
\hline & COPEL - Geração e Transmissão S.A \\
\hline \multirow{4}{*}{ CPFL } & CPFL Geração de Energia S.A. \\
\hline & Companhia Paulista de Força e Luz \\
\hline & Companhia Piratininga de Força e Luz \\
\hline & Rio Grande Energia S.A. \\
\hline \multirow{6}{*}{ ECORODOVIAS } & RODOVIAS AYRTON SENNA E CARVALHO PINTO S.A. - ECOPISTAS \\
\hline & ECOVIA CAMINHO DO MAR S.A. \\
\hline & ECOVIAS DOS IMIGRANTES S.A. \\
\hline & ECOPORTO SANTOS S.A. \\
\hline & RODOVIAS DO SUL S.A. - ECOSUL \\
\hline & RODOVIA DAS CATARATAS S.A. - ECOCATARATAS \\
\hline \multirow{3}{*}{ EDP } & EDP - COMERCIALIZAÇÃO E SERVIÇOS DE ENERGIA LTDA. \\
\hline & Bandeirante Energia S.A. \\
\hline & Espírito Santo Centrais Elétricas S.A. \\
\hline
\end{tabular}

Figura 25. Empresas com informações sobre unidades de negócios abertas

Na Tabela 1, as empresas foram agrupadas de acordo com o setor que atuam. 
Tabela 1. Empresas por setor de atuação

\begin{tabular}{lcc}
\hline \multicolumn{1}{c}{ Setor } & Frequência & Percentual \\
\hline Energia Elétrica & 8 & $27,6 \%$ \\
Financeiro & 7 & $24,1 \%$ \\
Comércio & 3 & $10,3 \%$ \\
Madeira e Papel & 3 & $10,3 \%$ \\
Construção e Transporte & 2 & $6,9 \%$ \\
Químico & 1 & $3,4 \%$ \\
Alimentos & 1 & $3,4 \%$ \\
Material de Transporte & 1 & $3,4 \%$ \\
Telecomunicações & 1 & $3,4 \%$ \\
Produto de uso pessoal & 1 & $3,4 \%$ \\
Máquinas e Equipamentos & 1 & $3,4 \%$ \\
\hline
\end{tabular}

Observa-se que os setores que concentram maior quantidade de empresas na amostra selecionada são: Energia Elétrica e Financeiro. A classificação por setor seguiu os critérios da BM\&F Bovespa. Para uma questão de análise, os setores foram agrupados em 4 grupos: utilidades (empresas de energia elétrica e empresas concessionárias de rodovias), serviços, indústrias e financeiro.

\subsection{Aderência dos Indicadores GRI e do questionário ISE com as dimensões da CSP}

As diretrizes GRI-G4 possuem 58 indicadores relacionados ao perfil de cada empresa, 91 indicadores relacionados a aspectos e 46 indicadores referentes à forma de gestão dos impactos de cada aspecto. Entre os indicadores de perfil, 8 estão relacionados com as variáveis que representam as dimensões da CSP. Em relação aos indicadores dos aspectos, 33 indicadores podem se relacionar com a CSP. Por fim, dos indicadores referentes à forma de gestão, 17 tem relação com a CSP.

No total, foram identificadas na literatura, 40 variáveis que representam as dimensões da CSP. Nas diretrizes GRI-G4 foram encontrados indicadores correspondentes a 33 variáveis, ou seja, uma aderência de $83 \%$. Alguns indicadores, podem corresponder a mais de uma variável, como por exemplo, o EC-1, que pode descrever diversas informações referentes ao valor econômico direto gerado, distribuído e retido, entre elas, as requisitadas pelas variáveis "Doações financeiras e de bens e patrocínios" e "Aumento do valor do acionista (retorno 
econômico". Outro ponto a salientar, é que a divulgação desses indicadores depende da análise de materialidade feita por cada empresa, que indica as prioridades da empresa de acordo com a importância para o negócio e para seus stakeholders. Ou seja, não é obrigatório a divulgação de todos os indicadores em seus relatórios de sustentabilidade.

Em relação ao ISE-2015, 31 variáveis são representadas pelas questões do ISE, ou seja, uma aderência de 78\%. No ISE, os questionários são divididos nas seguintes dimensões: ambiental, econômico-financeira, geral, governança corporativa, mudanças climáticas, natureza do produto e social. Apenas as questões referentes à dimensão "mudanças climáticas" não representaram nenhuma dimensão da CSP.

Essa pequena diferença em relação as aderências de ISE e GRI não influencia na escolha do ISE como padrão, na análise entre as duas fontes de dados. Uma vez que, as empresas que participam do processo de seleção para a carteira ISE, devem responder a todas as questões obrigatoriamente, diferente dos relatórios de sustentabilidade GRI. Além disso, as respostas às questões são comprovadas com envio de documentos.

Além disso, o que pode ter influenciado nessa diferença, é que no ISE as informações quantitativas (horas de treinamento, retorno econômico, informações sobre ocorrência e redução de lesões, doenças ocupacionais, dias perdidos e absenteísmo, número de óbitos relacionados ao trabalho, e estatísticas de redução do turnover) não são apresentadas por meio do questionário.

Algumas variáveis da CSP não foram encontradas nem nos indicadores GRI, nem no questionário ISE. São elas as relacionadas com: programas de flexibilidade no trabalho (horários flexíveis, home-office); parcerias entre empresa e fornecedores; qualidade do produto; e inovação e introdução de novas tecnologias. Essas variáveis representam 7,5\% da CSP.

\subsection{Análise da aderência dos resultados GRI com os resultados ISE}

Avaliou-se a associação entre as pontuações de duas diferentes métricas, elaboradas com os dados dos relatórios GRI e do questionário ISE, para cada stakeholder e para todos os stakeholders simultaneamente. Os questionários são formados pelos mesmos stakeholders e 
pelas mesmas variáveis, porém os indicadores e questões que compõe cada dimensão diferem entre eles.

Como cada métrica contém diferentes indicadores e questões, e quantidades de indicadores e questões em cada dimensão avaliada foi necessário trabalhar os dados antes de qualquer análise estatística. Além disso os valores no questionário ISE diferem entre as dimensões e dessa maneira primeiramente foi feita a padronização das questões deste questionário. A padronização dos valores obtidos por cada empresa foi feito segundo a fórmula ( $\mathrm{x}$ $\min ) /(\max -\min )$, o que garante que todas as respostas têm variação de 0 a 1.

Para obtermos um ranking com a classificação dos stakeholders com conceitos equivalentes, foi necessário garantir que cada variável presente nestes stakeholders tenham o mesmo peso no cálculo. Dessa maneira, optou-se por trabalhar com a média de cada empresa em cada variável e dimensão ao invés dos valores das questões diretamente.

A análise de dados iniciou-se com a descrição dos valores dos rankings stakeholders GRI e ISE para cada stakeholder e geral, conforme Tabela 2 e Tabela 3.

Tabela 2. Média, mediana e desvio padrão da CSP pelo GRI para cada Stakeholder

GRI

\begin{tabular}{cccccc} 
Stakeholder & Média & Desvio padrão & Mediana & Mínimo & Máximo \\
\hline Empregados & 0,632 & 0,289 & 0,633 & 0,117 & 1,000 \\
Fornecedores & 0,510 & 0,435 & 0,250 & 0,000 & 1,000 \\
Acionistas & 0,815 & 0,221 & 0,917 & 0,167 & 1,000 \\
Comunidade & 0,843 & 0,131 & 0,892 & 0,567 & 1,000 \\
Clientes & 0,521 & 0,345 & 0,563 & 0,000 & 1,000 \\
\hline Geral & 0,664 & 0,235 & 0,664 & 0,237 & 1,000 \\
\hline
\end{tabular}

\section{GRI}

\begin{tabular}{cccccc} 
Stakeholder & Média & Desvio padrão & Mediana & Mínimo & Máximo \\
\hline Empregados & 0,632 & 0,289 & 0,633 & 0,117 & 1,000 \\
Fornecedores & 0,510 & 0,435 & 0,250 & 0,000 & 1,000 \\
Acionistas & 0,815 & 0,221 & 0,917 & 0,167 & 1,000 \\
Comunidade & 0,843 & 0,131 & 0,892 & 0,567 & 1,000 \\
Clientes & 0,521 & 0,345 & 0,563 & 0,000 & 1,000 \\
\hline Geral & 0,664 & 0,235 & 0,664 & 0,237 & 1,000 \\
\hline
\end{tabular}


Tabela 3. Média, mediana e desvio padrão da CSP pelo ISE para cada Stakeholder

ISE

\begin{tabular}{cccccc}
\cline { 2 - 6 } Stakeholder & Média & Desvio padrão & Mediana & Mínimo & Máximo \\
\hline Empregados & 0,716 & 0,127 & 0,693 & 0,451 & 0,956 \\
Fornecedores & 0,549 & 0,194 & 0,555 & 0,166 & 0,875 \\
Acionistas & 0,775 & 0,150 & 0,816 & 0,272 & 0,905 \\
Comunidade & 0,918 & 0,083 & 0,944 & 0,648 & 1 \\
Clientes & 0,685 & 0,187 & 0,800 & 0,350 & 1 \\
\hline Geral & 0,729 & 0,094 & 0,728 & 0,498 & 0,892 \\
\hline
\end{tabular}

Em seguida, foi feita a análise de correlação, apresentada na Tabela 4. A associação entre os rankings foi calculada a partir de duas estatísticas de correlação, a correlação paramétrica de Pearson e a correlação não paramétrica de Spearman. Optou-se pelo uso das duas correlações como forma de certificar os resultados, e principalmente, pelo fato de que a correlação de Pearson apresenta a suposição de que a correlação entre as variáveis é linear, enquanto que a correlação de Spearman não apresenta suposição com relação a relação entre as variáveis.

Tabela 4. Correlação de Pearson e Spearman do ranking stakeholder da dimensão ISE com relação ao ranking de dimensão GRI

\begin{tabular}{ccc} 
Stakeholder & Pearson & Spearman \\
\hline Empregados & $-0,234$ & $-0,240$ \\
Fornecedores & $-0,269$ & $-0,377$ \\
Acionistas & $-0,002$ & 0,211 \\
Comunidade & $-0,124$ & $-0,173$ \\
Clientes & $-0,001$ & $-0,002$ \\
\hline Geral & $-0,150$ & $-0,129$ \\
\hline
\end{tabular}

Os resultados não apresentaram uma boa associação entre os grupos GRI e ISE, porém, ao analisar as médias de ambas as métricas, foi possível perceber uma certa coerência entre as avaliações. Ao ordenar as CSP de acordo com o resultado por stakeholder, considerando 1 para o menor valor e 5, para o maior valor, foi possível observar que cada um ocupava a mesma posição. 


\begin{tabular}{cccccc} 
& \multicolumn{2}{c}{ GRI } & & \multicolumn{2}{c}{ ISE } \\
\cline { 2 - 3 } \cline { 5 - 5 } Stakeholder & Média & Ordem & & Média & Ordem \\
\hline Empregados & 0,632 & 3 & & 0,716 & 3 \\
Fornecedores & 0,510 & 1 & & 0,549 & 1 \\
Acionistas & 0,815 & 4 & & 0,775 & 4 \\
Comunidade & 0,843 & 5 & & 0,918 & 5 \\
Clientes & 0,521 & 2 & & 0,685 & 2
\end{tabular}

Por fim, o Teste de Mann-Whitney foi aplicado para verificar se havia alguma relação entre a distribuições das duas medidas de CSP. O teste foi aplicado tanto para a escala original, quanto para a escala ordinal e está apresentado na Tabela 6.

Tabela 6. Teste não paramétrico de Mann-Whitney

\begin{tabular}{clc}
\hline Stakeholders & \multicolumn{1}{c}{ Mann Whitney } & Escala original \\
\hline \multirow{3}{*}{ Empregados } & Estatística Mann-Whitney U & 699,000 \\
& Valor-P (bicaudal) & 0,189 \\
\multirow{2}{*}{ Fornecedores } & Estatística Mann-Whitney U & 789,000 \\
& Valor-P (bicaudal) & 0,631 \\
\multirow{3}{*}{ Acionistas } & Estatística Mann-Whitney U & 620,000 \\
& Valor-P (bicaudal) & 0,039 \\
Comunidades & Estatística Mann-Whitney U & 584,500 \\
& Valor-P (bicaudal) & 0,017 \\
& Estatística Mann-Whitney U & 630,500 \\
& Valor-P (bicaudal) & 0,051
\end{tabular}

Nesse caso, a hipótese nula $\left(\mathrm{H}_{0}\right.$ : as distribuições das duas amostras são iguais) foi rejeitada para os stakeholders acionistas e comunidade, mostrando que existe uma relação entre as duas escalas, GRI e ISE, para empregados, fornecedores e clientes.

Para aprofundar a análise, procedeu-se a utilização de uma técnica de análise multivariada: a análise de regressão linear múltipla, pois quando se utiliza a correlação para medir aderência de duas variáveis, ou quando se utiliza um teste comparativo, como o de Mann-Whitney, desconsidera-se o efeito que outras variáveis possam ter simultaneamente sobre a relação que se está medindo. A regressão considerou além das dimensões de CSP determinadas nessa pesquisa para cada stakeholder, o tamanho da empresa, definido pelo log do ativo total (informações encontradas nos sites da BM\&F Bovespa) e o setor que cada empresa pertence. 
Os resultados estão apresentados a seguir:

Tabela 7. Estatística de regressão

\begin{tabular}{lccccc} 
& Empregados & Fornecedores & Acionistas & Comunidade & Clientes \\
\hline R múltiplo & 0,901 & 0,446 & 0,35 & 0,454 & 0,374 \\
R-Quadrado & 0,812 & 0,198 & 0,123 & 0,206 & 0,14 \\
R-quadrado ajustado & 0,711 & 0,056 & $-0,064$ & 0,066 & $-0,076$ \\
Erro padrão & 0,068 & 0,188 & 0,155 & 0,0799 & 0,180 \\
Valor-P & 0,003 & 0,001 & 0,047 & $5,03 \mathrm{E}-07$ & 0,541 \\
Observações & 41 & 41 & 41 & 41 & 41 \\
\hline
\end{tabular}

Observou-se o coeficiente de determinação $\left(\mathrm{R}^{2}\right)$ que indica quanto o modelo foi capaz de explicar os dados coletados. Nesse caso, buscou-se verificar se a CSP de cada um dos stakeholders medidos pelo ISE, poderiam ser explicados pelas dimensões que os compõem, medidos pelo GRI. Quanto mais próximo de 1 fosse o valor do $\mathrm{R}^{2}$, melhor a aderência do modelo de CSP calculado por GRI com o modelo calculado pelo ISE. Com os dados analisados, verificou-se que para o stakeholder empregado foi encontrada a maior aderência entre as duas métricas, CSP e ISE.

As análises estatísticas foram realizadas com o auxílio do Microsoft Excel e do software estatístico SPSS.

\subsection{Discussão dos resultados}

A mensuração de CSP vendo sendo estudada na área de administração de CSP há mais de 50 anos, porém ainda não existe uma métrica consolidada (Wood, 2010). Para que sejam consideradas, as métricas de CSP devem englobar as diversas dimensões e aspectos sociais existentes nas relações com seus stakeholders (Carroll, 2000).

É nesse contexto que essa dissertação se insere. Essa pesquisa traz uma contribuição em relação ao método de mensuração de CSP. Argumentou-se que é importante que haja modelos de mensuração que utilizem bases de dados acessíveis e amplas. Para isso, sugeriu-se a 
utilização das informações encontradas nos relatórios de sustentabilidade divulgados pelas organizações que seguem as diretrizes GRI, uma vez que são amplamente utilizadas por grandes empresas do mundo todo. Também, foi proposta uma validação dessa métrica, buscando associações com um modelo de mensuração que utiliza os dados dos questionários ISE. O ISE foi escolhido como padrão, por ser considerada uma base de dados confiável, uma vez que, as empresas devem responder, obrigatoriamente, a todas as questões e também, devem enviar documentos que comprovem suas respostas.

Após a revisão da literatura de CSP, foi possível identificar as principais dimensões e variáveis utilizadas no cálculo de CSP. Avaliando as dimensões identificadas e as respectivas variáveis, foi possível observar uma predominância clara de variáveis e dimensões relacionadas aos stakeholders empregados. Das 40 variáveis encontradas, 21 referem-se apenas aos empregados.

Em seguida, relacionou-se as variáveis da CSP com os indicadores GRI e as questões ISE. A análise desses dados mostrou uma aderência maior ou igual a 78\% para ambas as medidas de CSP. Sendo que, apenas 3 variáveis não foram consideradas nesse modelo de mensuração. Entre as 25 dimensões da CSP, a única dimensão que ficou de fora da análise foi "Qualidade do Produto", pois seria operacionalizada justamente por uma das variáveis faltantes.

O GRI busca evidenciar as ações e atividades de sustentabilidade que uma empresa realiza para seus stakeholders. Enquanto que o ISE busca mensurar o desempenho de uma empresa em diversas áreas, entre elas, a social, a econômica e a ambiental. Cabe salientar que tanto o ISE quanto o GRI têm o papel de refletir em seus questionários e indicadores as expectativas da sociedade, e não se ocupa em se alinhar a uma teoria. Ou seja, essa pesquisa buscou utilizar duas bases dados que foram construídos para outro fim. Dessa maneira, mesmo não atendendo a todas as dimensões, é possível dizer, que tanto o ISE quanto o GRI possuem uma boa aderência em relação a CSP, por isso foi possível seguir para a etapa seguinte. Mas de qualquer forma, os modelos apresentados não representam a CSP na sua totalidade, o que pode gerar um viés nessa pesquisa.

As análises de correlação não mostraram forte associação significante entre as duas medidas, de uma forma geral. O Teste de Mann-Whitney mostrou que há relação entre as distribuições das escalas construídas com dados do GRI e do ISE, para os stakeholders empregados, 
fornecedores e clientes. Ou seja, não há evidências que suportem a hipótese de que os relatórios de sustentabilidade GRI e o questionário ISE sejam diferentes para esses stakeholders. Por fim, foi realizada a Regressão Linear Múltipla, pois nas análises de correlação e no teste Mann-Whitney, não são considerados os efeitos que outras variáveis possam ter simultaneamente sobre a relação que se está medindo. Nesse caso, foi possível obter uma melhor associação entre as métricas para o stakeholder Empregados, o que pode ser explicado pelo maior número de variáveis encontradas.

Analisando o desempenho de cada empresa, foi possível perceber que para algumas delas, os resultados de CSP para GRI eram muito baixos, com um escore bem abaixo da média $(14,40)$, conforme Figura 26.

\begin{tabular}{|l|c|}
\hline EMPRESAS & CSP \\
\hline AES TIETE & 6,87 \\
\hline B2W & 7,73 \\
\hline BANCO DO BRASIL & 21,67 \\
\hline BRADESCO & 15,41 \\
\hline BRASKEM & 9,68 \\
\hline BRF & 15,67 \\
\hline CEMIG - Distribuição S.A. & 14,89 \\
\hline CEMIG - Geração e Transmissão S.A. & 14,89 \\
\hline CIELO & 7,21 \\
\hline COPEL - Distribuição S.A. & 10,84 \\
\hline COPEL - Geração e Transmissão S.A & 10,84 \\
\hline CPFL Geração de Energia S.A. & 10,03 \\
\hline Companhia Paulista de Força e Luz & 10,03 \\
\hline Companhia Piratininga de Força e Luz & 10,03 \\
\hline Rio Grande Energia S.A. & 10,03 \\
\hline DURATEX & 22,00 \\
\hline RODOVIAS AYRTON SENNA E CARVALHO PINTO S.A. - ECOPISTAS & 20,38 \\
\hline ECOVIA CAMINHO DO MAR S.A. & 20,38 \\
\hline ECOVIAS DOS IMIGRANTES S.A. & 20,38 \\
\hline ECOPORTO SANTOS S.A. & 19,88 \\
\hline RODOVIAS DO SUL S.A. - ECOSUL & 20,38 \\
\hline RODOVIA DAS CATARATAS S.A. - ECOCATARATAS & 20,38 \\
\hline EDP - COMERCIALIZAÇÃO E SERVIÇOS DE ENERGIA LTDA. & 22,00 \\
\hline Bandeirante Energia S.A. & 22,00 \\
\hline Espírito Santo Centrais Elétricas S.A. & 22,00 \\
\hline ELETROPAULO & 8,07 \\
\hline EMBRAER & 12,47 \\
\hline EVEN & 15,79 \\
\hline FIBRIA & 15,84 \\
\hline
\end{tabular}




\begin{tabular}{|l|c|} 
ITAU & 16,13 \\
\hline ITAUSA & 8,43 \\
\hline KLABIN & 9,43 \\
\hline LIGHT & 22,00 \\
\hline LOJAS AMERICANAS & 8,48 \\
\hline LOJAS RENNER & 9,18 \\
\hline NATURA & 12,13 \\
\hline SANTANDER & 15,17 \\
\hline SUL AMERICA & 12,58 \\
\hline TELEFONICA & 13,82 \\
\hline TRACTEBEL & 21,00 \\
\hline WEG & 4,37 \\
\hline
\end{tabular}

Figura 26. Resultados da mensuração de CSP utilizando GRI

Ao avaliar o conteúdo dos relatórios GRI de cada empresa, percebeu-se uma grande diferença na quantidade de indicadores reportados. Para algumas empresas isso se deve ao não reporte dos indicadores selecionados para pesquisa por uma questão de não materialidade, ou seja, os indicadores não são relevantes para as atividades da organização e seus stakeholders. Por outro lado, alguns relatórios parecem estar incompletos. Por exemplo, o relatório da CPFL não divulgou nenhum indicador de Forma de Gestão (DMA), que representam quase $30 \%$ dos indicadores. Ou o relatório da WEG tem pouquíssimos indicadores publicados. A Figura 27 mostra a quantidade de indicadores GRI reportados nos relatórios de sustentabilidade de cada empresa.

\begin{tabular}{|l|c|c|c|c|}
\cline { 2 - 5 } \multicolumn{1}{c|}{} & $\begin{array}{c}\text { Indicadores } \\
\text { de Perfil } \\
\text { reportados } \\
\text { (Total=58) }\end{array}$ & $\begin{array}{c}\text { Indicadores de } \\
\text { Aspectos } \\
\text { reportados } \\
\text { (Total=91) }\end{array}$ & $\begin{array}{c}\text { Indicadores de } \\
\text { Forma de gestão } \\
\text { reportados } \\
\text { (Total=46) }\end{array}$ & $\begin{array}{c}\text { \% } \\
\text { indicadores } \\
\text { reportados }\end{array}$ \\
\hline AES TIETE & 34 & 25 & 15 & $38 \%$ \\
\hline B2W & 44 & 27 & 5 & $39 \%$ \\
\hline BANCO DO BRASIL & 58 & 77 & 43 & $91 \%$ \\
\hline BRADESCO & 34 & 44 & 18 & $49 \%$ \\
\hline BRASKEM & 38 & 48 & 0 & $44 \%$ \\
\hline BRF & 58 & 69 & 35 & $83 \%$ \\
\hline CEMIG & 45 & 80 & 0 & $64 \%$ \\
\hline CIELO & 34 & 21 & 11 & $34 \%$ \\
\hline COPEL & 57 & 52 & 0 & $56 \%$ \\
\hline CPFL & 54 & 32 & 0 & $44 \%$ \\
\hline DURATEX & 58 & 91 & 46 & $100 \%$ \\
\hline ECORODOVIAS & 41 & 74 & 44 & $82 \%$ \\
\hline EDP & 58 & 91 & 46 & $100 \%$ \\
\hline
\end{tabular}




\begin{tabular}{|l|c|c|c|c|} 
ELETROPAULO & 34 & 27 & 15 & $39 \%$ \\
\hline EMBRAER & 52 & 44 & 17 & $58 \%$ \\
\hline EVEN & 53 & 56 & 31 & $72 \%$ \\
\hline FIBRIA & 58 & 91 & 0 & $76 \%$ \\
\hline ITAU & 42 & 38 & 25 & $54 \%$ \\
\hline ITAUSA & 58 & 19 & 13 & $46 \%$ \\
\hline KLABIN & 34 & 46 & 24 & $53 \%$ \\
\hline LIGHT & 57 & 91 & 46 & $99 \%$ \\
\hline LOJAS & & & 5 & $40 \%$ \\
AMERICANAS & 42 & 31 & 0 & $47 \%$ \\
\hline LOJAS RENNER & 37 & 54 & 0 & $41 \%$ \\
\hline NATURA & 0 & 80 & 25 & $68 \%$ \\
\hline SANTANDER & 58 & 50 & 6 & $57 \%$ \\
\hline SUL AMERICA & 58 & 48 & 27 & $48 \%$ \\
\hline TELEFONICA & 34 & 33 & 42 & $93 \%$ \\
\hline TRACTEBEL & 58 & 81 & 0 & $23 \%$ \\
\hline WEG & 34 & 10 & &
\end{tabular}

Figura 27. Quantidade de indicadores GRI reportados no relatório de sustentabilidade 2014 por empresa

Além disso, observou-se também, muitos resultados iguais para a CSP mensurada com relatórios GRI. Isso se deve a escolha pela utilização de uma escala binária ( 0 e 1$)$ para coleta de dados dos relatórios de sustentabilidade GRI. Essa escala foi escolhida, pois estava se buscando uma forma prática e objetiva de mensuração de CSP, onde não fosse necessário realizar uma análise que dependesse da subjetividade do pesquisador. Porém, percebeu-se que algumas informações relevantes para a mensuração de CSP poderiam ser mascaradas nessa forma de avaliação. 


\section{CONSIDERAÇÕES FINAIS}

Nesse capítulo serão apresentadas as conclusões em relação aos objetivos dessa pesquisa, as contribuições e as limitações decorrente do estudo, além das recomendações para pesquisas futuras.

\subsection{Considerações quanto aos objetivos dessa pesquisa}

O objetivo dessa dissertação foi avaliar se relatórios de sustentabilidade que seguem as diretrizes da Global Reporting Initiative - GRI, são fontes de dados apropriadas para cálculo da Corporate Social Performance - CSP, demonstrando assim, se é possível medi-la de forma objetiva e compará-la com os resultados obtidos de diferentes relatórios. Para atingir esse objetivo principal, alguns objetivos específicos foram estabelecidos.

Com relação ao primeiro objetivo: "Elaborar um framework das dimensões da Corporate Social Performance - CSP e suas variáveis", foi possível construir um modelo de CSP robusto com 25 dimensões e 40 variáveis correspondentes aos 5 stakeholders primários considerados nessa pesquisa. Na análise, observou-se a grande importância, identificada na literatura, dos stakeholders empregados, sendo eles relacionados a 51\% das variáveis da CSP.

O segundo e o terceiro objetivos específicos, se tratavam de apresentar dois modelos de mensuração de CSP que utilizassem como fonte de dados as informações contidas nos indicadores dos relatórios de sustentabilidade que seguem as diretrizes da GRI e as informações contidas nos questionários do Índice de Sustentabilidade Empresarial - ISE, respectivamente. Dessa forma, buscou-se nas diretrizes GRI e nos questionários ISE, indicadores e questões que pudessem responder ao solicitado por cada variável para avaliar a performance social corporativa em relação aos stakeholders. A aderência do ISE e do GRI foi maior que $78 \%$ e apenas uma dimensão não foi considerada por ambas as métricas.

O último objetivo específico, foi comparar os resultados de CSP obtidos com informações contidas nos relatórios de sustentabilidade GRI com o padrão. Para isso, análises de correlação de Pearson e Spearman foram realizadas, e resultaram em uma correlação muito baixa entre as duas métricas, GRI e ISE. O Teste Mann-Whitney mostrou que não há evidências que suportem a hipótese de que os relatórios de sustentabilidade GRI e o 
questionário ISE sejam diferentes para os stakeholders comunidade, clientes e fornecedores. Ainda, foi realizada a Regressão Linear Múltipla para que os efeitos de outras variáveis pudessem ser avaliados. Nessa análise foi possível verificar uma melhor associação entre as métricas de GRI e ISE para o stakeholder Empregados, o que pode ser explicado pelo maior número de variáveis encontradas.

\subsection{Contribuições e limitações da pesquisa}

O problema de pesquisa dessa dissertação se inseriu na dificuldade de se encontrar métricas acessíveis e práticas, com dimensões que fossem menos específicas a determinado país e que pudessem ser utilizadas para medir CSP, principalmente, empresas no Brasil.

Nesse sentido, essa dissertação traz uma contribuição metodológica aos estudos da mensuração de CSP, trazendo um modelo de mensuração com dimensões e variáveis identificadas na literatura. Além disso, a pesquisa se propôs a avaliar duas métricas, utilizando diferentes fontes de dados, GRI e ISE, sendo a primeira, de ampla utilização por empresas do mundo todo.

Por outro lado, algumas limitações podem ser identificadas. O tamanho da amostra avaliada, de 41 empresas, pode ter influenciado no resultado da análise. Um teste de correlação com maior número de observações poderia resultar em uma análise mais robusta. Porém, isso não seria possível da maneira que esse estudo foi desenhado, pois considerou-se apenas um ano da carteira ISE.

Outra possível limitação, refere-se às informações contidas nos relatórios de sustentabilidade GRI, que é o fato de serem reportadas voluntariamente pelas organizações, e, portanto, conterem apenas um ponto de vista. Nesse caso, os stakeholders das organizações não são consultados e também, as informações publicadas não são, necessariamente, validadas ou confirmadas.

Outro ponto em relação aos relatórios de sustentabilidade GRI consiste na não obrigatoriedade de relato de todos os indicadores. Ou seja, as empresas relatam apenas os temas que são materiais. Por isso, mesmo que não tenha relatado, é possível que a empresa 
esteja desenvolvendo atividades que correspondam à alguma variável. Porém, não será possível mensurá-las.

Por fim, segundo Sharfman (1996), a validação de uma métrica não é um fenômeno binário, com resposta única: sim ou não. Por isso, como sugestão para estudos futuros, sugere-se avaliar outra forma de coleta de dados nos relatórios de sustentabilidade GRI, utilizando uma escala maior de avaliação, e compará-la com a escala dicotômica. Mesmo aumentando a complexidade da avaliação, os resultados podem trazer resultados diferentes à análise. 


\section{REFERÊNCIAS}

AGUDO, J. M., GARGALLO, P., \& SALVADOR, M. (2015). Measuring corporative social performance in firms: a Bayesian factor analysis approach. Journal of Business Economics and Management, 16 (3), 638-659.

AHMED, S. U., ISLAM, D. U., \& HASAN1, I. (2012). Social Responsibility and Financial Performance Linkage - Evidence from the Banking Sector of Bangladesh. Journal of Organizational Management, 1 (1), 14-21.

BARNETT, M. L. (2007). Stakeholder influence capacity and the variability of financial returns to corporate social responsibility. Academy of Management Review, 32 (3), 794-816.

BOAVENTURA, J.M.G., CARDOSO, F.R., SILVA, E.S. da, \& SILVA, R.S. da. (2009). Teoria dos Stakeholders e Teoria da Firma: Um Estudo sobre a Hierarquização das FunçõesObjetivo em Empresas Brasileiras. RBGN - Revista Brasileira de Gestão de Negócios, 11 (32) 289-307.

BOAVENTURA, J.M.G., SILVA, R.S.; BANDEIRA-DE-MELLO, R. (2012). Performance Financeira Corporativa e Performance Social Corporativa: desenvolvimento metodológico e contribuição teórica dos estudos empíricos. Revista de Contabilidade e Finanças, 23 (60), 232-245.

BOUTENA, L., EVERAERTA, P., LIEDEKERKEB, L. V., DE MOORD, L., \& CHRISTIAENSA, J. (2011). Corporate social responsibility reporting: A comprehensive picture? Accounting Forum, 35 (3), 187-204.

BROWER, J., \& MAHAJAN, V. (2013). Driven to Be Good: A Stakeholder Theory Perspective on the Drivers of Corporate Social Performance. Journal of Business Ethics, 117 (2), 313-331.

BROWN, H.S., JONG, M. DE, \& LEVY, D. L. (2009). Building institutions based on information disclosure: lessons from GRI's sustainability reporting. Journal of Cleaner Production, 17 (6), 571-580. 
BUSSAB, W.O., \& MORETTIN, P.A. (2006). Estatística Básica. São Paulo: Saraiva.

CARROLL, A. B. (1979). A Three-Dimensional Conceptual Model as Corporate Social Performance. Academy of Management Review, 4, 497-506.

CARROLL, A. B. (1991). The pyramid of corporate social responsibility: Toward the moral management of organizational stakeholders. Business Horizons, 34 (4), 39-48.

CARROLL, A. B. (1999). Corporate Social Responsibility: Evolution of a Definition Construct. Business and Society, 38 (3), 268-295.

CARROLL, A. B. (2000). A Commentary and an Overview of Key Questions on Corporate Social Performance Measurement. Business and Society, 39 (4), 466-478.

CARROLL, A.B. (2015). Corporate Social Responsibility: The Centerpiece of Competing and Complementary Frameworks. Organizational Dynamics, 44, 87-96.

CHEN, C., \& DELMAS, M. (2011). Measuring Corporate Social Performance: An Efficiency Perspective. Productions and Operations Management, 20 (6), 789-804.

CHEN, C., DELMAS, M. A., \& LIEBERMAN, M. B. (2015). Production Frontier Methodologies and Efficiency as a Performance Measure in Strategic Management Research. Strategic Management Journal, 36, 19-36.

CHEUNG, Y., JIANG, K., MAK, S. C., TAN, W. (2013). Corporate Social Performance, Firm Valuation, and Industrial Difference: Evidence from Hong Kong. Journal of Business Ethics, 114, 625-631.

CLARKSON, M. B. E. (1995, janeiro). A Stakeholder Framework for Analyzing and Evaluating Corporate Social Performance. Academy of Management Review, 20 (1), 92-117.

COSTA, R.; \& MENICHINI, T. (2013). A multidimensional approach for CSR assessment: The importance of the stakeholder perception. Expert Systems with Applications, 40, 150161. 
DAM, L., \& SCHOLTENS, B. (2013). Ownership Concentration and CSR Policy of European Multinational Enterprises. Journal of Business Ethics, 118, 117-126.

DAWKIN, C.E., \& FRAAS, J. W. (2013). An Exploratory Analysis of Corporate Social Responsibility and Disclosure. Business Society, 52 (2), 245-281.

DE CAMPOS, I.C.S., \& SANTOS, J.B. (2013). Do managers believe in the corporate socialfinancial performance link? Revista de Gestão Social e Ambiental, 7 (3), 3-19.

DOMINGOS, S.R.M., \& MOURA, A.A.F. (2015). Reputação corporativa e desempenho: uma análise nas maiores companhias abertas do Brasil. Revista Brasileira de Contabilidade, $215,31-44$.

DONALDSON, T., \& PRESTON, L. E. (1999). Stakeholder Management and Organizational Wealth. Academy of Management Review, 24 (4), 619-620.

DONALDSON, T., \& PRESTON, L. E. (1995). The Stakeholder Theory of the Corporation: Concepts, Evidence and Implications. Academy of Management Review, 20 (1), 65-91.

DONATO, F., \& IZZO, F. (2015). The relation between corporate social responsibility and stock prices: an analysis of the italian listed companies. Corporate Ownership and Control, $12,600-609$.

DUCASSY, I., \& MONTANDRAU, S. (2015). Corporate social performance, ownership structure, and corporate governance in France. Research in International Business and Finance, 34, 383-396.

FISCHER, T. M., \& SAWCZYN, A. A. (2013). The relationship between corporate social performance and corporate financial performance and the role of innovation: evidence from German listed firms. Journal of Management Control, 24, 27-52. 
FRANCIS, R. N., HARRAST, S., MATTINGLY, J., \& OLSEN, L. (2013). The relation between accounting conservatism and corporate social performance: An empirical investigation. Business and Society Review, 118 (2), 193-222.

FREEMAN, R. E. (1984). Strategic Management: A Stakeholder Approach. Boston: Pitman;

FREEMAN, R. E. (1999). Divergent Stakeholder Theory. Academy of Management Review, $24(2), 233-236$.

IGALENS, J., \& GOND, J.P. (2005). Measuring Corporate Social Performance in France: A Critical and Empirical Analysis of ARESE data. Journal of Business Ethics, 56, 131-148.

GAO, Y. (2009). Corporate Social Performance in China: Evidence from Large Companies. Journal of Business Ethics, 89, 23-35.

GARGOURI, R. M., FRANCOEUR, C., SHABOU, R. (2010). The Relationship between Corporate Social Performance and Earnings Management. Canadian Journal of Administrative Sciences, 27, 320-334.

GIANNARAKIS, G., LITINAS, N., SARIANNIDIS, N. (2011). Evaluation of corporate social responsibility performance standards. African Journal of Business Management, 5(17), 7367-7374.

GLOBAL REPORTING INITIATIVE - GRI (2013). G4 - Diretrizes para relatos de sustentabilidade. Manual de Implementação.

GLOBAL REPORTING INITIATIVE - GRI (2013). G4 - Diretrizes para relatos de sustentabilidade. Princípios para relato e conteúdos padrão.

GLOBAL REPORTING INITIATIVE - GRI. Elaboração de Relatórios de Sustentabilidade. Disponível em: $\quad<$ https://www.globalreporting.org/languages/Portug uesebrazil/Pages/default.aspx>. Acesso em: 20/08/2015. 
GLOBAL REPORTING INITIATIVE - GRI. Quem somos. Disponível em: < http s://www.globalreporting.org/languages/Portuguesebrazil/Pages/default.aspx $>$. Acesso em: 20/08/2015.

GOMES JÚNIOR, S.F., \& GOMES, A.R. (2010). As Vantagens da Sustentabilidade Empresarial. Inovação, Gestão e Produção, 2 (6), 62-71.

GOND. J, \& CRANE, A. (2010). Corporate Social Performance Disoriented: Saving the Lost Paradigm? Business and Society, 44 (4), 677-703.

GRAVES, S. B., \& WADDOCK, S. E. (1994). Institutional Owners and Corporate Social Performance. Academy of Management Journal, 37 (4), 1034-1046.

GRIFFIN, J. J. (2000). Corporate Social Performance: Research Directions for the21st Century. Business and Society, 39 (4), 479-491.

HAIR, J., ANDERSON, R., TATHAM, R., \& BLACK, W. (2009). Multivariate data analysis ( $7^{\mathrm{a}}$ ed.). New Jersey: Prentice Hall.

HAIR JR, J.F., BABIN, B., MONEY, A. H., \& SAMOUEL, P. (2005). Fundamentos de Métodos de Pesquisa em Administração. Porto Alegre: Bookman.

HAHN, R., \& KÜHNEN, M. (2013). Determinants of sustainability reporting: a review of results, trends, theory, and opportunities in an expanding field of research. Journal of Cleaner Production, 59, 5-21.

HILLIARD, I. (2013) Responsible Management, Incentive Systems, and Productivity. Journal of Business Ethics, 118 (2), 365-377.

IOANNOU, I., \& SERAFEIM, G. (2012). What drives corporate social performance? The role of nation-level institutions. Journal of International Business Studies, 43 (9), 2012.

ISE - BM\&F BOVESPA. Carteiras e Questionários. Disponível em: < http://www.isebvmf.com.br/index.php?r=site/conteudo\&id=2>. Acesso em: 10/04/2016. 
KANSAL, M., \& SINGH, S. (2012). Measurement of corporate social performance: an Indian perspective. Social Responsibility Journal, 8 (4), 527-546.

KPMG (2013). Carrots and Sticks. Sustainability reporting policies worldwide - today's best practice, tomorrow's trends.

LEE, M. D. P. (2008). A review of the theories of corporate social responsibility: Its evolutionary path and the road ahead. International Journal of Management Reviews, 10, (1), 53-73.

LEE, D.D., FAFF, R.W., \& LANGFIELD-SMITH, K. (2009). Revisiting the Vexing Question: Does Superior Corporate Social Performance Lead to Improved Financial Performance? Australian Journal of Management, 34 (1), 21-49.

LEE, J., \& MAXFIELD, S. (2015). Doing Well by Reporting Good: Reporting Corporate Responsibility and Corporate Performance. Business and Society Review, 120 (4), 577-606.

LEHMANN, E. L. (2006). Nonparametrics: Statistics methods based on ranks; Revised Edition. Berkeley: Springer.

LI, N., PUUMALAINEN, K., \& TOPPINEN, A. (2014). Managerial perceptions of corporate social and financial performance in the global forest industry. International Forestry Review, $16(3), 319-338$.

LIN, M. J., LEE, D. C., \& LEE, L. T. (2011). Using Tobin's Q ratio to testing the stakeholder theory applied to the corporate social performance. African Journal of Business Management, $5(34), 12951-12957$.

LISTON-HEYES, C., CETON, G. (2009). An Investigation of Real versus Perceived CSP in S\&P-500 Firms. Journal of Business Ethics, 89, 283-296.

LOPEZ, M. V., GARCIA, A., \& RODRIGUEZ, L. (2007). Sustainable Development and Corporate Performance: A Study Based on the Dow Jones Sustainability Index. Journal of Business Ethics, 75, 285-300. 
LU, Y., \& ABEYSEKERA, I. (2014). Stakeholders' power, corporate characteristics, and social and environmental disclosure: evidence from China. Journal of Cleaner Production, 64, 426-436.

MAIGNAN, I., \& FERRELL, O. C. (2000). Measuring corporate citizenship in two countries: The case of the United States and France. Journal of Business Ethics, 23 (3), 283-297.

MAKNI, R., FRANCOEUR, C., \& BELLAVANCE, F. (2009). Causality between Corporate Social Performance and Financial Performance: Evidence from Canadian Firms. Journal of Business Ethics, 89, 409-422.

MANNER, M. H. (2010). The Impact of CEO Characteristics on Corporate Social Performance. Journal of Business Ethics, 93, 53-72.

MARCONI, M. A., \& LAKATOS, E. M. (2008). Técnicas de Pesquisa. 7 Ed. São Paulo: Atlas.

MEEK, G. K., ROBERTS, C. B., \& GRAY, S. J. (1995). Factors influencing voluntary annual report disclosures by U.S., U.K. and Continental European multinational corporations. Journal of International Business Studies, 26 (3), 555-572.

MICHELON, G. (2011). Sustainability Disclosure and Reputation: A Comparative Study. Corporate Reputation Review, 14, 79-96.

MITCHELL, R. K., AGLE, B. R., \& WOOD, D.J. (1997). Toward a Theory of Stakeholder Identification and Salience: Defining the Principle of Who and What Really Counts. Academy of Management Review, 22, 853-886.

MOORE, G. (2001). Corporate social and financial performance: An investigation in the UK supermarket industry. Journal of Business Ethics, 34 (3-40), 299-315.

NÓBREGA, M. M., \& CÂNDIDO, G. A. (2015). Avaliação da performance social corporativa na ótica dos stakeholders: proposta de uma metodologia multidimensional e sistêmica. Revista de Gestão Social e Ambiental - RGSA, 9 (2), 2- 22. 
ORLITZKY, M., SCHIMDT, F. L., \& RYNES, S. (2003). Corporate Social and Finance Performance: A Meta-Analysis. Organizational Studies, 24 (3), 403-441.

PENG, C.; \& YANG, M. (2014). The Effect of Corporate Social Performance on Financial Performance: The Moderating Effect of Ownership Concentration. Journal of Business Ethics, 64 (3), 285-301.

PIATTI, D. (2014). Corporate social performance and social disclosure: Evidence from italian mutual banks. Academy of Accounting and Financial Studies Journal, 18 (1), 11-36.

QUEVEDO-PUENTE, E., FUENTE-SABATÉ, J. M., \& DELGADO-GARCÍA, J. B. (2007). Corporate Social Performance and Corporate Reputation: Two Interwoven Perspectives. Corporate Reputation Review, 10, 60-72.

RAIS, S., \& GOEDEGEBUURE, R.V. (2008). Corporate social performance and financial performance. The case of Indonesian firms in the manufacturing industry. Problems and Perspectives in Management, 6 (1), 224-237.

REYNOLDS, S. J., SCHULTZ, F. C., \& HEKMAN, D. R. (2006). Stakeholder theory and managerial decision-making: Constraints and implications of balancing stakeholder interests. Journal of Business Ethics, 123, 171-182.

ROWLEY, T., \& BERMAN, S. (2000). A Brand New Brand of Corporate Social Performance. Business \& Society, 39 (4), 397-418.

RUF, B. M.; MURALIDHAR, K. e PAUL, K. (1998). The development of a systematic, aggregate measure of corporate social performance. Journal of Management, 24, 119-133.

SANTOS, G. L. (2011). The effect of CSR on financial performance. Rotterdam School of Management, Erasmus University.

SARTURI, G.; SERAVALLI, C. (2015). Afinal, o que é distribuir valor para os stakeholders? Uma análise bibliográfica sobre o tema. Revista de Administração da UFSM. 
SCALET, S., \& KELLY, T.F. (2010). CSR Rating Agencies: What is Their Global Impact? Journal of Business Ethics, 94 (1), 69-88.

SCHLEPER, M.C. \& BUSSE, C. (2013). Toward a standardized supplier code of ethics: development of a design concept based on diffusion of innovation theory. Logistics Research, $6(4), 187-216$.

SETHI, S. P. (1975). Dimensions of Corporate Social Performance: An Analytical Framework. California Management Review, 17 (3), 58-64.

SHARFMAN, M. (1996). The Construct Validity of the Kinder, Lydenberg \& Domini Social Performance Ratings Data. Journal of Business Ethics, 15, 287-296.

SILTAOJA, M. E. (2014). Revising the corporate social performance model-towards knowledge creation for sustainable development. Business Strategy and the Environment, 23 (5), 289-302.

SLATER, D. J., \& DIXON-FOWLER, H. R. (2009). CEO International Assignment Experience and Corporate Social Performance. Journal of Business Ethics, 89, 473-489.

SOANA, M. G. (2011). The Relationship Between Corporate Social Performance and Corporate Financial Performance in the Banking Sector. Journal of Business Ethics, 104, $133-148$.

SPILLER, R. (2000). Ethical Business and Investment: A Model for Business and Society. Journal of Business Ethics, 27, 149-160.

STITES, J. P., \& MICHAEL, J. H. (2011). Organizational Commitment in Manufacturing Employees: Relationships with Corporate Social Performance. Business \& Society, 50 (1), 5070.

SWANSON, D. L. (1995). Addressing a theoretical problem by reorienting the Corporate Social Performance model. Academy of Management Review, 20 (1), 43-64. 
SWANSON, D. L. (1999). Toward an integrative theory of Business and Society: a research strategy for Corporate Social Performance. Academy of Management Review, 24 (4), 506-521.

TABACHNICK, B.G; FIDELL, L.S. (2001) Using Multivariate Statistics. 4. ed. Needham Heights, MA: Allyn \& Bacon.

TANTALO, C.; PRIEM, R. L. (2014). Value creation through stakeholder synergy. Strategic Management Journal.

TOPPINEN, A., LI, N., TUPPURA, A., \& XIONG, Y. (2012). Corporate Responsibility and Strategic Groups in the Forest-based Industry: Exploratory Analysis based on the Global Reporting Initiative (GRI) Framework. Corporate Social Responsibility and Environmental Management, 19, 191-205.

TURKER, D. (2009). Measuring Corporate Social Responsibility: A Scale Development Study. Journal of Business Ethics, 85, 411-427.

UllmanN, A. A. (1985). Data In Search of a Theory: A Critical Examination of the Relationships among Social Performance, Social Disclosure, and Economic Performance of U.S. Firms. Academy of Management Review, 10 (3), 540-557.

VAliENTE, J. M. A., AYERBE, C. G., \& FIGUERAS, M. S. (2012). Social responsibility practices and evaluation of corporate social performance. Journal of Cleaner Production, 35, 25-38.

VALIENTE, J. M. A., GARGALLO, P., \& SALVADOR, M. (2015). Measuring corporative social performance in Firms: a Bayesian factor analysis approach. Journal of Business Economics and Management, 16 (3), 638-659.

VAN DER LAAN, G., VAN EES, H. \& VAN WITTELOOSTUIJN, A. (2008). Corporate Social and Financial Performance: An Extended Stakeholder Theory, and Empirical Test with Accounting Measures. Journal of Business Ethics, 79, 299-310. 
VAN DER PLOEG, L., \& VANCLAY, F. (2013). Credible claim or corporate Spin?: A checklist to evaluate corporate sustainability reports. Journal of Environmental Assessment Policy and Management 15 (3), 1350012 (21 pages).

VONG, F., \& WONG, I. A. (2013). Corporate and social performance links in the gaming industry. Journal of Business Research, 66, 1674-1681.

VURRO, C., \& PERRINI, F. (2011). Making the most of corporate social responsibility reporting: Disclosure structure and its impact on performance. Corporate Governance, 11 (4), 459-474.

WADDOCK, S. A., \& GRAVES, S. B. (1997). The Corporate Social Performance-Financial Performance Link. Strategic Management Journal, 18 (4), 303-319.

WARTICK, S. L. (2002). Measuring Corporate Reputation. Business Society, 41, 4, 371-392.

WARTICK, S. L., \& COCHRAN, P. L. (1985). The evolution of Corporate Social Performance Model. Academy of Management Review, 10 (4), 758-769.

WEBER, J., \& MARLEY, K. A. (2010). In Search of Stakeholder Salience: Exploring Corporate Social and Sustainability Reports. Business \& Society.

WILLIANS, S. J., \& ADAMS, C.A. (2013). Moral accounting? Employee disclosures from a stakeholder accountability perspective. Accounting, Auditing \& Accountability Journal, 26 (2), $449-495$.

WOOD, D. J. (1991). Corporate Social Performance Revisited. Academy of Management Review, 16 (4), 691-718.

WOOD, D. J. (1995). The Fortune Database as a CSP Measure. Business \& Society, 34 (2), 197-198.

WOOD, D. J. (2010). Measuring Corporate Social Performance: A Review. International Journal of Management Review, 12, Issue 1, 50-84. 
WOOD, D. J., \& JONES, R. E. (1995). Stakeholder Mismatching: A Theoretical Problem in Empirical Research on Corporate Social Performance. The International Journal of Organizational Analysis, 3 (3), 229-267.

YAMAMOTO, M. M., \& SALOTTI, B. M. (2006). Informação contábil: estudos sobre a sua divulgação no mercado de capitais. São Paulo: Atlas.

ZHANG, M., DI FAN, D., ZHU, C.J. (2014). High-Performance Work Systems, Corporate Social Performance and Employee Outcomes: Exploring the Missing Links. Journal of Business Ethics, 120

(3), 423-435. 


\section{APÊNDICE 1 - Dimensões da CSP}

\begin{tabular}{|c|c|c|c|c|}
\hline Stakeholder & Dimensões & Referências & Variáveis & Referências \\
\hline \multirow{4}{*}{ 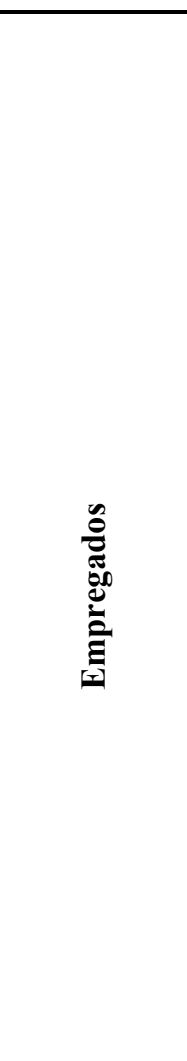 } & \multirow[t]{2}{*}{$\begin{array}{l}\text { Equilíbrio entre } \\
\text { vida profissional, } \\
\text { pessoal e familiar }\end{array}$} & \multirow{2}{*}{$\begin{array}{l}\text { HILLIARD, I. (2013); WILLIANS, S. J., \& } \\
\text { ADAMS, C. A. (2013); MAIGNAN, \& } \\
\text { FERRELL (2000); AGUDO-VALIENTE, } \\
\text { GARCÉS-AYERBE, \& SALVADOR- } \\
\text { FIGUERAS (2015); LI, N., PUUMALAINEN, } \\
\text { K., \& TOPPINEN, A. (2014); PAPASOLOMOU } \\
\text { ET AL (2005); BROWER, J., \& MAHAJAN, V. } \\
\text { (2013); VALIENTE, J. M. A., AYERBE, C. G., } \\
\text { \& FIGUERAS, M. S. (2012) }\end{array}$} & $\begin{array}{l}\text { Programa de flexibilidade no } \\
\text { trabalho (horários flexíveis, } \\
\text { home-office) }\end{array}$ & $\begin{array}{l}\text { WILLIANS, S. J., \& ADAMS, C. A. (2013); MAIGNAN, \& } \\
\text { FERRELL (2000); AGUDO-VALIENTE, GARCÉS-AYERBE, \& } \\
\text { SALVADOR-FIGUERAS (2015); VALIENTE, J. M. A., AYERBE, } \\
\text { C. G., \& FIGUERAS, M. S. (2012); DUCASSY, I., \& } \\
\text { MONTANDRAU, S. (2015); AGUDO, J. M., GARGALLO, P., \& } \\
\text { SALVADOR, M. (2015); CHEUNG, Y., JIANG, K., MAK, S. C., } \\
\text { TAN, W. (2013); TURKER, D. (2009). }\end{array}$ \\
\hline & & & $\begin{array}{l}\text { Programas especiais de licença } \\
\text { maternidade }\end{array}$ & $\begin{array}{l}\text { WILLIANS, S. J., \& ADAMS, C. A. (2013); AGUDO-VALIENTE, } \\
\text { GARCÉS-AYERBE, \& SALVADOR-FIGUERAS (2015); } \\
\text { KANSAL, M., \& SINGH, S. (2012); VALIENTE, J. M. A., } \\
\text { AYERBE, C. G., \& FIGUERAS, M. S. (2012) }\end{array}$ \\
\hline & \multirow[t]{2}{*}{$\begin{array}{l}\text { Saúde e } \\
\text { segurança } \\
\text { ocupacional }\end{array}$} & \multirow{2}{*}{$\begin{array}{l}\text { HILLIARD, I. (2013); DUCASSY, I., \& } \\
\text { MONTANDRAU, S. (2015); AGUDO- } \\
\text { VALIENTE, GARCÉS-AYERBE, \& } \\
\text { SALVADOR-FIGUERAS (2015); VURRO, C., } \\
\text { PERRINI, F. (2011); PAPASOLOMOU ET AL } \\
\text { (2005); BROWER, J., \& MAHAJAN, V. (2013); } \\
\text { IOANNOU, I., \& SERAFEIM, G. (2012); } \\
\text { GARGOURI, R. M., FRANCOEUR, C., } \\
\text { SHABOU, R. (2010); SPILLER (2000); } \\
\text { IGALENS, J., \& GOND, J.P. (2005); } \\
\text { VALIENTE, J. M. A., AYERBE, C. G., \& } \\
\text { FIGUERAS, M. S. (2012); NÓBREGA, M. M., } \\
\text { \& CÂNDIDO, G. A. (2015). }\end{array}$} & $\begin{array}{l}\text { Políticas de promoção de um } \\
\text { ambiente de trabalho saudável e } \\
\text { seguro (análise de riscos } \\
\text { ocupacionais, plano de } \\
\text { prevenção, treinamentos) }\end{array}$ & $\begin{array}{l}\text { AGUDO-VALIENTE, GARCÉS-AYERBE, \& SALVADOR- } \\
\text { FIGUERAS (2015); CHEUNG, Y., JIANG, K., MAK, S. C., \& } \\
\text { TAN, W. (2013); IOANNOU, I., \& SERAFEIM, G. (2012); } \\
\text { PIVATO, MISANI, \& TENCATIN (2008); DONATO, F., \& IZZO, } \\
\text { F. (2015); KANSAL, M., \& SINGH, S. (2012); COSTA, R.; \& } \\
\text { MENICHINI, T. (2013); AHMED, S. U., ISLAM, D. U., \& } \\
\text { HASAN1, I. (2012); RAIS, S., \& GOEDEGEBUURE, R.V. (2008); } \\
\text { VALIENTE, J. M. A., AYERBE, C. G., \& FIGUERAS, M. S. } \\
\text { (2012); TURKER, D. (2009). }\end{array}$ \\
\hline & & & $\begin{array}{l}\text { Informações sobre ocorrência e } \\
\text { redução de lesões, doenças } \\
\text { ocupacionais, dias perdidos e } \\
\text { absenteísmo, e número de óbitos } \\
\text { relacionados ao trabalho }\end{array}$ & $\begin{array}{l}\text { VURRO, C., PERRINI, F. (2011); FISCHER, T. M., \& SAWCZYN, } \\
\text { A. A. (2013); COSTA, R.; \& MENICHINI, T. (2013); }\end{array}$ \\
\hline
\end{tabular}

\section{Figura 28. Dimensões da CSP}

\section{Fonte: do autor}




\begin{tabular}{|c|c|c|c|c|}
\hline Stakeholder & Dimensões & Referências & Variáveis & Referências \\
\hline \multirow{5}{*}{ 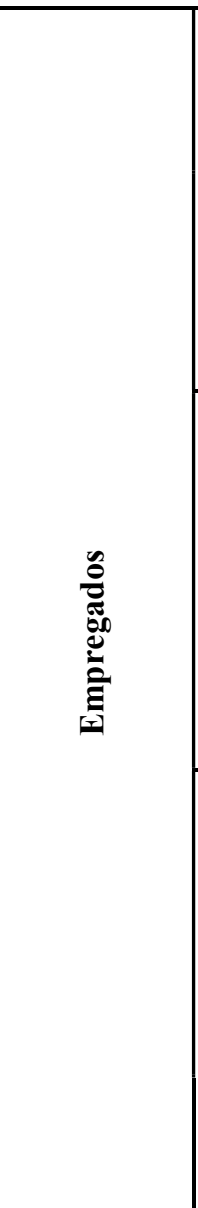 } & \multirow[t]{2}{*}{$\begin{array}{l}\text { Compromisso com } \\
\text { direitos humanos nas } \\
\text { práticas de trabalho }\end{array}$} & \multirow[t]{2}{*}{$\begin{array}{l}\text { HILLIARD, I. (2013); BROWER, J., \& } \\
\text { MAHAJAN, V. (2013); IOANNOU, I., \& } \\
\text { SERAFEIM, G. (2012); COSTA, R.; \& } \\
\text { MENICHINI, T. (2013); }\end{array}$} & $\begin{array}{l}\text { Políticas para garantir a } \\
\text { inexistência de trabalho } \\
\text { forçado ou análogo ao } \\
\text { escravo na cadeia. }\end{array}$ & $\begin{array}{l}\text { HILLIARD, I. (2013); IOANNOU, I., \& SERAFEIM, G. } \\
\text { (2012); FISCHER, T. M., \& SAWCZYN, A. A. (2013); } \\
\text { COSTA, R.; \& MENICHINI, T. (2013); }\end{array}$ \\
\hline & & & $\begin{array}{l}\text { Políticas para garantir a } \\
\text { inexistência de trabalho } \\
\text { infantil na cadeia. }\end{array}$ & $\begin{array}{l}\text { HILLIARD, I. (2013); IOANNOU, I., \& SERAFEIM, G. } \\
\text { (2012); FISCHER, T. M., \& SAWCZYN, A. A. (2013); } \\
\text { COSTA, R.; \& MENICHINI, T. (2013); CHEUNG, Y., } \\
\text { JIANG, K., MAK, S. C., TAN, W. (2013). }\end{array}$ \\
\hline & Treinamento e educação & $\begin{array}{l}\text { HILLIARD, I. (2013); WILLIANS, S. J., \& } \\
\text { ADAMS, C. A. (2013); MAIGNAN, \& FERRELL } \\
\text { (2000); DUCASSY, I., \& MONTANDRAU, S. } \\
\text { (2015); LI, N., PUUMALAINEN, K., \& } \\
\text { TOPPINEN, A. (2014); PAPASOLOMOU ET AL } \\
\text { (2005); IOANNOU, I., \& SERAFEIM, G. (2012); } \\
\text { SPILLER (2000); RAIS, S., \& GOEDEGEBUURE, } \\
\text { R.V. (2008); }\end{array}$ & $\begin{array}{l}\text { Treinamentos disponíveis } \\
\text { para os empregados } \\
\text { (programas / horas de } \\
\text { treinamento) }\end{array}$ & $\begin{array}{l}\text { WILLIANS, S. J., \& ADAMS, C. A. (2013); VURRO, } \\
\text { C., PERRINI, F. (2011); CHEUNG, Y., JIANG, K., } \\
\text { MAK, S. C., \& TAN, W. (2013); IOANNOU, I., \& } \\
\text { SERAFEIM, G. (2012); DONATO, F., \& IZZO, F. } \\
\text { (2015); FISCHER, T. M., \& SAWCZYN, A. A. (2013); } \\
\text { KANSAL, M., \& SINGH, S. (2012); COSTA, R.; \& } \\
\text { MENICHINI, T. (2013); PIATTI (2014); DE CAMPOS, } \\
\text { I.C.S., \& SANTOS, J.B. (2013); AGUDO, J. M., } \\
\text { GARGALLO, P., \& SALVADOR, M. (2015). }\end{array}$ \\
\hline & \multirow[t]{2}{*}{ Perspectivas de carreira } & \multirow[t]{2}{*}{$\begin{array}{l}\text { WILLIANS, S. J., \& ADAMS, C. A. (2013); } \\
\text { DUCASSY, I., \& MONTANDRAU, S. (2015); } \\
\text { NÓBREGA, M. M., \& CÂNDIDO, G. A. (2015). }\end{array}$} & $\begin{array}{l}\text { Programas de gestão de } \\
\text { carreira (plano, sistemas de } \\
\text { avaliação de desempenho) }\end{array}$ & $\begin{array}{l}\text { AGUDO-VALIENTE, GARCÉS-AYERBE, \& } \\
\text { SALVADOR-FIGUERAS (2015); IGALENS, J., \& } \\
\text { GOND, J.P. (2005); COSTA, R.; \& MENICHINI, T. } \\
\text { (2013); RAIS, S., \& GOEDEGEBUURE, R.V. (2008); } \\
\text { DE CAMPOS, I.C.S., \& SANTOS, J.B. (2013); } \\
\text { VALIENTE, J. M. A., AYERBE, C. G., \& FIGUERAS, } \\
\text { M. S. (2012); TURKER, D. (2009). }\end{array}$ \\
\hline & & & $\begin{array}{l}\text { Redução do turnover } \\
\text { (estatísticas e programas) }\end{array}$ & $\begin{array}{l}\text { VURRO, C., PERRINI, F. (2011); KANSAL, M., \& } \\
\text { SINGH, S. (2012); DE CAMPOS, I.C.S., \& SANTOS, } \\
\text { J.B. (2013); COSTA, R.; \& MENICHINI, T. (2013). }\end{array}$ \\
\hline
\end{tabular}

\section{Figura 28. Dimensões da CSP (continuação)}

\section{Fonte: do autor}




\begin{tabular}{|c|c|c|c|c|}
\hline Stakeholder & Dimensões & Referências & Variáveis & Referências \\
\hline \multirow{4}{*}{ 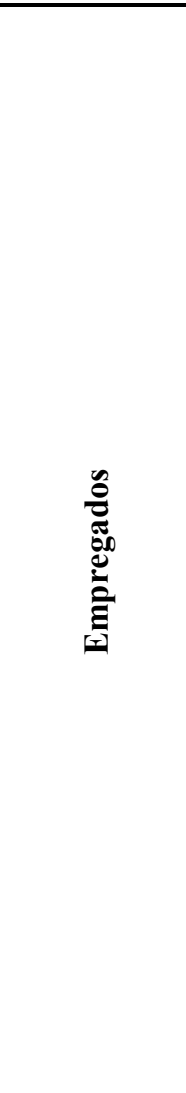 } & \multirow[t]{4}{*}{$\begin{array}{l}\text { Diversidade e igualdades de } \\
\text { oportunidades }\end{array}$} & \multirow{4}{*}{$\begin{array}{l}\text { HILLIARD, I. (2013); } \\
\text { AGUDO-VALIENTE, } \\
\text { GARCÉS-AYERBE, \& } \\
\text { SALVADOR-FIGUERAS } \\
\text { (2015); VURRO, C., } \\
\text { PERRINI, F. (2011); } \\
\text { BROWER, J., \& MAHAJAN, } \\
\text { V. (2013); IOANNOU, I., \& } \\
\text { SERAFEIM, G. (2012); } \\
\text { GARGOURI, R. M., } \\
\text { FRANCOEUR, C., SHABOU, } \\
\text { R. (2010); SPILLER (2000); } \\
\text { AHMED, S. U., ISLAM, D. } \\
\text { U., \& HASAN, I. (2012); } \\
\text { RAIS, S., \& } \\
\text { GOEDEGEBUURE, R.V. } \\
\text { (2008).; VAN BUREN (2005); } \\
\text { VALIENTE, J. M. A., } \\
\text { AYERBE, C. G., \& } \\
\text { FIGUERAS, M. S. (2012); } \\
\text { CHEUNG, Y., JIANG, K., } \\
\text { MAK, S. C., TAN, W. (2013); } \\
\text { FRANCIS, R. N., HARRAST, } \\
\text { S., MATTINGLY, J., \& } \\
\text { OLSEN, L. (2013); TURKER, } \\
\text { D. (2009). }\end{array}$} & Emprego de mulheres na liderança & $\begin{array}{l}\text { KANSAL, M., \& SINGH, S. (2012); PIATTI (2014); } \\
\text { GARGOURI, R. M., FRANCOEUR, C., SHABOU, } \\
\text { R. (2010); COSTA, R.; \& MENICHINI, T. (2013). }\end{array}$ \\
\hline & & & Pessoas com deficiência empregadas & $\begin{array}{l}\text { BROWER, J., \& MAHAJAN, V. (2013); RUF, } \\
\text { B.M., MURALIDHAR, K., BROWN, R.M., } \\
\text { JANNEY, J.J., PAUL, K. (2001); FRANCIS, R. N., } \\
\text { HARRAST, S., MATTINGLY, J., \& OLSEN, L. } \\
\text { (2013); WADDOCK, S. A., \& GRAVES, S. B. } \\
\text { (1997). }\end{array}$ \\
\hline & & & $\begin{array}{l}\text { Programas para estimulem a diversidade } \\
\text { na contratação e igualdade no tratamento, } \\
\text { envolvendo temas como: gênero, } \\
\text { deficiência, LGBT, Etnia. }\end{array}$ & $\begin{array}{l}\text { WILLIANS, S. J., \& ADAMS, C. A. (2013); } \\
\text { MAIGNAN, \& FERRELL (2000); BROWER, J., \& } \\
\text { MAHAJAN, V. (2013); IOANNOU, I., \& } \\
\text { SERAFEIM, G. (2012); PIVATO, MISANI, \& } \\
\text { TENCATIN (2008); DONATO, F., \& IZZO, F. } \\
\text { (2015); KANSAL, M., \& SINGH, S. (2012); RAIS, } \\
\text { S., \& GOEDEGEBUURE, R.V. (2008); FRANCIS, } \\
\text { R. N., HARRAST, S., MATTINGLY, J., \& OLSEN, } \\
\text { L. (2013). }\end{array}$ \\
\hline & & & $\begin{array}{l}\text { Igualdade de salários entre homens e } \\
\text { mulheres }\end{array}$ & $\begin{array}{l}\text { WILLIANS, S. J., \& ADAMS, C. A. (2013); } \\
\text { AGUDO-VALIENTE, GARCÉS-AYERBE, \& } \\
\text { SALVADOR-FIGUERAS (2015); FISCHER, T. M., } \\
\text { \& SAWCZYN, A. A. (2013); KANSAL, M., \& } \\
\text { SINGH, S. (2012); COSTA, R.; \& MENICHINI, T. } \\
\text { (2013). }\end{array}$ \\
\hline
\end{tabular}

Figura 28. Dimensões da CSP (continuação)

Fonte: do autor 


\begin{tabular}{|c|c|c|c|c|}
\hline Stakeholder & Dimensões & Referências & Variáveis & Referências \\
\hline \multirow[b]{2}{*}{ 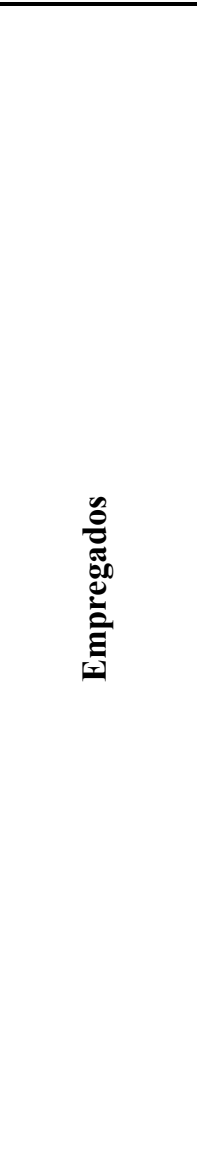 } & \multirow[t]{2}{*}{$\begin{array}{l}\text { Salários, recompensas e } \\
\text { benefícios justos }\end{array}$} & \multirow{2}{*}{$\begin{array}{l}\text { WILLIANS, S. J., \& ADAMS, } \\
\text { C. A. (2013); MAIGNAN, \& } \\
\text { FERRELL (2000); } \\
\text { GARGOURI, R. M., } \\
\text { FRANCOEUR, C., SHABOU, } \\
\text { R. (2010); RAIS, S., \& } \\
\text { GOEDEGEBUURE, R.V. } \\
\text { (2008); LIN, M. J., LEE, D. } \\
\text { C., \& LEE, L. T. (2011); DE } \\
\text { CAMPOS, I.C.S., \& SANTOS, } \\
\text { J.B. (2013); VAN BUREN } \\
\text { (2005); AGUDO, J. M., } \\
\text { GARGALLO, P., \& } \\
\text { SALVADOR, M. (2015); } \\
\text { CHEUNG, Y., JIANG, K., } \\
\text { MAK, S. C., TAN, W. (2013); } \\
\text { NÓBREGA, M. M., \& } \\
\text { CÂNDIDO, G. A. (2015). }\end{array}$} & $\begin{array}{l}\text { Programas e políticas formais de salários, } \\
\text { recompensas e mérito }\end{array}$ & $\begin{array}{l}\text { DUCASSY, I., \& MONTANDRAU, S. (2015); } \\
\text { AGUDO-VALIENTE, GARCÉS-AYERBE, \& } \\
\text { SALVADOR-FIGUERAS (2015); VURRO, C., } \\
\text { PERRINI, F. (2011); IOANNOU, I., \& } \\
\text { SERAFEIM, G. (2012); PIVATO, MISANI, \& } \\
\text { TENCATIN (2008); IGALENS, J., \& GOND, } \\
\text { J.P. (2005); KANSAL, M., \& SINGH, S. } \\
\text { (2012); RAIS, S., \& GOEDEGEBUURE, R.V. } \\
\text { (2008). VALIENTE, J. M. A., AYERBE, C. } \\
\text { G., \& FIGUERAS, M. S. (2012); TURKER, D. } \\
(2009) \text {. }\end{array}$ \\
\hline & & & $\begin{array}{l}\text { Benefícios para aposentadoria: existência } \\
\text { de fundos, plano de aposentadoria. }\end{array}$ & $\begin{array}{l}\text { AGUDO-VALIENTE, GARCÉS-AYERBE, \& } \\
\text { SALVADOR-FIGUERAS (2015); BROWER, } \\
\text { J., \& MAHAJAN, V. (2013); CHEUNG, Y., } \\
\text { JIANG, K., MAK, S. C., \& TAN, W. (2013); } \\
\text { KANSAL, M., \& SINGH, S. (2012); AHMED, } \\
\text { S. U., ISLAM, D. U., \& HASAN1, I. (2012); } \\
\text { RAIS, S., \& GOEDEGEBUURE, R.V. (2008), } \\
\text { VALIENTE, J. M. A., AYERBE, C. G., \& } \\
\text { FIGUERAS, M. S. (2012); FRANCIS, R. N., } \\
\text { HARRAST, S., MATTINGLY, J., \& OLSEN, } \\
\text { L. (2013). } \\
\end{array}$ \\
\hline
\end{tabular}

Figura 28. Dimensões da CSP (continuação)

Fonte: do autor 


\begin{tabular}{|c|c|c|c|c|}
\hline Stakeholder & Dimensões & Referências & Variáveis & Referências \\
\hline \multirow{5}{*}{ 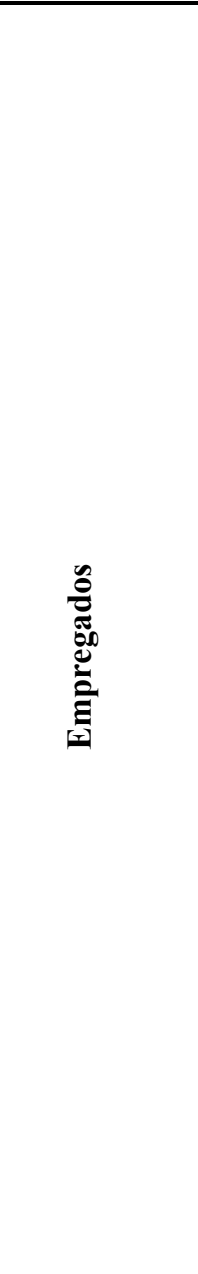 } & Anti-discriminação & $\begin{array}{l}\text { HILLIARD, I. (2013); DUCASSY, I., \& } \\
\text { MONTANDRAU, S. (2015) }\end{array}$ & \begin{tabular}{|l|} 
Esforços anti- \\
discriminação (políticas ou \\
programas)
\end{tabular} & $\begin{array}{l}\text { MAIGNAN, \& FERRELL (2000); DUCASSY, I., \& } \\
\text { MONTANDRAU, S. (2015); IOANNOU, I., \& SERAFEIM, } \\
\text { G. (2012); SPILLER (2000); FISCHER, T. M., \& } \\
\text { SAWCZYN, A. A. (2013); COSTA, R.; \& MENICHINI, T. } \\
\text { (2013). }\end{array}$ \\
\hline & $\begin{array}{l}\text { Envolvimento com a } \\
\text { comunidade }\end{array}$ & $\begin{array}{l}\text { HILLIARD, I. (2013); LI, N., } \\
\text { PUUMALAINEN, K., \& TOPPINEN, A. } \\
\text { (2014); SPILLER (2000); SPILLER } \\
\text { (2000); }\end{array}$ & $\begin{array}{l}\text { Programas de voluntariado } \\
\text { empresarial }\end{array}$ & $\begin{array}{l}\text { HILLIARD, I. (2013); LI, N., PUUMALAINEN, K., \& } \\
\text { TOPPINEN, A. (2014); BROWER, J., \& MAHAJAN, V. } \\
\text { (2013); GAO (2009); SPILLER (2000); KANSAL, M., \& } \\
\text { SINGH, S. (2012); AHMED, S. U., ISLAM, D. U., \& } \\
\text { HASAN1, I. (2012). }\end{array}$ \\
\hline & \multirow[t]{2}{*}{$\begin{array}{l}\text { Satisfação do } \\
\text { empregado e clima } \\
\text { organizacional }\end{array}$} & \multirow[t]{2}{*}{$\begin{array}{l}\text { WILLIANS, S. J., \& ADAMS, C. A. } \\
\text { (2013); IGALENS, J., \& GOND, J.P. } \\
\text { (2005); KANSAL, M., \& SINGH, S. } \\
\text { (2012); VALIENTE, J. M. A., AYERBE, } \\
\text { C. G., \& FIGUERAS, M. S. (2012); } \\
\text { VURRO, C., PERRINI, F. (2011); } \\
\text { NÓBREGA, M. M., \& CÂNDIDO, G. A. } \\
\text { (2015). }\end{array}$} & $\begin{array}{l}\text { Canais de comunicação } \\
\text { para sugestões e } \\
\text { reclamações, com garantia } \\
\text { de confidencialidade. }\end{array}$ & $\begin{array}{l}\text { MAIGNAN, \& FERRELL (2000); AGUDO-VALIENTE, } \\
\text { GARCÉS-AYERBE, \& SALVADOR-FIGUERAS (2015); } \\
\text { WILLIANS, S. J., \& ADAMS, C. A. (2013); RAIS, S., \& } \\
\text { GOEDEGEBUURE, R.V. (2008); VALIENTE, J. M. A., } \\
\text { AYERBE, C. G., \& FIGUERAS, M. S. (2012); AGUDO, J. } \\
\text { M., GARGALLO, P., \& SALVADOR, M. (2015). }\end{array}$ \\
\hline & & & $\begin{array}{l}\text { Pesquisas de clima } \\
\text { organizacional / satisfação } \\
\text { do empregado }\end{array}$ & $\begin{array}{l}\text { AGUDO-VALIENTE, GARCÉS-AYERBE, \& } \\
\text { SALVADOR-FIGUERAS (2015); LI, N., PUUMALAINEN, } \\
\text { K., \& TOPPINEN, A. (2014); VALIENTE, J. M. A., } \\
\text { AYERBE, C. G., \& FIGUERAS, M. S. (2012); AGUDO, J. } \\
\text { M., GARGALLO, P., \& SALVADOR, M. (2015). }\end{array}$ \\
\hline & $\begin{array}{l}\text { Relacionamento com } \\
\text { sindicatos e união de } \\
\text { trabalhadores }\end{array}$ & $\begin{array}{l}\text { BROWER, J., \& MAHAJAN, V. (2013); } \\
\text { IOANNOU, I., \& SERAFEIM, G. (2012); } \\
\text { GARGOURI, R. M., FRANCOEUR, C., } \\
\text { SHABOU, R. (2010); RUF, B.M., } \\
\text { MURALIDHAR, K., BROWN, R.M., } \\
\text { JANNEY, J.J., PAUL, K. (2001); RAIS, S., } \\
\text { \& GOEDEGEBUURE, R.V. (2008); } \\
\text { NÓBREGA, M. M., \& CÂNDIDO, G. A. } \\
\text { (2015). }\end{array}$ & $\begin{array}{l}\text { Liberdade de associação } \\
\text { sindical e direito à } \\
\text { negociação coletiva }\end{array}$ & $\begin{array}{l}\text { WILLIANS, S. J., \& ADAMS, C. A. (2013); AHMED, S. U., } \\
\text { ISLAM, D. U., \& HASAN1, I. (2012); VALIENTE, J. M. A., } \\
\text { AYERBE, C. G., \& FIGUERAS, M. S. (2012); ZHANG, M., } \\
\text { DI FAN, D., ZHU, C.J. (2014), AGUDO, J. M., } \\
\text { GARGALLO, P., \& SALVADOR, M. (2015). }\end{array}$ \\
\hline
\end{tabular}

Figura 28. Dimensões da CSP (continuação)

\section{Fonte: do autor}




\begin{tabular}{|c|c|c|c|c|}
\hline Stakeholder & Dimensões & Referências & Variáveis & Referências \\
\hline \multirow{3}{*}{ 晜 } & \multirow[t]{2}{*}{$\begin{array}{l}\text { Relacionamento } \\
\text { com fornecedores }\end{array}$} & \multirow[t]{2}{*}{$\begin{array}{l}\text { DUCASSY, I., \& MONTANDRAU, S. } \\
\text { (2015); PAPASOLOMOU ET AL (2005); } \\
\text { SPILLER (2000); NÓBREGA, M. M., \& } \\
\text { CÂNDIDO, G. A. (2015). }\end{array}$} & Parceria entre a empresa e fornecedores & $\begin{array}{l}\text { PAPASOLOMOU ET AL (2005); AGUDO- } \\
\text { VALIENTE, GARCÉS-AYERBE, \& } \\
\text { SALVADOR-FIGUERAS (2015); VALIENTE, J. } \\
\text { M. A., AYERBE, C. G., \& FIGUERAS, M. S. } \\
\text { (2012); SPILLER (2000); GAO, Y. (2009), DAM, } \\
\text { L., \& SCHOLTENS, B. (2013); NÓBREGA, M. } \\
\text { M., \& CÂNDIDO, G. A. (2015). }\end{array}$ \\
\hline & & & $\begin{array}{l}\text { Programas para contratação e manutenção } \\
\text { de fornecedores para assegurar a } \\
\text { responsabilidade socioambiental de } \\
\text { fornecedores (cláusulas contratuais, } \\
\text { código de ética ou conduta) }\end{array}$ & $\begin{array}{l}\text { AGUDO-VALIENTE, GARCÉS-AYERBE, \& } \\
\text { SALVADOR-FIGUERAS (2015); VURRO, C., } \\
\text { PERRINI, F. (2011); PAPASOLOMOU ET AL } \\
\text { (2005); SPILLER (2000); VALIENTE, J. M. A., } \\
\text { AYERBE, C. G., \& FIGUERAS, M. S. (2012); } \\
\text { AGUDO, J. M., GARGALLO, P., \& SALVADOR, } \\
\text { M. (2015). }\end{array}$ \\
\hline & $\begin{array}{l}\text { Fornecedores } \\
\text { locais e menores }\end{array}$ & MAIGNAN, \& FERRELL (2000); & $\begin{array}{l}\text { Priorização e estímulo a parcerias com } \\
\text { fornecedores locais e menores. }\end{array}$ & $\begin{array}{l}\text { SPILLER (2000); FISCHER, T. M., \& } \\
\text { SAWCZYN, A. A. (2013); COSTA, R.; \& } \\
\text { MENICHINI, T. (2013); NOBBREGA, M. M., \& } \\
\text { CÂNDIDO, G. A. (2015). }\end{array}$ \\
\hline
\end{tabular}

Figura 28. Dimensões da CSP (continuação)

Fonte: do autor 


\begin{tabular}{|c|c|c|c|c|}
\hline Stakeholder & Dimensões & Referências & Variáveis & Referências \\
\hline \multirow{5}{*}{ 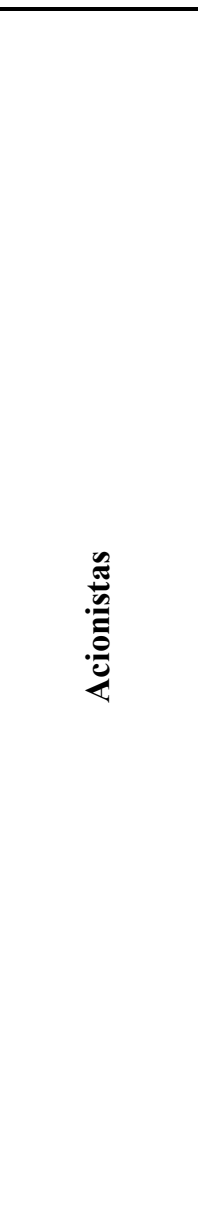 } & \multirow[t]{2}{*}{$\begin{array}{l}\text { Informações sobre o conselho de } \\
\text { Administração (BOARD) }\end{array}$} & \multirow[t]{2}{*}{$\begin{array}{l}\text { GARGOURI, R. M., } \\
\text { FRANCOEUR, C., SHABOU, R. } \\
\text { (2010); FISCHER, T. M., \& } \\
\text { SAWCZYN, A. A. (2013) }\end{array}$} & $\begin{array}{l}\text { Apresentação da composição do conselho de } \\
\text { administração e função }\end{array}$ & $\begin{array}{l}\text { IGALENS, J., \& GOND, J.P. } \\
\text { (2005); FISCHER, T. M., \& } \\
\text { SAWCZYN, A. A. (2013); } \\
\text { AHMED, S. U., ISLAM, D. U., \& } \\
\text { HASAN1, I. (2012); LIN, M. J., } \\
\text { LEE, D. C., \& LEE, L. T. (2011). }\end{array}$ \\
\hline & & & Independência do conselho de administração & $\begin{array}{l}\text { GARGOURI, R. M., } \\
\text { FRANCOEUR, C., SHABOU, R. } \\
\text { (2010); LIN, M. J., LEE, D. C., \& } \\
\text { LEE, L. T. (2011); }\end{array}$ \\
\hline & \multirow[t]{2}{*}{ Remuneração } & \multirow[t]{2}{*}{ VURRO, C., PERRINI, F. (2011) } & $\begin{array}{l}\text { Aumento do valor do acionista (retorno } \\
\text { econômico) }\end{array}$ & $\begin{array}{l}\text { MAIGNAN, \& FERRELL (2000); } \\
\text { GAO (2009); SPILLER (2000); } \\
\text { RAIS, S., \& GOEDEGEBUURE, } \\
\text { R.V. (2008); LIN, M. J., LEE, D. } \\
\text { C., \& LEE, L. T. (2011); PIATTI } \\
\text { (2014); DE CAMPOS, I.C.S., \& } \\
\text { SANTOS, J.B. (2013); } \\
\text { NÓBREGA, M. M., \& } \\
\text { CÂNDIDO, G. A. (2015). }\end{array}$ \\
\hline & & & $\begin{array}{l}\text { Política clara de distribuição e pagamento de } \\
\text { dividendos }\end{array}$ & $\begin{array}{l}\text { VURRO, C., PERRINI, F. (2011); } \\
\text { GARGOURI, R. M., } \\
\text { FRANCOEUR, C., SHABOU, R. } \\
\text { (2010); SPILLER (2000); } \\
\text { AHMED, S. U., ISLAM, D. U., \& } \\
\text { HASAN, I. (2012); NÓBREGA, } \\
\text { M. M., \& CÂNDIDO, G. A. } \\
\text { (2015). } \\
\end{array}$ \\
\hline & Estratégia de longo prazo & MAIGNAN, \& FERRELL (2000). & $\begin{array}{l}\text { Estratégia de negócios clara visando à } \\
\text { sustentabilidade do negócio a longo prazo }\end{array}$ & $\begin{array}{l}\text { MAIGNAN, \& FERRELL (2000); } \\
\text { SPILLER (2000); }\end{array}$ \\
\hline
\end{tabular}

Figura 28. Dimensões da CSP (continuação)

\section{Fonte: do autor}




\begin{tabular}{|c|c|c|c|c|}
\hline Stakeholder & Dimensões & Referências & Variáveis & Referências \\
\hline \multirow{4}{*}{ ن⿺辶ّ } & Doações / Filantropia & $\begin{array}{l}\text { MAIGNAN, \& FERRELL (2000); } \\
\text { VURRO, C., PERRINI, F. (2011); } \\
\text { BROWER, J., \& MAHAJAN, V. } \\
\text { (2013); GAO (2009); AHMED, S. U., } \\
\text { ISLAM, D. U., \& HASAN1, I. (2012); } \\
\text { RAIS, S., \& GOEDEGEBUURE, } \\
\text { R.V. (2008); FRANCIS, R. N., } \\
\text { HARRAST, S., MATTINGLY, J., \& } \\
\text { OLSEN, L. (2013). }\end{array}$ & Doações financeiras e de bens e patrocínios & $\begin{array}{l}\text { MAIGNAN, \& FERRELL (2000); DUCASSY, I., } \\
\text { \& MONTANDRAU, S. (2015); IOANNOU, I., \& } \\
\text { SERAFEIM, G. (2012); SPILLER (2000); LIN, M. } \\
\text { J., LEE, D. C., \& LEE, L. T. (2011); PIATTI } \\
\text { (2014); CHEUNG, Y., JIANG, K., MAK, S. C., } \\
\text { TAN, W. (2013); ZHANG, M., DI FAN, D., ZHU, } \\
\text { C.J. (2014); TURKER, D. (2009). }\end{array}$ \\
\hline & \multirow[t]{2}{*}{$\begin{array}{l}\text { Transparência, ética e } \\
\text { combate à corrupção }\end{array}$} & \multirow{2}{*}{$\begin{array}{l}\text { MAIGNAN, \& FERRELL (2000); } \\
\text { BROWER, J., \& MAHAJAN, V. } \\
\text { (2013); IOANNOU, I., \& } \\
\text { SERAFEIM, G. (2012); AHMED, S. } \\
\text { U., ISLAM, D. U., \& HASAN1, I. } \\
\text { (2012); NÓBREGA, M. M., \& } \\
\text { CÂNDIDO, G. A. (2015); ZHANG, } \\
\text { M., DI FAN, D., ZHU, C.J. (2014); } \\
\text { TURKER, D. (2009). }\end{array}$} & Código de conduta empresarial & $\begin{array}{l}\text { AGUDO-VALIENTE, GARCÉS-AYERBE, \& } \\
\text { SALVADOR-FIGUERAS (2015); VURRO, C., } \\
\text { PERRINI, F. (2011); GARGOURI, R. M., } \\
\text { FRANCOEUR, C., SHABOU, R. (2010). }\end{array}$ \\
\hline & & & $\begin{array}{l}\text { Existência de Programa de Ética e } \\
\text { Compliance/ Combate à Corrupção e } \\
\text { Análise de Riscos de Corrupção }\end{array}$ & $\begin{array}{l}\text { DUCASSY, I., \& MONTANDRAU, S. (2015); } \\
\text { VURRO, C., PERRINI, F. (2011); FISCHER, T. } \\
\text { M., \& SAWCZYN, A. A. (2013); COSTA, R.; \& } \\
\text { MENICHINI, T. (2013); }\end{array}$ \\
\hline & $\begin{array}{l}\text { Comprometimento e } \\
\text { impacto na } \\
\text { comunidade }\end{array}$ & $\begin{array}{l}\text { DUCASSY, I., \& MONTANDRAU, } \\
\text { S. (2015); IOANNOU, I., \& } \\
\text { SERAFEIM, G. (2012); KANSAL, } \\
\text { M., \& SINGH, S. (2012); COSTA, R.; } \\
\text { \& MENICHINI, T. (2013); AHMED, } \\
\text { S. U., ISLAM, D. U., \& HASAN1, I. } \\
(2012)\end{array}$ & $\begin{array}{l}\text { Programas e práticas para avaliar e } \\
\text { gerenciar impactos da atuação da empresa } \\
\text { na comunidade; }\end{array}$ & $\begin{array}{l}\text { DUCASSY, I., \& MONTANDRAU, S. (2015); } \\
\text { AGUDO-VALIENTE, GARCÉS-AYERBE, \& } \\
\text { SALVADOR-FIGUERAS (2015); IOANNOU, I., } \\
\text { \& SERAFEIM, G. (2012); GAO (2009); SPILLER } \\
\text { (2000); COSTA, R.; \& MENICHINI, T. (2013); DE } \\
\text { CAMPOS, I.C.S., \& SANTOS, J.B. (2013); } \\
\text { VALIENTE, J. M. A., AYERBE, C. G., \& } \\
\text { FIGUERAS, M. S. (2012); NÓBREGA, M. M., \& } \\
\text { CÂNDIDO, G. A. (2015). }\end{array}$ \\
\hline
\end{tabular}

Figura 28. Dimensões da CSP (continuação)

\section{Fonte: do autor}




\begin{tabular}{|c|c|c|c|c|}
\hline Stakeholder & Dimensões & Referências & Variáveis & Referências \\
\hline \multirow{4}{*}{ 离 } & $\begin{array}{l}\text { Qualidade do } \\
\text { produto }\end{array}$ & $\begin{array}{l}\text { AGUDO-VALIENTE, GARCÉS-AYERBE, \& } \\
\text { SALVADOR-FIGUERAS (2015); } \\
\text { PAPASOLOMOU ET AL (2005); BROWER, } \\
\text { J., \& MAHAJAN, V. (2013); NOBBREGA, M. } \\
\text { M., \& CÂNDIDO, G. A. (2015); FRANCIS, R. } \\
\text { N., HARRAST, S., MATTINGLY, J., \& } \\
\text { OLSEN, L. (2013); TURKER, D. (2009). }\end{array}$ & $\begin{array}{l}\text { Certificação, programas e } \\
\text { práticas de garantia de } \\
\text { qualidade }\end{array}$ & $\begin{array}{l}\text { AGUDO-VALIENTE, GARCÉS-AYERBE, \& SALVADOR- } \\
\text { FIGUERAS (2015); IOANNOU, I., \& SERAFEIM, G. (2012); GAO } \\
\text { (2009); PIVATO, MISANI, \& TENCATIN (2008); KANSAL, M., \& } \\
\text { SINGH, S. (2012); VALIENTE, J. M. A., AYERBE, C. G., \& } \\
\text { FIGUERAS, M. S. (2012); AGUDO, J. M., GARGALLO, P., \& } \\
\text { SALVADOR, M. (2015); FRANCIS, R. N., HARRAST, S., } \\
\text { MATTINGLY, J., \& OLSEN, L. (2013); SPILLER (2000). }\end{array}$ \\
\hline & $\begin{array}{l}\text { Inovação e } \\
\text { introdução de } \\
\text { novas tecnologias }\end{array}$ & $\begin{array}{l}\text { BROWER, J., \& MAHAJAN, V. (2013); } \\
\text { IOANNOU, I., \& SERAFEIM, G. (2012); } \\
\text { SPILLER (2000); RAIS, S., \& } \\
\text { GOEDEGEBUURE, R.V. (2008); FRANCIS, } \\
\text { R. N., HARRAST, S., MATTINGLY, J., \& } \\
\text { OLSEN, L. (2013). }\end{array}$ & $\begin{array}{l}\text { Investimentos de Pesquisa \& } \\
\text { Desenvolvimento para } \\
\text { produtos e serviços } \\
\text { considerando a } \\
\text { sustentabilidade }\end{array}$ & $\begin{array}{l}\text { IOANNOU, I., \& SERAFEIM, G. (2012); SPILLER (2000); } \\
\text { IGALENS, J., \& GOND, J.P. (2005); KANSAL, M., \& SINGH, S. } \\
\text { (2012); FRANCIS, R. N., HARRAST, S., MATTINGLY, J., \& } \\
\text { OLSEN, L. (2013). }\end{array}$ \\
\hline & \multirow[t]{2}{*}{$\begin{array}{l}\text { Responsabilidade } \\
\text { pelo Produto }\end{array}$} & \multirow[t]{2}{*}{$\begin{array}{l}\text { AGUDO-VALIENTE, GARCÉS-AYERBE, \& } \\
\text { SALVADOR-FIGUERAS (2015); IOANNOU, } \\
\text { I., \& SERAFEIM, G. (2012); }\end{array}$} & $\begin{array}{l}\text { Informações sobre o produto } \\
\text { e rotulagem precisas e claras }\end{array}$ & $\begin{array}{l}\text { MAIGNAN, \& FERRELL (2000); AGUDO-VALIENTE, GARCÉS- } \\
\text { AYERBE, \& SALVADOR-FIGUERAS (2015); VURRO, C., } \\
\text { PERRINI, F. (2011); PAPASOLOMOU ET AL (2005). IOANNOU, } \\
\text { I., \& SERAFEIM, G. (2012); SPILLER (2000); COSTA, R.; \& } \\
\text { MENICHINI, T. (2013); RAIS, S., \& GOEDEGEBUURE, R.V. } \\
\text { (2008); NÓBREGA, M. M., \& CÂNDIDO, G. A. (2015); KANSAL, } \\
\text { M., \& SINGH, S. (2012); TURKER, D. (2009). }\end{array}$ \\
\hline & & & $\begin{array}{l}\text { Procedimentos para assegurar } \\
\text { que a composição e a } \\
\text { produção de produtos e } \\
\text { serviços garantam a saúde e a } \\
\text { segurança do consumidor }\end{array}$ & $\begin{array}{l}\text { PAPASOLOMOU ET AL (2005), IOANNOU, I., \& SERAFEIM, G. } \\
\text { (2012); SPILLER (2000); FISCHER, T. M., \& SAWCZYN, A. A. } \\
\text { (2013); KANSAL, M., \& SINGH, S. (2012); COSTA, R.; \& } \\
\text { MENICHINI, T. (2013); DE CAMPOS, I.C.S., \& SANTOS, J.B. } \\
\text { (2013); NÓBREGA, M. M., \& CÂNDIDO, G. A. (2015). }\end{array}$ \\
\hline
\end{tabular}

Figura 28. Dimensões da CSP (continuação)

Fonte: do autor 


\begin{tabular}{|c|c|c|c|c|}
\hline Stakeholder & Dimensões & Referências & Variáveis & Referências \\
\hline \multirow{3}{*}{ 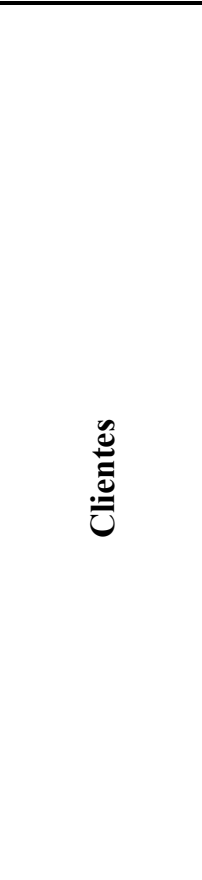 } & $\begin{array}{l}\text { Ações de comunicação e } \\
\text { promoção }\end{array}$ & VURRO, C., PERRINI, F. (2011) & $\begin{array}{l}\text { Não veiculação de propagandas falsas e } \\
\text { enganosas }\end{array}$ & $\begin{array}{l}\text { AGUDO-VALIENTE, GARCÉS- } \\
\text { AYERBE, \& SALVADOR- } \\
\text { FIGUERAS (2015); SPILLER } \\
\text { (2000); VALIENTE, J. M. A., } \\
\text { AYERBE, C. G., \& FIGUERAS, } \\
\text { M. S. (2012); }\end{array}$ \\
\hline & Satisfação dos clientes & $\begin{array}{l}\text { VURRO, C., PERRINI, F. (2011); } \\
\text { PIVATO, MISANI, \& TENCATIN } \\
\text { (2008); RAIS, S., \& } \\
\text { GOEDEGEBUURE, R.V. (2008); } \\
\text { TURKER, D. (2009). }\end{array}$ & $\begin{array}{l}\text { Sistemas de mensuração da satisfação dos } \\
\text { clientes }\end{array}$ & $\begin{array}{l}\text { IGALENS, J., \& GOND, J.P. } \\
\text { (2005); COSTA, R.; \& } \\
\text { MENICHINI, T. (2013); } \\
\text { VALIENTE, J. M. A., AYERBE, } \\
\text { C. G., \& FIGUERAS, M. S. } \\
(2012)\end{array}$ \\
\hline & Privacidade do Cliente & VURRO, C., PERRINI, F. (2011) & Confidencialidade das informações dos clientes & $\begin{array}{l}\text { AGUDO-VALIENTE, GARCÉS- } \\
\text { AYERBE, \& SALVADOR- } \\
\text { FIGUERAS (2015); VALIENTE, } \\
\text { J. M. A., AYERBE, C. G., \& } \\
\text { FIGUERAS, M. S. (2012); } \\
\text { COSTA, R.; \& MENICHINI, T. } \\
\text { (2013); }\end{array}$ \\
\hline
\end{tabular}

Figura 28. Dimensões da CSP (continuação)

Fonte: do autor 


\section{APÊNDICE 2 - Indicadores GRI-G4 utilizados}

\begin{tabular}{|c|c|}
\hline INDICADOR & DESCRIÇÃO \\
\hline G4-LA3 & $\begin{array}{l}\text { Taxas de retorno ao trabalho e retenção após uma licença maternidade/paternidade, discriminadas por } \\
\text { gênero }\end{array}$ \\
\hline G4-LA5 & $\begin{array}{l}\text { Percentual da força de trabalho representada em comitês formais de saúde e segurança, compostos por } \\
\text { empregados de diferentes níveis hierárquicos, que ajudam a monitorar e orientar programas de saúde e } \\
\text { segurança no trabalho }\end{array}$ \\
\hline G4-LA6 & $\begin{array}{l}\text { Tipos e taxas de lesões, doenças ocupacionais, dias perdidos, absenteísmo e número de óbitos relacionados } \\
\text { ao trabalho, discriminados por região e gênero }\end{array}$ \\
\hline G4-HR2 & $\begin{array}{l}\text { Número total de horas de treinamento de empregados em políticas de direitos humanos ou procedimentos } \\
\text { relacionados a aspectos dos direitos humanos relevantes para as operações da organização, incluindo o } \\
\text { percentual de empregados treinados }\end{array}$ \\
\hline G4-HR6 & $\begin{array}{l}\text { Operações e fornecedores identificados como de risco significativo para a ocorrência de trabalho forçado } \\
\text { ou análogo ao escravo e medidas tomadas para contribuir para a eliminação de todas as formas de trabalho } \\
\text { forçado ou análogo ao escravo }\end{array}$ \\
\hline G4-HR5 & $\begin{array}{l}\text { Operações e fornecedores identificados como de risco para a ocorrência de casos de trabalho infantil e } \\
\text { medidas tomadas para contribuir para a efetiva erradicação do trabalho infantil }\end{array}$ \\
\hline G4-LA9 & $\begin{array}{l}\text { Número médio de horas de treinamento por ano por empregado, discriminado por gênero e categoria } \\
\text { funcional }\end{array}$ \\
\hline G4-LA11 & $\begin{array}{l}\text { Percentual de empregados que recebem regularmente análises de desempenho e de desenvolvimento de } \\
\text { carreira, discriminado por gênero e categoria funcional }\end{array}$ \\
\hline G4-LA1 & $\begin{array}{l}\text { Número total e taxas de novas contratações de empregados e rotatividade de empregados por faixa etária, } \\
\text { gênero e região }\end{array}$ \\
\hline G4-LA12 & $\begin{array}{l}\text { Composição dos grupos responsáveis pela governança e discriminação de empregados por categoria } \\
\text { funcional, de acordo com gênero, faixa etária, minorias e outros indicadores de diversidade }\end{array}$ \\
\hline G4-LA13 & $\begin{array}{l}\text { Razão matemática do salário e remuneração entre mulheres e homens, discriminada por categoria funcional } \\
\text { e unidades operacionais relevantes }\end{array}$ \\
\hline G4-LA2 & $\begin{array}{l}\text { Benefícios concedidos a empregados de tempo integral que não são oferecidos a empregados temporários } \\
\text { ou em regime de meio período, discriminados por unidades operacionais importantes da organização }\end{array}$ \\
\hline G4-EC3 & Cobertura das obrigações previstas no plano de pensão de benefício da organização \\
\hline G4-LA10 & $\begin{array}{l}\text { Programas de gestão de competências e aprendizagem contínua que contribuem para a continuidade da } \\
\text { empregabilidade dos empregados em período de preparação para a aposentadoria }\end{array}$ \\
\hline G4-LA2 & $\begin{array}{l}\text { Benefícios concedidos a empregados de tempo integral que não são oferecidos a empregados temporários } \\
\text { ou em regime de meio período, discriminados por unidades operacionais importantes da organização }\end{array}$ \\
\hline G4-HR3 & Número total de casos de discriminação e medidas corretivas tomadas \\
\hline G4-LA16 & $\begin{array}{l}\text { Número de queixas e reclamações relacionadas a práticas trabalhistas registradas, processadas e } \\
\text { solucionadas por meio de mecanismo formal }\end{array}$ \\
\hline G4-HR4 & $\begin{array}{l}\text { Operações e fornecedores identificados em que o direito de exercer a liberdade de associação e a } \\
\text { negociação coletiva possa estar sendo violado ou haja risco significativo e as medidas tomadas para apoiar } \\
\text { esse direito }\end{array}$ \\
\hline G4-EC9 & Proporção de gastos com fornecedores locais em unidades operacionais importantes \\
\hline G4-34 & $\begin{array}{l}\text { Relate a estrutura de governança da organização, incluindo os comitês do mais alto órgão de governança. } \\
\text { Identifique todos os comitês responsáveis pelo assessoramento do conselho na tomada de decisões que } \\
\text { possuam impactos econômicos, ambientais e sociais }\end{array}$ \\
\hline
\end{tabular}




\section{APÊNDICE 2 - Indicadores GRI-G4 utilizados (continuação)}

\begin{tabular}{|c|c|}
\hline INDICADOR & DESCRIÇÃO \\
\hline G4-38 & $\begin{array}{l}\text { a. Relate a composição do mais alto órgão de governança e dos seus comitês por: Função executiva ou não } \\
\text { executiva, Independência, Mandato dos membros do mais alto órgão de governança, Número de outras funções } \\
\text { e compromissos importantes de cada indivíduo, bem como a natureza desses compromissos (p. ex.: participação } \\
\text { em outros conselhos, comitês, comissões, grupos de trabalho, etc.), Gênero, Participação de grupos sociais sub- } \\
\text { representados, Competências relacionadas a impactos econômicos, ambientais e sociais e Participação de } \\
\text { stakeholders. }\end{array}$ \\
\hline G4-39 & $\begin{array}{l}\text { a. Relate se o presidente do mais alto órgão de governança é também um diretor executivo (e, nesse caso, sua } \\
\text { função na gestão da organização e as razões para esse acúmulo) }\end{array}$ \\
\hline G4-EC1 & Valor econômico direto gerado e distribuído \\
\hline G4-51 & $\begin{array}{l}\text { a. Relate as políticas de remuneração aplicadas ao mais alto órgão de governança e a executivos seniores para os } \\
\text { seguintes tipos de remuneração: Salário fixo e remuneração variável, Bônus de atração ou pagamentos de } \\
\text { incentivos ao recrutamento, Pagamentos de rescisão, Clawbacks e Benefícios de aposentadoria, inclusive a } \\
\text { diferença entre plano de benefícios e taxas de contribuições para o mais alto órgão de governança, altos } \\
\text { executivos e todos os demais empregados. } \\
\text { b. Relate como os critérios de desempenho da política de remuneração aplicam-se aos objetivos econômicos, } \\
\text { ambientais e sociais do mais alto órgão de governança e executivos seniores. }\end{array}$ \\
\hline G4-1 & $\begin{array}{l}\text { a. Apresente uma declaração do decisor mais graduado da organização (p. ex.: seu diretor-presidente, presidente do } \\
\text { conselho de administração ou cargo equivalente) sobre a relevância da sustentabilidade para a organização e sua } \\
\text { estratégia de sustentabilidade. } \\
\text { A declaração deve apresentar a visão global e estratégia de curto, médio e longo prazo, particularmente para a gestão } \\
\text { de impactos econômicos, ambientais e sociais significativos gerados pela organização ou para os quais ela contribui } \\
\text { ou de impactos que podem estar relacionados às suas operações em decorrência de relações com outros atores ou } \\
\text { organizações (p. ex.: fornecedores, pessoas ou organizações de comunidades locais). A declaração deve incluir: } \\
\text { - Prioridades estratégicas e tópicos fundamentais de curto e médio prazo relacionados à sustentabilidade, inclusive a } \\
\text { observância de normas internacionalmente reconhecidas e como essas normas estão ligadas à estratégia e ao sucesso } \\
\text { da empresa no longo prazo. } \\
\text { - Tendências mais amplas (p. ex.: macroeconômicas ou políticas) que afetam a organização e influenciam prioridades } \\
\text { de sustentabilidade. } \\
\text { - Principais eventos, realizações e fracassos ocorridos no período coberto pelo relatório. } \\
\text { - Opiniões sobre o desempenho em relação à consecução de metas. } \\
\text { - Perspectivas para os principais desafios e metas da organização para o ano seguinte e objetivos para os próximos três } \\
\text { a cinco anos. } \\
\text { - Outros elementos relativos à abordagem estratégica da organização. }\end{array}$ \\
\hline G4-2 & $\begin{array}{l}\text { a. Apresente uma descrição dos principais impactos, riscos e oportunidades. } \\
\text { A organização deve apresentar duas seções narrativas concisas sobre os principais impactos, riscos e oportunidades. } \\
\text { A primeira seção deve enfocar os principais impactos da organização sobre a sustentabilidade e seus efeitos para } \\
\text { stakeholders, inclusive sobre direitos previstos na legislação nacional e normas internacionalmente reconhecidas } \\
\text { relevantes. A segunda seção deve se concentrar no impacto de tendências, riscos e oportunidades de sustentabilidade } \\
\text { sobre as perspectivas de longo prazo e desempenho financeiro da organização. Aqui, é preciso concentrar-se } \\
\text { especificamente em informações relevantes para stakeholders financeiros ou que poderiam se tornar relevantes para } \\
\text { elas no futuro. }\end{array}$ \\
\hline G4-56 & $\begin{array}{l}\text { a. Descreva os valores, princípios, padrões e normas de comportamento da organização, como códigos de } \\
\text { conduta e de ética. }\end{array}$ \\
\hline G4-57 & $\begin{array}{l}\text { a. Relate os mecanismos internos e externos adotados pela organização para solicitar orientações sobre } \\
\text { comportamentos éticos e } \\
\text { em conformidade com a legislação, como canais de relacionamento (p. ex.: ouvidoria). }\end{array}$ \\
\hline G4-SO3 & $\begin{array}{l}\text { Número total e percentual de operações submetidas a avaliações de riscos relacionados à corrupção e os riscos } \\
\text { significativos identificados }\end{array}$ \\
\hline G4-SO4 & Comunicação e treinamento em políticas e procedimentos de combate à corrupção \\
\hline
\end{tabular}


APÊNDICE 2 - Indicadores GRI-G4 utilizados (continuação)

\begin{tabular}{|c|l|}
\hline INDICADOR & \multicolumn{1}{|c|}{ DESCRIÇÃO } \\
\hline G4-EC7 & Desenvolvimento e impacto de investimentos em infraestrutura e serviços oferecidos \\
\hline G4-EC8 & Impactos econômicos indiretos significativos, inclusive a extensão dos impactos \\
\hline G4-SO1 & $\begin{array}{l}\text { Percentual de operações com programas implementados de engajamento da comunidade local, } \\
\text { avaliação de } \\
\text { impactos e desenvolvimento local }\end{array}$ \\
\hline G4-SO2 & Operações com impactos negativos significativos reais e potenciais nas comunidades locais \\
\hline G4-PR3 & $\begin{array}{l}\text { Tipo de informações sobre produtos e serviços exigidas pelos procedimentos da organização } \\
\text { referentes a } \\
\text { informações e rotulagem de produtos e serviços e percentual de categorias significativas sujeitas a } \\
\text { essas exigências }\end{array}$ \\
\hline G4-PR1 & $\begin{array}{l}\text { Percentual de categorias de produtos e serviços significativas para as quais são avaliados impactos } \\
\text { na saúde e } \\
\text { segurança buscando melhorias }\end{array}$ \\
\hline G4-PR7 & $\begin{array}{l}\text { Número total de casos de não conformidade com regulamentos e códigos voluntários relativos a } \\
\text { comunicações de } \\
\text { marketing, incluindo publicidade, promoção e patrocínio, discriminados por tipo de resultados }\end{array}$ \\
\hline G4-PR5 & \begin{tabular}{l} 
Resultados de pesquisas de satisfação do cliente \\
\hline G4-PR8
\end{tabular} $\begin{array}{l}\text { Número total de queixas comprovadas relativas à violação de privacidade e perda de dados de } \\
\text { clientes }\end{array}$ \\
\hline
\end{tabular}

\begin{tabular}{|c|c|}
\hline INDICADOR & DESCRIÇÃO \\
\hline $\begin{array}{l}\text { G4-DMA-Saúde e Segurança no Trabalho } \\
\text { G4-DMA-Trabalho Forçado ou Análogo ao Escravo } \\
\text { G4-DMA-Trabalho Infantil } \\
\text { G4-DMA-Treinamento e Educação } \\
\text { G4-DMA - Diversidade e Igualdade de Oportunidades } \\
\text { G4-DMA- Igualdade de Remuneração para Mulheres } \\
\text { e Homens } \\
\text { G4-DMA-Liberdade de Associação e Negociação } \\
\text { Coletiva } \\
\text { G4-DMA-Avaliação Ambiental de Fornecedores } \\
\text { G4-DMA-Avaliação de Fornecedores em Práticas } \\
\text { Trabalhistas } \\
\text { G4-DMA-Avaliação de Fornecedores em Direitos } \\
\text { Humanos } \\
\text { G4-DMA-Práticas de Compra } \\
\text { G4-DMA-Combate à Corrupção } \\
\text { G4-DMA-Impactos Econômicos Indiretos } \\
\text { G4-DMA-Saúde e Segurança do Cliente } \\
\text { G4-DMA-Rotulagem de Produtos e Serviços } \\
\text { G4-DMA- Privacidade do cliente }\end{array}$ & $\begin{array}{l}\text { a. Relate por que o Aspecto é material. Relate os impactos } \\
\text { que o tornam material. } \\
\text { b. Relate como a organização administra o Aspecto } \\
\text { material ou seus impactos. } \\
\text { c. Relate como a abordagem de gestão é avaliada, } \\
\text { incluindo: } \\
\text { - Mecanismos de avaliação da eficácia da abordagem de } \\
\text { gestão } \\
\text { - Os resultados da avaliação da abordagem de gestão } \\
\text { - Quaisquer ajustes introduzidos na abordagem de gestão }\end{array}$ \\
\hline
\end{tabular}




\section{APÊNDICE 3 - Questões ISE}

\section{Questionário ISE: questões e pesos atribuídos a cada alternativa}

Dimensão: Equilibrio entre vida profissional, pessoal e familiar

SOC 30. Indique o percentual de funcionárias que retornaram da licença-maternidade e permaneceram por no minimo 12 meses após o retorno, nos últimos 3 anos:
a) Maior que $90 \%$
a) 3
b) Maior que $70 \%$ e menor ou igual a $90 \%$
b) 2
c) Menor ou igual a $70 \%$
c) 1
d) Não se aplica
d) -

Dimensão: Saúde e segurança ocupacional

SOC 13. Em relação à preocupação com a qualidade de vida de seus funcionários, a companhia:

a) Oferece beneficios como opção de alimentos saudáveis, academia, ginástica laboral, e outras atividades que promovam o bem estar e uma vida mais saudável (fisica e psiquica)

b) Conscientiza, informa e estimula seus funcionários quanto a um estilo de vida saudável

c) Acompanha a situação de seus funcionários quanto a aspectos relacionados à sua qualidade de vida e estrutura programas que incentivem progressos em relação ao tema

d) Possui programas que incentivem a redução de horas-extras e equilibrio entre carga

horária disponivel e demanda de trabalho

e) Nenhuma das anteriores

AMB-IF 21. Indique o percentual das unidades da instituição (administrativas, de apoio e atendimento) nas quais as práticas de gestão de saúde e segurança no trabalho (SST) estão plenamente implementadas:

\section{PRÁTICAS DE GESTÃO DE SST}

a) Análise prévia e incorporação de requisitos de saúde e segurança do trabalho no desenvolvimento de novos processos, atividades, equipamentos e empreendimentos

b) Avaliação ambiental sistemática e periódica e registro dos perigos e riscos

c) Estabelecimento de programas de gestão que contenham objetivos e metas de SST compativeis com os perigos e riscos ocupacionais

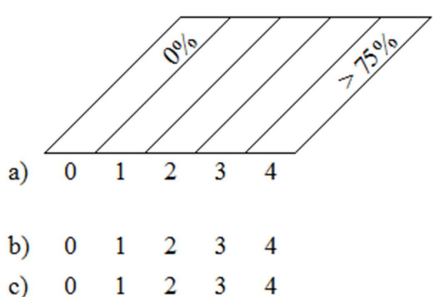

Total $=12$

AMB-A 2. A companhia possui uma política corporativa que contemple aspectos de Saúde e Segurança no Trabalho (SST) cujas diretrizes são refletidas nos seus processos de planejamento e gestão?

a) Não possui politica corporativa que contemple aspectos de SST

b) Sim, possui politica corporativa que contemple aspectos de SST, mas esta não contempla os elementos minimos requeridos no protocolo

c) Sim, possui politica corporativa que contemple aspectos de SST compativel com os elementos mínimos requeridos no protocolo e dela derivam objetivos estratégicos para todas as suas unidades, atividades, produtos e serviços

d) Sim, possui politica corporativa que contemple aspectos de SST compativel com os elementos minimos requeridos no protocolo, dela derivam objetivos estratégicos para todas as suas unidades, atividades e processos e possui práticas e procedimentos sistemáticos para difundir seus compromissos em sua cadeia de valor a) 0

b) 1

c) 2

d) 3

Dimensão: Compromisso com direitos humanos nas práticas de trabalho

SOC 1. Assinale os temas para os quais a companhia possui compromisso formal:

a) Erradicação do trabalho infantil (TI)

b) Erradicação do trabalho forçado ou compulsório (TF)

c) Combate à prática de discriminação em todas as suas formas (DI)

d) Valorização da diversidade (DV)

e) Prevenção do assédio moral e do assédio sexual (AS)

e) 0

f) Respeito à livre associação sindical e direito à negociação coletiva (LA)

f) 0

g) Nenhum dos anteriores 
SOC 6. Assinale as alternativas que caracterizam os processos e procedimentos implementados pela companhia, incluindo trabalhadores terceirizados: TI - Erradicar o trabalho infantil

TF - Erradicar o trabalho forçado ou compulsório

DI - Eliminar qualquer prática de discriminação em matéria de emprego e ocupação

DV - Promover a valorização da diversidade em matéria de emprego e ocupação

AS - Prevenir e coibir o assédio moral e o assédio sexual em todas as suas formas

LA - Respeito à livre associação sindical e direito à negociação coletiva

DT - Assegurar os direitos trabalhistas de funcionários diretos e trabalhadores terceirizados

ED - Prover o acesso dos funcionários, diretos e trabalhadores terceirizados, a atividades de educação e desenvolvimento, visando ampliar sua competência, empregabilidade e evolução pessoal ou profissional

EQ - Promover a equidade de tratamento e condições de trabalho entre funcionários e trabalhadores terceirizados

DL - Praticar o diálogo com o público interno, incluindo funcionários diretos e trabalhadores terceirizados, acolhendo, registrando, respondendo e esclarecendo todas suas críticas e sugestões, atendendo-as quando cabivel

a) Relação direta com uma politica corporativa ou compromisso formal sobre o assunto b) Indicação de recursos a serem disponibilizados para obtenção dos resultados visados e os responsáveis por sua disponibilização

c) Monitoramento e fiscalização dos termos do compromisso pela própria companhia d) Monitoramento e fiscalização do compromisso por uma terceira parte independente contratada para este fim

e) Sanção por meio de medidas disciplinares e/ou legais para situações de descumprimento ocorridas na companhia

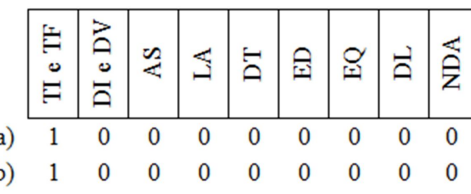

c) $1 \quad 0 \quad 0000000000$

d) $1 \quad 0 \quad 0000000000$

e) $1 \quad 0 \quad 0 \quad 00000000$

Total $=5$

SOC 37. Indique abaixo o volume de negócios realizados com fornecedores que são monitorados pela companhia e objeto de verificação externa independente, com base em cada um dos principios abaixo:

\section{TEMA}

a) Não utilização de trabalho infantil

b) Não utilização de trabalho forçado ou compulsório

c) Valorização da diversidade

d) Combate à prática de discriminação

e) Pagamento pontual e correto de suas obrigações com fornecedores, com empregados e de tributos a)

$\begin{array}{lll}1 & 2 & 3\end{array}$

c) $0 \quad 0 \quad 0 \quad 0$

d) $0 \quad 0 \quad 0 \quad 0$

e) $\begin{array}{llll}0 & 0 & 0 & 0\end{array}$

SOC 1. Assinale os temas para os quais a companhia possui compromisso formal:

a) Erradicação do trabalho infantil (TI)

b) Erradicação do trabalho forçado ou compulsório (TF)

c) Combate à prática de discriminação em todas as suas formas (DI)

d) Valorização da diversidade (DV)

e) Prevenção do assédio moral e do assédio sexual (AS)

$\begin{array}{ll}\text { f) Respeito à livre associação sindical e direito à negociação coletiva (LA) } & \text { f) } 0\end{array}$

g) Nenhum dos anteriores 
SOC 6. Assinale as alternativas que caracterizam os processos e procedimentos implementados pela companhia, incluindo trabalhadores terceirizados: TI - Erradicar o trabalho infantil

TF - Erradicar o trabalho forçado ou compulsório

DI - Eliminar qualquer prática de discriminação em matéria de emprego e ocupação

DV - Promover a valorização da diversidade em matéria de emprego e ocupação

AS - Prevenir e coibir o assédio moral e o assédio sexual em todas as suas formas

LA - Respeito à livre associação sindical e direito à negociação coletiva

DT - Assegurar os direitos trabalhistas de funcionários diretos e trabalhadores terceirizados

ED - Prover o acesso dos funcionários, diretos e trabalhadores terceirizados, a atividades de educação e desenvolvimento, visando

EQ - Promover a equidade de tratamento e condições de trabalho entre funcionários e trabalhadores terceirizados

DL - Praticar o diálogo com o público interno, incluindo funcionários diretos e trabalhadores terceirizados, acolhendo, registrando, respondendo e esclarecendo todas suas criticas e sugestões, atendendo-as quando cabivel

a) Relação direta com uma politica corporativa ou compromisso formal sobre o assunto

b) Indicação de recursos a serem disponibilizados para obtenção dos resultados visados e os responsáveis por sua disponibilização

c) Monitoramento e fiscalização dos termos do compromisso pela própria companhia

d) Monitoramento e fiscalização do compromisso por uma terceira parte independente contratada para este fim

e) Sanção por meio de medidas disciplinares e/ou legais para situações de descumprimento ocorridas na companhia

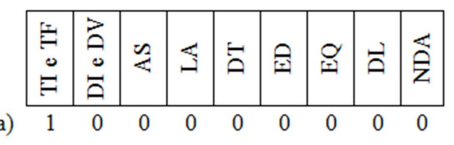

b) $1 \quad 0 \quad 0 \quad 0 \quad 0 \quad 00000$

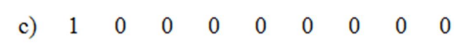

d) $1 \quad 0 \quad 0 \quad 00000000$

e) $1 \quad 0 \quad 0 \quad 000000000$

Total $=5$

SOC 37. Indique abaixo o volume de negócios realizados com fornecedores que são monitorados pela companhia e objeto de verificação externa

\section{TEMA}

a) Não utilização de trabalho infantil

b) Não utilização de trabalho forçado ou compulsório

c) Valorização da diversidade

d) Combate à prática de discriminação

e) Pagamento pontual e correto de suas obrigações com fornecedores, com empregados e de tributos

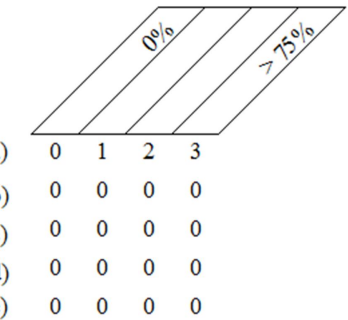

Dimensão: Treinamento e Educação

SOC 6. Assinale as alternativas que caracterizam os processos e procedimentos implementados pela companhia, incluindo trabalhadores

TI - Erradicar o trabalho infantil

TF - Erradicar o trabalho forçado ou compulsório

DI - Eliminar qualquer prática de discriminação em matéria de emprego e ocupação

DV - Promover a valorização da diversidade em matéria de emprego e ocupação

AS - Prevenir e coibir o assédio moral e o assédio sexual em todas as suas formas

LA - Respeito à livre associação sindical e direito à negociação coletiva

DT - Assegurar os direitos trabalhistas de funcionários diretos e trabalhadores terceirizados

ED - Prover o acesso dos funcionários, diretos e trabalhadores terceirizados, a atividades de educação e desenvolvimento, visando

EQ - Promover a equidade de tratamento e condições de trabalho entre funcionários e trabalhadores terceirizados

DL - Praticar o diálogo com o público interno, incluindo funcionários diretos e trabalhadores terceirizados, acolhendo, registrando,

respondendo e esclarecendo todas suas criticas e sugestões, atendendo-as quando cabivel

a) Relação direta com uma politica corporativa ou compromisso formal sobre o assunto

b) Indicação de recursos a serem disponibilizados para obtenção dos resultados visados e os responsáveis por sua disponibilização

c) Monitoramento e fiscalização dos termos do compromisso pela própria companhia

d) Monitoramento e fiscalização do compromisso por uma terceira parte independente contratada para este fim

e) Sanção por meio de medidas disciplinares e/ou legais para situações de descumprimento ocorridas na companhia

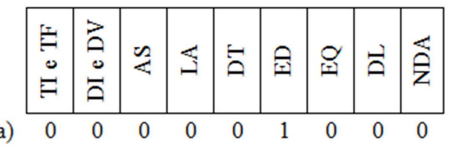

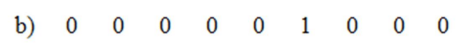

c) $\begin{array}{lllllllll}0 & 0 & 0 & 0 & 0 & 1 & 0 & 0 & 0\end{array}$

d) $\begin{array}{lllllllll}0 & 0 & 0 & 0 & 0 & 1 & 0 & 0 & 0\end{array}$

e) $\begin{array}{lllllllll}0 & 0 & 0 & 0 & 0 & 1 & 0 & 0 & 0\end{array}$

Total $=5$ 
Dimensão: Diversidade e igualdades de oportunidades

SOC 19. Indique na tabela abaixo a diferença de proporção entre pessoas que ocupam cargos de gerência e cargos de diretoria, considerando os critérios raça/cor e gênero:

a) Mulheres em cargos de diretoria

a) $0 \begin{array}{lllll}0 & 2 & 3 & \text { - }\end{array}$

b) Negros (as) em cargos de diretoria

b) $\begin{array}{lllll}0 & 0 & 0 & 0 & 0\end{array}$

c) Mulheres em cargos de gerência

c) $\begin{array}{llllll}0 & 0 & 0 & 0 & 0\end{array}$

d) Negros (as) em cargos de gerênci

d) $\begin{array}{llllll}0 & 1 & 2 & 3 & \text { - }\end{array}$

e) $\begin{array}{lllll}0 & 0 & 0 & 0 & 0\end{array}$

Total $=6$

GOV 21. Em relação à participação de mulheres no Conselho de Administração, indique a situação da companhia:

a) Há a participação de uma ou mais mulheres no Conselho de Administração, como conselheiras efetivas

b) Não há mulheres no Conselho de Administração, no entanto, há planos para

promover a diversidade e o equilibrio de gênero

c) Não há mulheres no Conselho de Administração e não há planos para promover a $\quad$ c) 0

diversidade $\mathrm{e} o$ equilibrio de gênero

SOC 32. Indique as medidas adotadas pela companhia visando promover a empregabilidade de pessoas com deficiência:

a) Investimento em meios de acessibilidade $\quad$ a) 1

$\begin{array}{ll}\text { b) Investimento em tecnologias adequadas para a realização do trabalho } & \text { b) } 1\end{array}$

$\begin{array}{ll}\text { c) Capacitação profissional } & \text { c) } 1\end{array}$

d) Sensibilização e conscientização de seus funcionários para a recepção e boa $\quad$ d) 1

convivência profissional

$\begin{array}{ll}\text { e) Nenhuma das anteriores } & \text { e) } 0\end{array}$

Total $=4$

SOC 39. A companhia cumpre a legislação relativa à contratação de pessoas com deficiência?

$\begin{array}{ll}\text { a) } \mathrm{Sim} & \text { a) } 2\end{array}$

$\begin{array}{ll}\text { b) Não } & \text { b) } 0\end{array}$

c) Não, porém está em processo de atendimento a Termo de Ajustamento de Conduta $\quad$ c) 1

(TAC)

d) Não se aplica (controlada no exterior)

d) -

SOC 1. Assinale os temas para os quais a companhia possui compromisso formal:

a) Erradicação do trabalho infantil (TI)

a) 0

b) Erradicação do trabalho forçado ou compulsório (TF)

$\begin{array}{ll}\text { d) Valorização da diversidade (DV) } & \text { d) } 1\end{array}$

$\begin{array}{ll}\text { e) Prevenção do assédio moral e do assédio sexual (AS) } & \text { e) } 0\end{array}$

$\begin{array}{ll}\text { f) Respeito à livre associação sindical e direito à negociação coletiva (LA) } & \text { f) } 0\end{array}$

g) Nenhum dos anteriores

SOC 6. Assinale as alternativas que caracterizam os processos e procedimentos implementados pela companhia, incluindo trabalhadores terceirizados: TI - Erradicar o trabalho infantil

TF - Erradicar o trabalho forçado ou compulsório

DI - Eliminar qualquer prática de discriminação em matéria de emprego e ocupação

DV - Promover a valorização da diversidade em matéria de emprego e ocupação

AS - Prevenir e coibir o assédio moral e o assédio sexual em todas as suas formas

LA - Respeito à livre associação sindical e direito à negociação coletiva

DT - Assegurar os direitos trabalhistas de funcionários diretos e trabalhadores terceirizados

$\mathrm{ED}$ - Prover o acesso dos funcionários, diretos e trabalhadores terceirizados, a atividades de educação e desenvolvimento, visando

EQ - Promover a equidade de tratamento e condições de trabalho entre funcionários e trabalhadores terceirizados

DL - Praticar o diálogo com o público interno, incluindo funcionários diretos e trabalhadores terceirizados, acolhendo, registrando,

respondendo e esclarecendo todas suas criticas e sugestões, atendendo-as quando cabivel

a) Relação direta com uma politica corporativa ou compromisso formal sobre o assunto b) Indicação de recursos a serem disponibilizados para obtenção dos resultados visados e os responsáveis por sua disponibilização

c) Monitoramento e fiscalização dos termos do compromisso pela própria companhia

d) Monitoramento e fiscalização do compromisso por uma terceira parte independente contratada para este fim

e) Sanção por meio de medidas disciplinares e/ou legais para situações de descumprimento ocorridas na companhia

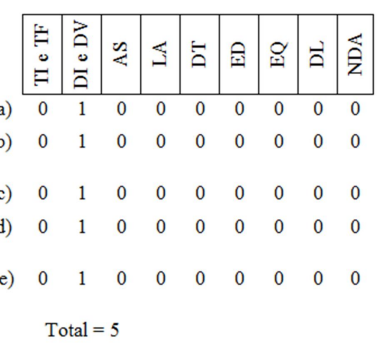

SOC 9. O compromisso com a valorização da diversidade em matéria de emprego e ocupação abrange as atividades de:

a) Seleção e contratação

b) Promoção

c) Acesso a treinamento

d) Sensibilização dos funcionários diretos e trabalhadores terceirizados para o tema a) 1

b) 1

c) 1

d) 1

Total $=4$ 
SOC 31. Indique as medidas adotadas pela companhia visando respeitar a diversidade em termos de orientação sexual:

a) Possibilita a indicação de pessoas do mesmo sexo como cônjuges

b) Inclui o tema em suas atividades de sensibilização e valorização da diversidade

c) Nenhuma das anteriores a) 1

c) 0

Total $=2$

SOC 24. Indique na tabela abaixo o Fator de Equidade na Remuneração (FER) que relaciona a remuneração dos integrantes de cada um dos grupos indicados e a remuneração do conjunto de todos os ocupantes de cargos de diretoria e cargos de gerência:

a) Mulheres em cargos de diretoria

b) Negros (as) em cargos de diretoria

c) Mulheres em cargos de gerência

d) Negros (as) em cargos de gerência

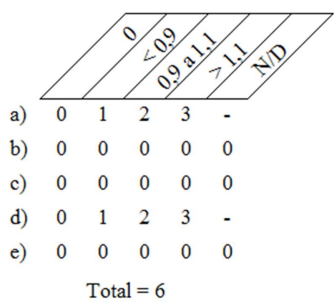

Total $=6$

Dimensão: Salários, recompensas e beneficios justos

SOC 11. Ao estabelecer a remuneração de seus funcionários, a companhia:

a) Considera a relação entre o menor salário da companhia e o salário mínimo vigente e/ou o custo de vida local para o estabelecimento da remuneração dos funcionários

b) Contempla a realização de pesquisa para medir a satisfação dos funcionários quanto

à remuneração e beneficios oferecidos pela companhia

c) Inclui o(s) sindicato(s) representativo(s) do(s) funcionário(s) na negociação de sua politica salarial, além da negociação de reajustes nas datas-bases de cada categoria

d) Nenhuma das anteriores

Total $=3$

SOC 13. Em relação à preocupação com a qualidade de vida de seus funcionários, a companhia:

a) Oferece beneficios como opção de alimentos saudáveis, academia, ginástica laboral,

e outras atividades que promovam o bem estar e uma vida mais saudável (fisica

b) Conscientiza, informa e estimula seus funcionários quanto a um estilo de vida

c) Acompanha a situação de seus funcionários quanto a aspectos relacionados à sua qualidade de vida e estrutura programas que incentivem progressos em relação ao tema

d) Possui programas que incentivem a redução de horas-extras e equilibrio entre carga horária disponivel e demanda de trabalho

e) Nenhuma das anteriores

Dimensão: Anti-discriminação

SOC 1. Assinale os temas para os quais a companhia possui compromisso formal:

a) Erradicação do trabalho infantil (TI)

a) 0

c) 1

e) Prevenção do assédio moral e do assédio sexual (AS)

f) Respeito à livre associação sindical e direito à negociação coletiva (LA)

g) 0

0
0
1
0
0
0

SOC 6. Assinale as alternativas que caracterizam os processos e procedimentos implementados pela companhia, incluindo trabalhadores terceirizados:

TI - Erradicar o trabalho infantil

TF - Erradicar o trabalho forçado ou compulsório

DI - Eliminar qualquer prática de discriminação em matéria de emprego e ocupação

DV - Promover a valorização da diversidade em matéria de emprego e ocupação

AS - Prevenir e coibir o assédio moral $\mathrm{e} o$ assédio sexual em todas as suas formas

LA - Respeito à livre associação sindical e direito à negociação coletiva

DT - Assegurar os direitos trabalhistas de funcionários diretos e trabalhadores terceirizados

$\mathrm{ED}$ - Prover o acesso dos funcionários, diretos e trabalhadores terceirizados, a atividades de educação e desenvolvimento, visando

EQ - Promover a equidade de tratamento e condições de trabalho entre funcionários e trabalhadores terceirizados

DL - Praticar o diálogo com o público interno, incluindo funcionários diretos e trabalhadores terceirizados, acolhendo, registrando, respondendo e esclarecendo todas suas criticas e sugestões, atendendo-as quando cabivel

a) Relação direta com uma politica corporativa ou compromisso formal sobre o assunto b) Indicação de recursos a serem disponibilizados para obtenção dos resultados visados e os responsáveis por sua disponibilização

c) Monitoramento e fiscalização dos termos do compromisso pela própria companhia d) Monitoramento e fiscalização do compromisso por uma terceira parte independente contratada para este fim

e) Sanção por meio de medidas disciplinares e/ou legais para situações de descumprimento ocorridas na companhia

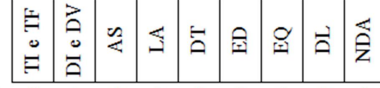

a) $\begin{array}{llllllllll}0 & 1 & 0 & 0 & 0 & 0 & 0 & 0 & 0\end{array}$

b) $\begin{array}{lllllllll}0 & 1 & 0 & 0 & 0 & 0 & 0 & 0 & 0\end{array}$

c) $\begin{array}{lllllllll}0 & 1 & 0 & 0 & 0 & 0 & 0 & 0 & 0\end{array}$

d) $0 \begin{array}{lllllllll}0 & 1 & 0 & 0 & 0 & 0 & 0 & 0 & 0\end{array}$

e) $\begin{array}{lllllllll}0 & 1 & 0 & 0 & 0 & 0 & 0 & 0 & 0\end{array}$

Total $=5$ 
SOC 8. A companhia promove o engajamento do seu público interno, incluindo funcionários diretos e trabalhadores terceirizados, no combate a qualquer prática de discriminação em matéria de emprego e ocupação?
a) $\operatorname{Sim}$
a) 1

b) Não

b) 0

Dimensão: Envolvimento com a comunidade

SOC 17. A companhia incentiva o voluntariado por meio de programa estruturado, incluindo etapas de monitoramento e avaliação, respeitando as aptidões e desejos do funcionário?
a) $\operatorname{Sim}$
a) 1

b) Não

b) 0

Dimensão: Satisfação do empregado e clima organizacional

SOC 6. Assinale as alternativas que caracterizam os processos e procedimentos implementados pela companhia, incluindo trabalhadores terceirizados:

TI - Erradicar o trabalho infantil

TF - Erradicar o trabalho forçado ou compulsório

DI - Eliminar qualquer prática de discriminação em matéria de emprego e ocupação

DV - Promover a valorização da diversidade em matéria de emprego e ocupação

AS - Prevenir e coibir o assédio moral e o assédio sexual em todas as suas formas

LA - Respeito à livre associação sindical e direito à negociação coletiva

DT - Assegurar os direitos trabalhistas de funcionários diretos e trabalhadores terceirizados

ED - Prover o acesso dos funcionários, diretos e trabalhadores terceirizados, a atividades de educação e desenvolvimento, visando

EQ - Promover a equidade de tratamento e condições de trabalho entre funcionários e trabalhadores terceirizados

DL - Praticar o diálogo com o público interno, incluindo funcionários diretos e trabalhadores terceirizados, acolhendo, registrando, respondendo e esclarecendo todas suas críticas e sugestões, atendendo-as quando cabível

a) Relação direta com uma política corporativa ou compromisso formal sobre o assunto b) Indicação de recursos a serem disponibilizados para obtenção dos resultados visados e os responsáveis por sua disponibilização

c) Monitoramento e fiscalização dos termos do compromisso pela própria companhia

d) Monitoramento e fiscalização do compromisso por uma terceira parte independente contratada para este fim

e) Sanção por meio de medidas disciplinares e/ou legais para situações de descumprimento ocorridas na companhia

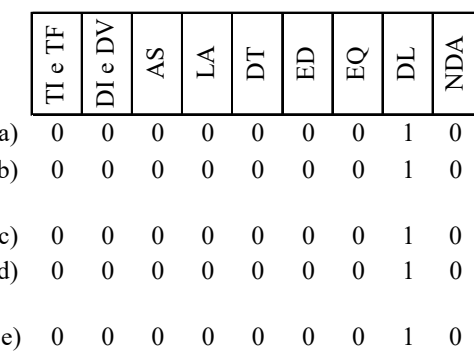

Total $=5$

SOC 12. Indique para quais aspectos abaixo a companhia avalia a satisfação de seus funcionários:

a) Clima organizacional (exposição a estresse, ambiente harmônico, cooperação entre funcionários, etc.)

b) Carga de trabalho (horas trabalhadas, metas de produção e outros tipos de demandas) $\quad$ b) 1

$\begin{array}{ll}\text { c) Remuneração compatível com a carga de trabalho } & \text { c) } 1\end{array}$

d) Benefícios $\quad$ d) 1

$\begin{array}{ll}\text { e) Não realiza pesquisa de satisfação relativa a esses aspectos } & \text { e) }\end{array}$ 
Dimensão: Relacionamento com sindicatos e união de trabalhadores

SOC 1. Assinale os temas para os quais a companhia possui compromisso formal:

a) Erradicação do trabalho infantil (TI)

b) Erradicação do trabalho forçado ou compulsório (TF)

b) 0

c) Combate à prática de discriminação em todas as suas formas (DI)

c) 0

d) Valorização da diversidade (DV)

d) 0

e) 0

e) Prevenção do assédio moral e do assédio sexual (AS)

f) 1

f) Respeito à livre associação sindical e direito à negociação coletiva (LA)

g) 0

g) Nenhum dos anteriores

SOC 6. Assinale as alternativas que caracterizam os processos e procedimentos implementados pela companhia, incluindo trabalhadores terceirizados:

TI - Erradicar o trabalho infantil

$\mathrm{TF}$ - Erradicar o trabalho forçado ou compulsório

DI - Eliminar qualquer prática de discriminação em matéria de emprego e ocupação

DV - Promover a valorização da diversidade em matéria de emprego e ocupação

AS - Prevenir e coibir o assédio moral e o assédio sexual em todas as suas formas

LA - Respeito à livre associação sindical e direito à negociação coletiva

DT - Assegurar os direitos trabalhistas de funcionários diretos e trabalhadores terceirizados

ED - Prover o acesso dos funcionários, diretos e trabalhadores terceirizados, a atividades de educação e desenvolvimento, visando

EQ - Promover a equidade de tratamento e condições de trabalho entre funcionários e trabalhadores terceirizados

DL - Praticar o diálogo com o público interno, incluindo funcionários diretos e trabalhadores terceirizados, acolhendo, registrando, respondendo e esclarecendo todas suas críticas e sugestões, atendendo-as quando cabível

a) Relação direta com uma política corporativa ou compromisso formal sobre o assunto

b) Indicação de recursos a serem disponibilizados para obtenção dos resultados visados e os responsáveis por sua disponibilização

c) Monitoramento e fiscalização dos termos do compromisso pela própria companhia

d) Monitoramento e fiscalização do compromisso por uma terceira parte independente contratada para este fim

e) Sanção por meio de medidas disciplinares e/ou legais para situações de descumprimento ocorridas na companhia

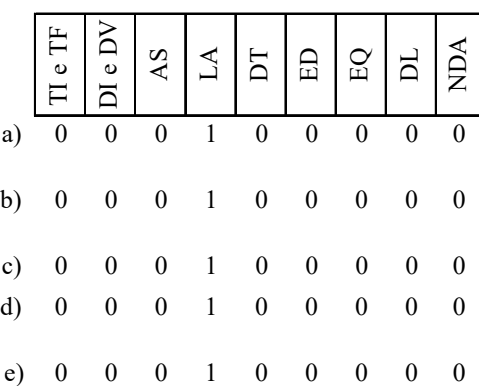

Total $=5$

SOC 7. Indique que práticas estão presentes nos processos e procedimentos para fazer respeitar os acordos e as negociações coletivas firmadas com organizações legitimamente representativas dos trabalhadores:

a) Informa seu público sobre esses direitos e garante que o seu exercício não resulta em a) 1 consequências negativas

b) Não interfere no estabelecimento, funcionamento ou administração das organizações trabalhistas ou acordos coletivos

c) Contempla uma agenda aberta de diálogo, independente das negociações coletivas e da data-base definidas pelo governo e/ou entidades de representação dos funcionários d) Prevê o envolvimento do sindicato sempre que uma atividade é terceirizada pela 


\begin{abstract}
Dimensão: Relacionamento com fornecedores
GER 17.1. Se SIM para PERGUNTA 17, marcar no quadro abaixo as células correspondente aos critérios e etapas do processo cobertas pelos processos e procedimentos relativos à gestão dos fornecedores críticos:

(I) Seleção e contratação dos fornecedores críticos da própria companhia ("nível 1" ou "tier 1")

(II) Monitoramento dos fornecedores críticos da própria companhia ("nível 1" ou "tier 1")

(III) Desenvolvimento dos fornecedores críticos da própria companhia ("nível 1" ou "tier 1")

(IV) Estimulo para que os mesmo processos e procedimentos sejam aplicados aos fornecedores críticos dos seus fornecedores críticos ("nível 2" ou “tier 2")
\end{abstract}

\section{CRITÉRIOS SOCIOAMBIENTAIS}

\author{
a) Exigência de cumprimento da legislação trabalhista em relação ao seu quadro de \\ empregados, incluindo: \\ - pagamento pontual e correto das obrigações salariais e acessórias \\ - garantia das condições de saúde e segurança dos trabalhadores \\ - não utilização de trabalho infantil \\ - não utilização de trabalho forçado ou compulsório \\ - contratação de aprendizes e de pessoas com deficiência \\ - combate à prática de discriminação \\ - combate ao assédio moral e ao assédio sexual
}

b) Adoção voluntária de práticas em relação ao seu quadro de empregados, visando valorização, capacitação e emprego de pessoas com deficiência, a valorização da diversidade e a promoção da equidade

c) Adoção voluntária de práticas visando garantir aos trabalhadores terceirizados condições de trabalho, tratamento e remuneracão equivalentes aos de seus empregados diretos

d) Exigência do pagamento pontual e correto de suas obrigações com a Receita Federal, a previdência social e demais obrigações tributárias

e) Adoção voluntária de práticas para desenvolvimento da economia local, por meio da contratação de fornecedores locais (da região) e/ou da contratação de pequenos e médios fornecedores

f) Incentivo à adesão e/ou implementação de iniciativas para promoção do desenvolvimento sustentável ao nível local e/ou nacional (como exemplos: adesão ao Pacto Global e Agenda 21 Local, entre outros)

g) Exigência de conformidade legal de suas instalações, atividades, produtos e serviços (como exemplos: licenciamento ambiental, limites de emissão de poluentes atmosféricos e hídricos, gerenciamento de resíduos sólidos, uso e ocupação do solo, outorgas e autorizações para uso de recursos ambientais, entre outros)

h) Adoção voluntária de sistemas de gestão ambiental ou correlatos, certificados por terceira parte (por exemplo ISO 14001)

i) Adoção voluntária de métodos ou práticas específicas de avaliação de desempenho ambiental para os aspectos ambientais críticos (como exemplos: indicadores setoriais, pegada hídrica, pegada de carbono, análise do ciclo de vida do produto, entre outros)
ETAPAS DO PROCESSO à
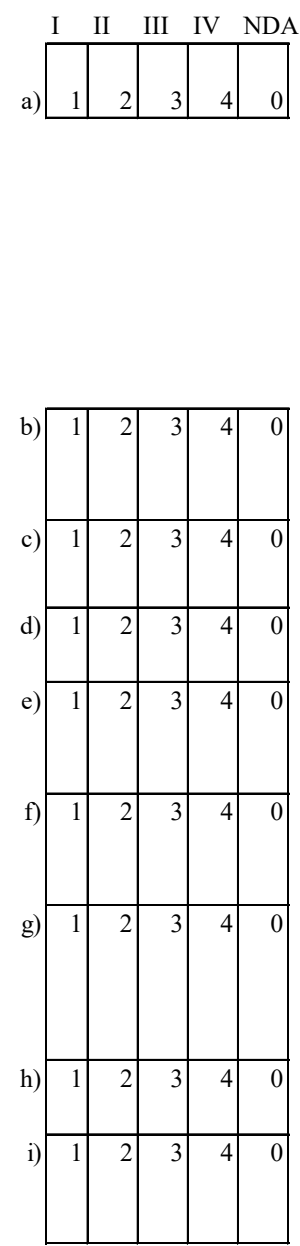

Total $=36$

SOC 35.1. Se SIM para a PERGUNTA 35, tendo como base o total de fornecedores críticos ativos durante o último ano, assinalar percentual que corresponde aos que foram incluídos em cada uma das atividades indicadas:

\section{Atividade}

a) Atividades promovidas pela companhia, voltadas à sensibilização para questões relativas à sustentabilidade, bem como ao compartilhamento de visões e compromissos b) Apoio ao desenvolvimento de práticas produtivas e gerenciais voltadas à sustentabilidade, inclusive para adequação às demandas da companhia

c) Fornecedores elegíveis ao reconhecimento por meio de prêmios ou campanhas de comunicação que valorizam a adoção de práticas socioambientais

d) Processos de gestão (homologação, seleção etc.) que diferenciam fornecedores pelo atendimento a critérios socioambientais

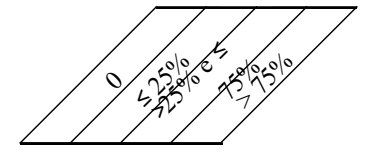

a) $0 \quad 1 \quad 2 \quad 3$

b) $0 \quad 1 \quad 2 \quad 3$

c) $\quad \begin{array}{llll}0 & 1 & 2 & 3\end{array}$

d) $\quad \begin{array}{llll}0 & 1 & 2 & 3\end{array}$ 
AMB-A 11. Indique as práticas da companhia relacionadas à melhoria do desempenho ambiental na cadeia de suprimentos:

a) Desenvolvimento de fornecedores de bens e serviços com vistas à melhoria do $\quad$ a) 1 desempenho ambiental

$\begin{array}{ll}\text { b) Exigência de conformidade legal ambiental para fornecedores críticos } & \text { b) } 1\end{array}$

c) Exigência de comprovação de boas práticas de gestão ambiental para fornecedores críticos $\quad$ c) 1

$\begin{array}{ll}\text { d) Nenhuma das anteriores } & \text { d) } 0\end{array}$

Total $=3$

Dimensão: Fornecedores locais e menores

SOC 36. Indique abaixo o volume de negócios realizados com:

a) Fornecedores locais

b) Pequenos e médios fornecedores a)

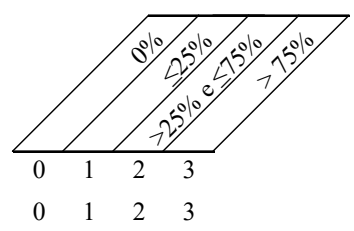

Total $=6$

Dimensão: Informações sobre o Conselho de Administração

GOV 31. Existe um processo institucionalizado de avaliação do desempenho do executivo principal pelo Conselho de Administração, com frequência no mínimo, anual?
a) $\mathrm{Sim}$
a) 0
b) Não
b) 1

GOV 18. As posições de Presidente do Conselho de Administração e Principal Executivo são ocupadas pela mesma pessoa?
a) $\mathrm{Sim}$
a) 0
b) Não
b) 1

Dimensão: Remuneração

GER 8. A companhia divulga a remuneração dos seus administradores (conselheiros de administração e diretores)?
a) Separadamente (valores individuais)
a) 5
b) Separadamente (valores individuais), identificando a remuneração fixa e a variável
b) 4
c) Em blocos (um bloco para o Conselho e outro bloco para a Diretoria)
c) 3
d) Em blocos (um bloco para o Conselho e outro bloco para a Diretoria), identificando
d) 2
a remuneração fixa e a variável
e) Consolidada (montante global)
e) 1

GOV 2. O Estatuto Social da companhia confere direitos de tag along de $100 \%$ para todas as ações ordinárias?
a) $\mathrm{Sim}$
a) 0
b) Não
b) 1

GER 9. A companhia divulga os tipos e os critérios de remuneração e benefícios atribuídos aos seus administradores (conselheiros de administração e diretores)?
a) $\mathrm{Sim}$
a) 1
b) Não
b) 0 
Dimensão: Estratégia de longo prazo

GOV 29. De que maneira o Conselho de Administração se assegura de que as questões de ordem socioambientais estejam integradas ao planejamento estratégico da organização e ao dia-a-dia de suas operações?

a) Existência de política corporativa para tratamento dos temas socioambientais

a) 1

b) Garante que diretrizes socioambientais estejam presentes no planejamento estratégico

c) Inclusão de critérios/indicadores relacionados ao desempenho socioambiental da companhia entre as métricas de avaliação e de remuneração variável dos administradores (conselheiros e/ou diretores)

d) Avaliação/discussão periódica desses temas nas reuniões do conselho ou de comitê do $\quad$ d) 1 conselho de administração

e) Exigência formal (em política ou outra diretriz do conselho) para que a gestão

incorpore essas questões em seus processos decisórios

f) Incorpora, no processo de seleção de administradores (conselheiros e diretores), critérios e

aspectos relativos à sua conduta e a seus conhecimentos sobre aspectos socioambientais

g) Nenhuma das anteriores

Total $=6$

GOV 36. O Conselho de Administração realiza pelo menos duas discussões anuais com os auditores externos?
a) $\operatorname{Sim}$
a) 1
b) Não
b) 0

GOV 39. O Conselho de Administração se assegura de que o sistema de controles internos seja avaliado no mínimo anualmente?
a) $\operatorname{Sim}$
a) 1
b) Não
b) 0

ECO 10. Existe sistema de gestão de desempenho baseado em indicadores vinculados ao planejamento estratégico?
a) $\operatorname{Sim}$
a) 1
b) Não
b) 0

GER 1. O compromisso com o Desenvolvimento Sustentável está formalmente inserido na estratégia da companhia
a) $\mathrm{Sim}$
a) 1
b) Não
b) 0

Dimensão: Doações / Filantropia

SOC 3. A companhia possui uma política corporativa que contemple o tema de Investimento Social Privado (ISP)?
a) $\operatorname{Sim}$
a) 1
b) Não
b) 0

SOC 15. A companhia promove iniciativas de Investimento Social Privado (ISP)?
a) $\mathrm{Sim}$
a) 1
b) Não
b) 0

Dimensão: Transparência, ética e combate a corrupção

GOV 46. A companhia possui Código de Conduta?
a) $\mathrm{Sim}$
a) 1

b) Não

b) 0

GER 23. A companhia possui compromisso formal em relação ao combate a todas as formas de corrupção?
a) Sim, em seu Código de Conduta
a) 1
b) Sim, como uma Política Corporativa específica sobre o tema
b) 1
c) Sim, por meio de adesão formal ou declaração pública relativa a compromissos e
c) 1
iniciativas voluntárias sobre o tema
d) 0

d) Não 
GER 25. A companhia possui processos e procedimentos implementados que permitem o gerenciamento de situações envolvendo qualquer forma de corrupção e/ou conflitos de interesses?
a) $\mathrm{Sim}$
a) 1
b) Não
b) 0

SOC 10. A companhia oferece mecanismos formais de denúncia aos funcionários diretos e trabalhadores terceirizados?
a) $\mathrm{Sim}$
a) 1
b) Não
b) 0

Dimensão: Comprometimento e impacto na comunidade

SOC 2. A companhia possui uma política corporativa que contemple o tema de relacionamento com comunidades?
a) Sim, aprovada pela alta direção
a) 1
b) Sim, aprovada pelo Conselho de Administração
b) 1
c) Não
c) 0

SOC 14.1. Se SIM para a PERGUNTA 14, indique por meio de quais práticas cotidianas a companhia busca construir um relacionamento com a comunidade visando o desenvolvimento local:

a) Realiza mapeamento dos impactos e análises de risco para definir as suas prioridades

b) Assegura o acesso a informações sobre a atuação da empresa, seus impactos e

A

as partes interessadas para o diálogo

c) Possui metodologia para seu relacionamento com a comunidade, que reconheça e

valorize suas expectativas e capacidade de organização

d) Internaliza este relacionamento na própria companhia, de forma transversal em todas

as suas áreas

e) Atua em parceria com a comunidade na identificação e solução de seus principais problemas e necessidades, oferecendo suporte técnico, e/ou espaço físico, ou outros

f) Engaja a comunidade na construção de redes sociais e/ou espaços públicos de participação social para a solução de problemas locais, tais como fóruns, comitês etc.

g) Recomenda que sua cadeia de valor realize mapeamento dos impactos e análises de risco para definir as suas prioridades estratégicas

h) Participa na formulação e/ou execução de políticas públicas no âmbito municipal, estadual ou federal, se engajando nas questões do local em que está inserida

i) Evita a dependência entre a comunidade local e a companhia

j) Nenhuma das anteriores

SOC 14.2. Se NÃO para PERGUNTA 14, indique por meio de quais práticas cotidianas, a companhia busca construir um relacionamento com a comunidade visando o desenvolvimento local:

a) Articula com outras empresas em favor da comunidade local, de modo a contribuir

a) 1

com o desenvolvimento territorial

b) Assegura canais de diálogo com a comunidade

b) 1

c) Promove iniciativas ou fortalece a capacidade e oportunidade dos fornecedores locais

c) 1 para contribuir com cadeias de valor

d) Avalia as potencialidades e vocações do território e incentiva outras cadeias de valor

d) 1

e) Participa de Fóruns Locais

e) 1

f) Participa na formulação e/ou execução de políticas públicas no âmbito municipal,

estadual ou federal, se engajando nas questões do local em que está inserida

g) Nenhuma das anteriores

g) 0

Total $=6$

ECO 6. Existem processos e procedimentos implementados para monitorar impactos econômicos indiretos das atividades da companhia?
a) $\mathrm{Sim}$
a) 1
b) Não
b) 0 
Dimensão: Inovação e introdução de novas tecnologias

GER 13. Nos processos de formulação de estratégias e/ou Pesquisa \& Desenvolvimento voltados à definição dos seus produtos e/ou modelos de a) Considera as implicações das potencias mudanças nos padrões de oferta e demanda do capital natural para posicionamento ou reposicionamento dos seus produtos e/ou modelos de negócio

b) Busca soluções para compatibilizar o atendimento das necessidades de inclusão de um número crescente de clientes/consumidores com os limites na disponibilidade de capital natural, em escala local, regional e/ou global

Total $=2$

Dimensão: Responsabilidade pelo Produto

SOC 18.6 Se SIM para a PERGUNTA 18 alternativa (a), a companhia disponibiliza informações de seus produtos e/ou serviços de forma acessível?
a) $\operatorname{Sim}$
a) 1
b) Não
b) 0
c) Não se aplica
c) -

SOC 18.7 Se SIM para a PERGUNTA 18, alternativa (b), na relação com seus clientes a companhia:

a) Pratica de maneira sistemática o diálogo e engajamento em busca de soluções que a) 0 reduzam impactos socioambientais de produtos e serviços

b) Promove iniciativas, influenciando a adoção de práticas de modo a contribuir com o desenvolvimento sustentável

c) Articula com clientes em favor da comunidade local, de modo a contribuir com o desenvolvimento territorial

d) Garante aos clientes mecanismos de queixas e reclamações relativas à violação de privacidade, sigilo e perda de dados

e) Disponibiliza aos clientes canais de atendimento alternativos ou pós-venda, em casos onde o canal principal de atendimento ao cliente não tenha sido capaz de resolver a demanda

f) Fornece aos clientes informações claras, compreensíveis e acessíveis, relacionadas aos seus produtos e serviços

g) Adota medidas para evitar práticas abusivas na relação com clientes

g) 0

h) Nenhuma das anteriores

NAT 4. A companhia mantém um sistema de informação quanto a potenciais riscos de segurança ou sanidade que os produtos e serviços que oferece possam trazer aos seus consumidores, à saúde pública e/ou ao meio ambiente, decorrentes de seu consumo ou utilização normal, formulação, componentes e/ou processos de produção?

a) Sim, por meio de processos técnicos de análise dos produtos e serviços que oferece

a) 1

b) Sim, por meio do monitoramento, coleta ou registro sistemático de informações sobre a existência de questionamentos realizados por organizações da sociedade civil, por órgãos do governo e/ou por instituições de pesquisa

d) Não se aplica

d) -

Total $=2$

Dimensão: Ações de comunicação e promoção

SOC 5. A companhia tem política corporativa visando autorregular o uso de instrumentos de marketing de suas atividades e produtos, incorporando preceitos éticos e de respeito ao consumidor, ao cidadão e ao meio ambiente?
a) $\operatorname{Sim}$
a) 1
b) Não
b) 0

Dimensão: Satisfação dos clientes

SOC 18.8 Se SIM para a PERGUNTA 18 alternativa (b), a companhia realiza periodicamente pesquisa de satisfação dos clientes.
a) Sim, referente aos principais produtos/serviços
a) 1
b) Sim, referente à companhia como um todo
c) Não 


\section{Dimensão: Privacidade do Cliente}

SOC 4. A companhia tem política corporativa visando impedir que sejam utilizadas de forma não previamente autorizada as informações sobre

a) Não

b) Sim, incluindo orientações para as áreas responsáveis pela atividade comercial (como marketing e vendas)

c) Sim, incluindo orientações para as áreas responsáveis pela coleta, guarda e análise de dados (como tecnologia da informação e sistemas)

d) Sim, identificando os responsáveis pela implementação e cumprimento dessa política

e) Sim, estabelecendo as sanções para os responsáveis em caso de falhas na aplicação dessa política a) 0

b) 1

c) 1

d) 1

e) 1

Total $=4$ 